\title{
Towards skilled doctor-patient communication
}

Citation for published version (APA):

Giroldi, E. J. W. (2016). Towards skilled doctor-patient communication: putting goal-directed and contextspecific communication into (educational) practice. [Doctoral Thesis, Maastricht University]. Maastricht University. https://doi.org/10.26481/dis.20161207eg

Document status and date:

Published: 01/01/2016

DOI:

10.26481/dis.20161207eg

Document Version:

Publisher's PDF, also known as Version of record

\section{Please check the document version of this publication:}

- A submitted manuscript is the version of the article upon submission and before peer-review. There can be important differences between the submitted version and the official published version of record.

People interested in the research are advised to contact the author for the final version of the publication, or visit the DOI to the publisher's website.

- The final author version and the galley proof are versions of the publication after peer review.

- The final published version features the final layout of the paper including the volume, issue and page numbers.

Link to publication

\footnotetext{
General rights rights.

- You may freely distribute the URL identifying the publication in the public portal. please follow below link for the End User Agreement:

www.umlib.nl/taverne-license

Take down policy

If you believe that this document breaches copyright please contact us at:

repository@maastrichtuniversity.nl

providing details and we will investigate your claim.
}

Copyright and moral rights for the publications made accessible in the public portal are retained by the authors and/or other copyright owners and it is a condition of accessing publications that users recognise and abide by the legal requirements associated with these

- Users may download and print one copy of any publication from the public portal for the purpose of private study or research.

- You may not further distribute the material or use it for any profit-making activity or commercial gain

If the publication is distributed under the terms of Article $25 \mathrm{fa}$ of the Dutch Copyright Act, indicated by the "Taverne" license above, 


\section{Towards skilled doctor-patient communication}

Putting goal-directed and context-specific communication into (educational) practice 


\section{Colophon}

Lay-out: Annerika Gidding-Slok

Cover: Martijn Chel

Printed by: Gildeprint

ISBN: 978-94-6233-446-5

CC Esther Giroldi, Maastricht 2016

The research presented in this dissertation was conducted at the School for Public Health and Primary Care (CAPHRI), Department of Family Medicine, Maastricht University, and the School of Health Professions Education (SHE), Department of Educational Development and Research, Maastricht University.

This research described in this dissertation was funded by the SBOH and the GP vocational training centres in Rotterdam and Maastricht.

All rights are reserved. No part of this book may be reproduced or transmitted in any form or by any means, without the written permission from the author or, where appropriate, the publisher of the article. 


\title{
Towards skilled doctor-patient communication Putting goal-directed and context-specific communication into (educational) practice
}

\author{
PROEFSCHRIFT \\ Ter verkrijging van de graad van doctor \\ aan de Universiteit Maastricht, \\ op gezag van de Rector Magnificus, Prof. Dr. Rianne M. Letschert, \\ volgens het besluit van het College van Decanen, \\ in het openbaar te verdedigen op \\ Woensdag 7 december 2016 om 16.00 uur \\ door \\ Esther Giroldi \\ Geboren op 25 juni 1989 te Kerkrade
}




\section{Promotores}

Prof. dr. C. van der Vleuten

Prof. dr. T. van der Weijden

\section{Co-promotor}

Dr. J.W. Veldhuijzen

\section{Beoordelingscommissie}

Prof. dr. R. Koopmans (voorzitter)

Prof. dr. S. van Dulmen, Radboud University Nijmegen / Nivel Utrecht

Prof. dr. J. Metsemakers

Dr. M. van Nuland, Huisartsopleiding KU Leuven

Dr. A. Timmerman 


\section{Contents}

\section{CHAPTER 1}

General Introduction

\section{WHAT TO TRAIN: GATHERING INFORMATION}

\section{CHAPTER 2}

'I still don't know why this patient was here': an exploration of the challenges GP trainees experience during information gathering Patient Education \& Counseling, 2015, 98: 837-42.

\section{CHAPTER 3}

How to gather information from talkative patients in a respectful and efficient manner: a qualitative study of GPs' communication strategies

Family Practice, 2016, 33: 100-6.

Nederlands Tijdschrift voor Geneeskunde, 2016, 160: D184.

\section{WHAT TO TRAIN: REASSURING PATIENTS}

\section{CHAPTER 4}

'Doctor, please tell me it's nothing serious': an exploration of patients' worrying and reassuring cognitions using stimulated recall interviews

BMC Family Practice, 2014, 15: 73.

\section{CHAPTER 5}

No need to worry': an exploration of family physicians' reassuring strategies

BMC Family Practice, 2014, 15: 133.

\section{HOW TO TRAIN: LEARNING DOCTOR-PATIENT COMMUNICATION}

\section{CHAPTER 6}

Nurturing skilled communication in the workplace: towards a personalised communication repertoire

Submitted

\section{CHAPTER 7}

General Discussion

Summary

Samenvatting

Valorisation

Dankwoord

Curriculum vitae 

General Introduction 



\section{INTRODUCTION}

Effective doctor-patient communication is essential to good health care $(1,2)$. Its positive effects on patient satisfaction (3-5), health status $(3,6)$, adherence (7), and the doctor-patient relationship (8) have been clearly demonstrated. Furthermore, good communication has been shown to reduce health care costs and malpractice claims (9). Given that good communication has proven to be such a powerful diagnostic and therapeutic tool, it is considered a key medical competency. In recent decades, efforts have been increasingly channelled into offering future doctors training in generic communication skills, both in undergraduate and in postgraduate medical education. Despite these efforts, various studies have revealed that the skills learned during training are insufficiently transferred to daily clinical practice (10-14). This has sparked a debate on whether training and assessing generic skills is the right approach to take in teaching medical communication (15), inspiring researchers to explore the nature of doctor-patient communication in actual practice. In the clinical workplace, doctor-patient communication has been shown to be a complex process that very much depends on the uniqueness of the consultation, that is, on the goals that doctors and patients try to pursue (16) and the specific contextual factors that play a role (17-19). In view of this knowledge, it is recommended that goaldirectedness and context-specificity be incorporated into medical communication training (20). This is not an easy undertaking given the complexity involved. Hence, the question of how to integrate this complexity in an effective and feasible manner remains unanswered. The purpose of this dissertation, therefore, is to explore how goal-directed and context-specific doctor-patient communication can be put into clinical and educational practice. In this introductory chapter, we will elaborate on the shift toward a context-specific and goal-directed approach in medical communication training and the complexity involved. Subsequently, we will give a short overview of the dissertation's objectives, methodology and research questions. We will end this introductory chapter with a short outline of the dissertation.

\section{THE SHIFT TOWARD A CONTEXT-SPECIFIC AND GOAL-DIRECTED APPROACH}

Given the importance of effective communication, medical schools have gradually incorporated communication training into their programmes over the last two decades (21). Moreover, communication training has become an established component of General Practice (GP) specialty training. Other medical specialties, too, 
are increasingly feeling a need to improve communication (22). Most of the current training programmes are based on a "skills approach", which assumes that communication can be taught by training and assessing predetermined behaviours, such as "summarising the patient's story" or "active listening" (23). Over the last couple of years, however, various stakeholders, including educators, researchers and future and fully-fledged doctors, have come to criticize this approach. An important inhibiting factor of the skills approach lies in the rigidity of the generic communication guidelines, which does not fit the uniqueness of real-life consultations (24). Similarly, the use of generic behavioural checklists as a tool to assess communication has been found to impede learning as it does not consider the complexity of practice, may induce artificial behaviour and does not provide the learner with rich, meaningful or constructive feedback $(25,26)$. These criticisms seem justified in the light of several study findings which reveal that the effects of generic communication skills training have been limited (10-14). Research among experienced doctors has also demonstrated that the widely advocated patient-centred communication skills, such as exploring the patients' ideas, concerns and expectations, are rarely used $(23,27-$ 29).

Hence, there seems to be a need for an alternative approach to training communication. A key publication that has inspired researchers to embark on a quest for the "right" approach is the one by Salmon \& Young (15) in which they call for a shift from "communication skills" toward "skilled communication". Communication training should take a holistic approach that does justice to the complexity of medical practice and accommodates the learner's flexibility and creativity. To obtain insight into possible starting points for the design of more holistic and flexible communication trainings, various researchers have explored this complexity. Essers et al., for instance, identified 19 discrete contextual factors that may require doctors to deviate from generic communication guidelines, including doctor-, patient- and consultation-related factors (18). Veldhuijzen et al., moreover, demonstrated the importance of goals in doctor-patient communication (20). The nature of doctor's communication behaviour is, indeed, highly goal-driven (16). A study exploring the variety of goals that doctors pursue during encounters identified 30 different consultation goals (30). Doctors mostly pursue multiple goals during one consultation (16) which are often dynamic and/or contradictory to their own or the patient's goals (31). 
In summary, we know that medical communication is highly contextualized and goaldriven and that training should pay attention to the uniqueness of real-life patient encounters. We want to take this knowledge to heart and continue with the quest for an effective approach to training communication. In order to incorporate contextspecificity and goal-directedness in training, we must thoroughly understand what constitutes appropriate communication in a certain context in the first place. The complexity of practice cannot be captured by generic behavioural guidelines. We expect that in order for doctors to be able to apply communication strategies flexibly, they have to understand the underlying mechanisms of these actions: What works? For whom? And why? These mechanisms have hitherto received scant attention in the literature. Therefore, this dissertation first explores the content of communication in specific contexts, that is, what may be effective in a certain situation and why? Meanwhile, we must not forget that the "right" content does not automatically get transferred to actual practice if it is taught in an isolated communication training. Just as communication itself cannot be isolated from the clinical context, likewise communication training should not be separated from this context. Learning communication involves a complex process of interaction with the clinical environment, during which doctors learn how to communicate in different situations. This demands a different didactic approach with a greater focus on workplace learning. Hence, we need to understand how the learning of goal-directed and context-specific communication in the actual workplace can be supported.

\section{CURRENT STUDY}

\section{Objectives}

The main objective of this dissertation is to gather knowledge on how to put contextspecific and goal-directed communication into clinical and educational practice. To this end, we must first understand what constitutes effective communication given a certain goal and context, so that we know what we should train. Subsequently, we need to understand how learners learn context-specific and goal-directed communication and how they can be supported in this process, so that we know how we should train.

\section{Setting and participants}

We chose general practice and its related specialty training programme as our research setting, because we considered it a representative example: since patient- 
centeredness, generalism and long-term relationship-building are core values in general practice, the GP specialty training programme offers its trainees periodic communication training. As stated earlier, we first want to know what to train, that is, which communication strategies are appropriate in a certain context and what are their underlying mechanisms. In our endeavour to answer this question, we will take into account that current communication guidelines have been criticized for the limited involvement of doctors in their development (32). To ensure that the communication strategies identified are feasible in daily practice, we will explore the perspectives of experienced doctors; how do they communicate in a specific context and why? However, we cannot draw any conclusions about actual effectiveness without the patient's perspective. Therefore, we will also seize every possible occasion to explore how patients experience their doctors' communication strategies. Since we are also interested to know how we can support the learning of skilled communication, it is of course essential to explore the experiences of learners themselves. As described above, learning communication predominantly takes place in the clinical workplace. In postgraduate medical training, trainees try to transfer what they have learned in training to their patient encounters on a daily basis. Serving as coaches and role models, clinical supervisors play a crucial role in this learning process, which is why, besides exploring trainees' experiences regarding their learning, we also solicited supervisors' perceptions.

\section{Communication goals: gathering information and reassuring patients}

To identify what to train in a specific context, we explored communication strategies to achieve specific consultation goals. The timeframe of this research project allowed us to select two goals our case studies. We selected the goals "information gathering" and "reassurance" for the following reasons: 1) They are highly relevant for and frequently pursued by doctors; 2) Achieving them is essential to good health care; and 3) We know that doctors experience problems achieving them and that their goalrelated communication behaviours are subject to improvement

Gathering information about patients' symptoms and their ideas, concerns and expectations is essential to appropriate diagnostics and treatment and to the delivery of patient-centred care (33-35). Many studies have emphasised that doctors' information-gathering skills need to be improved, for example because they ask too many closed-ended questions and insufficiently respond to patients' cues and concerns $(27,28,36,37)$. In many situations, however, it may not be so easy for 
doctors to gather information, and alternative strategies may be needed that warrant deviation from the traditional patient-centred communication guidelines.

In a similar fashion, it is an essential task of doctors to effectively reassure their patients (38-40). Many patients consult their doctor because they are worried (41-43). In fact, GPs try to reassure their patients in approximately $75 \%$ of consultations (30). Successfully easing patients' worries can improve patients' health status and wellbeing, helps them to better understand information and strengthens the doctorpatient relationship $(39,44-47)$. Yet, studies have demonstrated that unsuccessful reassurance is not uncommon (48-52). Although researchers have recognized the importance and difficulty of reassuring patients, there is a paucity of empirical evidence on effective reassuring strategies (53).

\section{Research questions}

Consistent with the previously described "what" and "how" objectives, this dissertation tries to find an answer to the following three research questions:

1) Which communication strategies are useful for gathering information from patients?

2) Which communication strategies are useful for reassuring worried patients?

3) How can we help trainees to learn goal-directed, context-specific communication?

\section{Theoretical orientation}

As stated earlier, by exploring what to train we aim to identify not only behavioural actions, but also the mechanisms that drive these actions. In line with what Realist Theory postulates, recognizing underlying mechanisms can be instrumental in determining what works, for whom, in what circumstances, and why (54). This is highly relevant when dealing with complex interventions, such as gathering information and reassuring patients, which can produce different outcomes in different situations. When exploring how to train, we adopt a social constructivist perspective, assuming that learning is the product of a complex interplay between a certain social activity and its environment (55). This theoretical position fits the focus of our study, specifically learning skilled communication in the clinical workplace. In this dissertation we draw heavily on qualitative research methods because they fit both theoretical positions described above - realist theory and social constructivism as well as the explorative nature of this dissertation. 


\section{DISSERTATION OUTLINE}

We used several target populations which varied according to the research topic from experienced GPs and/or patients who consulted the GP, to GP trainees and GP supervisors. Chapters 2 and 3 address the first research question. Chapter 2 describes a study with GP trainees in which we explored the challenges they experienced when gathering information from patients. The challenge that trainees mentioned most frequently, specifically gathering information from talkative patients, will be further explored in Chapter 3 using the input of experienced GPs. In this chapter we will provide a description of the communication strategies that GPs employ to gather information from talkative patients in an efficient and respectful manner. In chapters 4 and 5 we will try to answer the second research question. Chapter 4 presents a study that explores what worries patients when visiting their GP and what reassures them. Chapter 5 elaborates on the reassuring strategies that experienced GPs use and consider effective. The penultimate chapter, Chapter 6, addresses the third and last research question: it reports GP trainee and supervisor perceptions of how trainees learn communication in the workplace and what supervisors do to support this process. Chapter $\mathbf{7}$ discusses the main findings of this dissertation at hand, as well as their implications for further research and educational and clinical practice. Since this dissertation is based on journal articles, some repetition of information across chapters is inevitable. 


\section{REFERENCES}

1. Street RL, Jr., Makoul G, Arora NK, Epstein RM. How does communication heal? Pathways linking clinician-patient communication to health outcomes. Patient Educ Couns. 2009;74(3):295-301.

2. Makoul G. The SEGUE Framework for teaching and assessing communication skills. Patient Educ Couns. 2001;45:23-34.

3. Stewart M, Brown JB, Donner A, McWhinney IR, Oates J, Weston WW, et al. The impact of patientcentered care on outcomes. J Fam Pract. 2000;49(9):796-804.

4. Bertakis KD, Roter D, Putnam SM. The relationship of physician medical interview style to patient satisfaction. J Fam Pract. 1991;32(2):175-81.

5. Kinnersley P, Stott N, Peters TJ, Harvey I. The patient-centredness of consultations and outcome in primary care. Br J Gen Pract. 1999;49:711-6.

6. Stewart MA. Effective physician-patient communication and health outcomes: a review. CMAJ. 1995;152(9):1423-33.

7. Zolnierek KB, Dimatteo MR. Physician communication and patient adherence to treatment: a metaanalysis. Med Care. 2009;47(8):826-34.

8. Bensing JM, Deveugele M, Moretti F, Fletcher I, Vliet LV, Bogaert MV, et al. Patient Education and Counseling How to make the medical consultation more successful from a patient 's perspective ? Tips for doctors and patients from lay people in the United Kingdom, Italy, Belgium and the Netherlands. Patient Educ Couns. 2011;84:287-93.

9. Huntington B, Kuhn N. Communication gaffes: a root cause of malpractice claims. Proceedings (Baylor University Medical Center). 2003;16(2):157-61; discussion 61.

10. Kramer AWM, Düsman H, Tan LHC, Jansen JJM, Grol RPTM, van der Vleuten CPM. Acquisition of communication skills in postgraduate training for general practice. Med Educ. 2004;38:158-67.

11. Fernndez-Olano C, Montoya-Fernndez J, Salinas-Snchez AS. Impact of clinical interview training on the empathy level of medical students and medical residents. Med Teach. 2008;30(3):322-4.

12. Bombeke K, Van Roosbroeck S, De Winter B, Debaene L, Schol S, Van Hal G, et al. Medical students trained in communication skills show a decline in patient-centred attitudes: An observational study comparing two cohorts during clinical clerkships. Patient Educ Couns. 2011; 84(3):310-8.

13. Wouda JC, van de Wiel HBM. The communication competency of medical students, residents and consultants. Patient Educ Couns. 2011 86(1):57-62.

14. Hulsman RL, Ros WJ, Winnubst Ja, Bensing JM. Teaching clinically experienced physicians communication skills. A review of evaluation studies. Med Educ. 1999;33:655-68.

15. Salmon P, Young B. Creativity in clinical communication: from communication skills to skilled communication. Med Educ. 2011;45:217-26.

16. Veldhuijzen W, Mogendorff K, Ram P, van der Weijden T, Elwyn G, van der Vleuten C. How doctors move from generic goals to specific communicative behavior in real practice consultations. Patient Educ Couns. 2013;90:170-6.

17. Bensing J. Communication in context: new directions in communication research. Patient Educ Couns. 2003;50:27-32.

18. Essers G, van Dulmen S, van Weel C, van der Vleuten C, Kramer A. Identifying context factors explaining physician's low performance in communication assessment: an explorative study in general practice. BMC Fam Prac. 2011;12:138.

19. de Haes $\mathrm{H}$, Bensing J. Endpoints in medical communication research, proposing a framework of functions and outcomes. Patient Educ Couns. 2009;74(3):287-94.

20. Veldhuijzen W. Challenging the patient-centred paradigm: Designing feasible guidelines for doctorpatient communication. Maastricht: Datawyse; 2011.

21. Van Dalen J, Bartholomeus P, Kerkhofs E, Lulofs R, Van Thiel J, Rethans J-J, et al. Teaching and assessing communication skills in Maastricht: the first twenty years. Med Teach. 2001;23:245-51.

22. Silverman J. Clinical communication training in continuing medical education: possible, do-able and done? Patient Educ Couns. 2011;84:141-2.

23. Silverman J, Kurtz S, Draper J. Skills for communicating with patients. Second ed. Oxford: Radcliffe Publishing; 2005. 58-105 p. 
24. Veldhuijzen W, Ram PM, van der Weijden T, Niemantsverdriet S, van der Vleuten CPM. Characteristics of communication guidelines that facilitate or impede guideline use: a focus group study. BMC Fam Prac. 2007;8:31.

25. Van Nuland M, Thijs G, Van Royen P, Van den Noortgate W, Goedhuys J. Vocational trainees' views and experiences regarding the learning and teaching of communication skills in general practice. Patient Educ Couns. 2010;78(1):65-71.

26. Veldhuijzen $\mathrm{W}$, Ram PM, van der Weijden T, van der Vleuten CPM. Communication guidelines as a learning tool: an exploration of user preferences in general practice. Patient Educ Couns. 2013;90:213-9.

27. Marvel MK, Epstein RM, Flowers K, Beckman HB. Soliciting the Patient's Agenda: Have We Improved? JAMA. 1999;281:283-7.

28. Levinson W, Gorawara-Bhat R, Lamb J. A study of patient clues and physician responses in primary care and surgical settings. JAMA. 2000;284(8):1021-7.

29. Rhoades DR, McFarland KF, Finch WH, Johnson aO. Speaking and interruptions during primary care office visits. Fam Med. 2001;33:528-32.

30. Veldhuijzen W. Beyond patient centeredness: the multitude of competing goals that doctors pursue in consultations. Challenging the patient centred paradigm: designing feasible guidelines for doctor patient communication. Maastricht: Datawyse; 2011.

31. Veldhuijzen W, Portegijs P, van der Weijden T, Ram P, Kruisifix L, Elwyn G, et al. An exploration of the extent to which doctors modify their goals to those of their patients and its effect on goal achievement by patients. Challenging the patient-centred paradigm :Designing feasible guidelines for doctor-patient communication. Maastricht: Universitaire pers Maastricht; 2011. p. 153-68.

32. Veldhuijzen W, Ram P, van der Weijden T, Wassink M, van der Vleuten C. Much variety and little evidence: a description of guidelines for doctor-patient communication. Med Educ. 2007;41(2):13845.

33. Hampton JR, Harrison MJ, Mitchell JR, Prichard JS, Seymour C. Relative contributions of historytaking, physical examination, and laboratory investigation to diagnosis and management of medical outpatients. Br Med J. 1975;2:486-9.

34. Peterson MC, Holbrook JH, Von Hales D, Smith NL, Staker LV. Contributions of the history, physical examination, and laboratory investigation in making medical diagnoses. West J Med. 1992;156:163-5.

35. Deveugele M, Derese A, De Bacquer D, van den Brink-Muinen A, Bensing J, De Maeseneer J. Is the communicative behavior of GPs during the consultation related to the diagnosis? A cross-sectional study in six European countries. Patient Educ Couns. 2004;54:283-9.

36. Beckman HB, Frankel RM. The effect of physician behavior on the collection of data. Ann Intern Med. 1984;101:692-6.

37. Mjaaland Ta, Finset A, Jensen BF, Gulbrandsen P. Physicians' responses to patients' expressions of negative emotions in hospital consultations: a video-based observational study. Patient Educ Couns. 2011;84:332-7.

38. Buchsbaum DG. Reassurance reconsidered. Soc Sci Med. 1986;23:423-7.

39. Kessel N. Reassurance. Lancet. 1979;1:1128-33.

40. Coia P, Morley S. Medical reassurance and patients' responses. J Psychosom Res. 1998;45:377-86.

41. Barry CA, Bradley CP, Britten N, Stevenson FA, Barber N. Patients' unvoiced agendas in general practice consultations: qualitative study. Br Med J (Clin Res Ed). 2000;320(7244):1246-50.

42. McKinley RK, Middleton JF. What do patients want from doctors? Content analysis of written patient agendas for the consultation. Br J Gen Pract. 1999;49:796-800.

43. van Bokhoven MA, Pleunis-van Empel MC, Koch H, Grol RP, Dinant GJ, van der Weijden T. Why do patients want to have their blood tested? A qualitative study of patient expectations in general practice. BMC Fam Prac. 2006;7:75.

44. Fassaert $T$, van Dulmen S, Schellevis F, van der Jagt $L$, Bensing J. Raising positive expectations helps patients with minor ailments: a cross-sectional study. BMC Fam Prac. 2008;9:38.

45. Fogarty LA, Curbow BA, Wingard JR, McDonnell K, Somerfield MR. Can 40 seconds of compassion reduce patient anxiety? J Clin Oncol. 1999;17:371-9.

46. Liénard A, Merckaert I, Libert Y, Delvaux N, Marchal S, Boniver J, et al. Factors that influence cancer patients' anxiety following a medical consultation: impact of a communication skills training programme for physicians. Ann Oncol. 2006;17:1450-8. 
47. Warwick HM, Salkovskis PM. Reassurance. Br Med J (Clin Res Ed). 1985;290:1028.

48. McDonald IG, Daly J, Jelinek VM, Panetta F, Gutman JM. Opening Pandora's box: the unpredictability of reassurance by a normal test result. Br Med J (Clin Res Ed). 1996;313:329-32.

49. Lucock MP, Morley S, White C, Peake MD. Responses of consecutive patients to reassurance after gastroscopy: results of self administered questionnaire survey. Br Med J (Clin Res Ed). 1997;315:5725.

50. Petrie KJ, Müller JT, Schirmbeck F, Donkin L, Broadbent E, Ellis CJ, et al. Effect of providing information about normal test results on patients' reassurance: randomised controlled trial. $\mathrm{Br} \mathrm{Med} J$ (Clin Res Ed). 2007;334:352.

51. Stark D, Kiely M, Smith A, Morley S, Selby P, House A. Reassurance and the anxious cancer patient. Br J Cancer. 2004;91:893-9.

52. van Ravesteijn H, van Dijk I, Darmon D, van de Laar F, Lucassen P, Hartman TO, et al. The reassuring value of diagnostic tests: a systematic review. Patient Educ Couns. 2012;86:3-8.

53. Linton SJ, McCracken LM, Vlaeyen JW. Reassurance: help or hinder in the treatment of pain. Pain. 2008;134(1-2):5-8.

54. Wong G, Greenhalgh T, Westhorp G, Pawson R. Realist methods in medical education research: what are they and what can they contribute? Med Educ. 2012;46(1):89-96.

55. Mann KV. Theoretical perspectives in medical education: past experience and future possibilities. Med Educ. 2011;45(1):60-8. 



\section{CHAPTER}

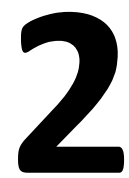

\section{'I still have no idea why this patient was here': an exploration of the difficulties GP trainees experience when gathering information}

Esther Giroldi, Wemke Veldhuijzen, Tijme de Leve, Trudy van der Weijden, Herman Bueving, Cees van der Vleuten

Patient Education and Counseling. 2015, 98:837-42. 


\section{ABSTRACT}

\section{Objective}

Collecting information during patient encounters is essential for the delivery of patient-centred care. To obtain insight into areas that require more attention in medical communication training, this study explores what difficulties GP trainees encounter when gathering information.

\section{Methods}

In this phenomenological study, we observed a morning clinic of 15 GP trainees. To explore trainees' experiences with information-gathering, we held brief interviews after every consultation and a lengthier interview directly after the morning clinic. The resulting data were analysed using template analysis.

\section{Results}

From trainees' reflections, we distilled five difficulties that trainees experience when gathering information: 1) Goal conflicts; 2) Ineffectiveness of trained communication skills in specific situations; 3) Trainees' distress hampers open communication; 4) Untrustworthy information; 5) Tunnel vision.

\section{Conclusion}

Information-gathering is difficult for GP trainees. Current generic communication skills training does not seem to support trainees sufficiently to handle effectively the challenges they encounter during consultations.

\section{Practice implications}

Medical communication training needs to support trainees in handling their goalconflicts and feelings that hamper information-gathering, while also providing them with communication strategies adapted to handling specific challenging situations. 


\section{INTRODUCTION}

During encounters with patients, physicians spend a large proportion of their time on gathering relevant information about patients' complaints, medical histories, contextual backgrounds, concerns and preferences (1). This information is essential for appropriate diagnostics and treatment and for the delivery of patient-centred care (1-3).

Many studies have emphasised that physicians' behaviour regarding informationgathering needs to be improved. They have found that physicians often interrupt or redirect patients' opening statement of concerns; ask many closed-ended questions and frequently do not respond to patients' emotional cues (4-7), thereby possibly missing opportunities to gather important information about patients' complaints and underlying concerns.

We have not, however, encountered any comprehensive studies designed specifically to explore difficulties that physicians themselves experience when gathering information, although the literature does suggest that this is difficult for physicians in various situations. For example, cultural differences and linguistic discordance can lead to misunderstandings between physicians and their ethnic minority patients (8) who are also less likely to express their wishes, expectations, thoughts, emotions and feelings of disagreement $(8,9)$. Although it has been shown that children are well able to give information about their feelings, ideas and expectations, they are frequently ignored as parents often dominate the conversation and interrupt the child, even when physicians direct their questions specifically to the child (10-12). Several studies have shown that patients with medically unexplained symptoms tend to present symptoms with great intensity in order to convey their severity, due, perhaps, to patients seeking engagement $(13,14)$. However, physicians might wrongly interpret this behaviour as a wish for medical interventions and therefore offer interventions in response (13).

As the examples above illustrate, difficulties in information-gathering may be related to various interplaying factors, including physician factors, patient factors and consultation factors. It is thus unlikely that such difficulties can be fully resolved by applying patient-centred communication skills as advocated in medical communication training, which are primarily aimed at stimulating patients to talk, e.g. by active listening, asking open questions and not interrupting the patient during the opening of a consultation (15-18). 
To support physicians, trainees and students in collecting information, we first need to have a thorough understanding of what makes information-gathering difficult. We explored this in the context of primary care, since general practitioners (GPs) rely heavily on the information they receive from their patients due to limited use of diagnostic means and the important role of the patients' contextual background in GPs' diagnostics and management decisions (17). We expect that GP trainees, as learners, struggle actively with gathering information and are therefore very well able to reflect upon difficulties.

\section{METHODS}

\section{Design}

In order to obtain a thorough understanding of trainees' experiences while gathering information, we used hermeneutic phenomenology. Hermeneutic phenomenology aims to describe and interpret elements of a person's life-world $(19,20)$. A morning clinic of trainees was observed, with brief interviews of a few minutes after every consultation, followed by a lengthier interview after the morning clinic. We used template analysis as the analytical method (21).

\section{Ethics}

The Netherlands Association for Medical Education (NVMO) granted its approval for our study protocol. Participating trainees gave written informed consent. Patients were informed in the waiting room that a researcher would observe the trainee's morning clinic after which, in addition, the trainee verbally asked for consent before the consultation. The trainees' demographic data, audiotaped interviews and transcripts were anonymized with codes.

\section{Study population and context}

We purposively sampled first year GP trainees since we expected them, as novices, to experience many difficulties during information-gathering, as well as last (third) year trainees who are more experienced and tend to see patients with more complex complaints. During educational meetings of the Family Medicine Specialty training, 60 trainees were informed about the study, both verbally and with an informative letter. To ensure a variety of both trainees and their patients, we recruited trainees from two universities located in two areas that differ demographically (urbanization, age, ethnic backgrounds). Apart from these purposive sampling procedures, the sample was 
opportunistic as those trainees that were willing to participate were included in the study.

The communication programme that the GP trainees receive during their undergraduate and GP training is predominantly focused on training and assessing general patient-centred communication skills. The communication guidelines GP trainees are trained to apply, treat information primarily from a positivistic perspective in which information is considered to be present in the patient and can therefore be 'mined' during the consultation (22). Although there is some emphasis on discussing findings and management options, information is primarily something to be gathered from the patient or to be given by the GP. There is less emphasis on the constructivist perspective in which doctor and patient together construct meaning during the conversation (22).

\section{Interviews}

In phenomenology, the participant is observed in the context in which the phenomenon is experienced (23). The researcher observed one morning clinic of the trainee and used the consultations as stimuli for discussion. To stay as close as possible to the actual experience while minimally disturbing the natural course of the morning clinic, a brief interview was held immediately after every consultation. The trainee was asked whether he felt he had succeeded in gathering all the information he needed and what had made gathering information difficult/easy in that particular consultation. Directly after the clinic, a lengthier follow-up interview was held, allowing more in-depth elaboration on previously-mentioned difficulties. Probing questions were formulated to be as open as possible and depended on the trainee's previous account of that particular situation. At the end of the interview, trainees were asked whether they had experienced difficulties other than those encountered during that particular morning clinic.

\section{Analysis}

All interviews were transcribed verbatim. In order to familiarize ourselves with the data, all transcripts were read in detail by three researchers with backgrounds in medicine (WV, TL), medical education (WV) and health sciences (EG). Two researchers ( $E G$ and $W V / T L$ ) used independently a line-by-line approach, i.e. a detailed reading of every sentence (20), to identify phrases that shed light on the experience of gathering information. These phrases were assigned a preliminary code. Attention was paid to 
the nature of participants' reflections such as: use of metaphors; words and intonation indicating emotions, e.g. insecurity, frustration and powerlessness; changes in language-use and phrases related to time, all of which could help us to understand the phenomenon (20). Interpretative and reflexive thoughts and ideas were recorded in memos. A subset of four transcripts was then analysed, during which themes were revised, split and clustered under broader themes, resulting in an initial template $(21,24)$. This template was developed into a network depicting the relationships between themes and how low hierarchy themes could be associated with multiple high hierarchy themes. The template was used to analyse additional interviews, and, during this process, was revised and refined. During our analysis, we also paid attention to deviant cases, especially to trainees that seemed less troubled by difficulties than other trainees. An important aspect of phenomenological analysis is writing and rewriting as this process helps to extract meaning (20). In our study, the templates and memos facilitated the development of interpretive written accounts of the essential themes that characterize the phenomenon of challenges encountered during information-gathering. These written accounts were discussed in-depth with all authors.

\section{RESULTS}

\section{Participants}

Fifteen trainees participated in the study. For a description of the trainees' characteristics see Table 2.1 .

\section{Interviews}

We held 108 brief interviews (mean: 7 interviews; range: 3 to 15 interviews per trainee) and fifteen long interviews. The mean duration of the interviews was 5 and 30 minutes respectively for the brief and long interviews. Both first and third year trainees were well able to reflect upon the situations they had experienced as difficult. Compared with first year trainees, third year trainees gave a more in-depth reflection on what made challenging situations difficult. After analysing the interviews of fifteen trainees, the authors considered that they had obtained a rich sense of the trainees' experiences.

Although the last two interviews did contain new examples of difficult situations, they did not contribute to a deeper level of understanding of what makes informationgathering difficult. 
Table 2.1 Trainees' characteristics

\begin{tabular}{|c|c|c|c|c|c|c|}
\hline Trainee & Age & Sex & $\begin{array}{l}\text { Working experience } \\
\text { before entering GP- } \\
\text { training }\end{array}$ & $\begin{array}{l}\text { Practice } \\
\text { setting }\end{array}$ & $\begin{array}{l}\text { Country of } \\
\text { origin }\end{array}$ & $\begin{array}{l}\text { GP } \\
\text { training } \\
\text { year }\end{array}$ \\
\hline 1 & 32 & Female & 1 year surgery & $\begin{array}{l}\text { Rural, } \\
\text { Group }\end{array}$ & $\begin{array}{l}\text { The } \\
\text { Netherlands }\end{array}$ & 1 \\
\hline 2 & 27 & Female & 1 year infant centre & $\begin{array}{l}\text { Rural, } \\
\text { Group }\end{array}$ & $\begin{array}{l}\text { The } \\
\text { Netherlands }\end{array}$ & 1 \\
\hline 3 & 25 & Female & $\begin{array}{l}9 \text { months pulmonary } \\
\text { medicine }\end{array}$ & $\begin{array}{l}\text { Rural, } \\
\text { Solo }\end{array}$ & $\begin{array}{l}\text { The } \\
\text { Netherlands }\end{array}$ & 1 \\
\hline 4 & 27 & Female & 1 year gynaecology & $\begin{array}{l}\text { Rural, } \\
\text { Solo }\end{array}$ & $\begin{array}{l}\text { The } \\
\text { Netherlands }\end{array}$ & 1 \\
\hline 5 & 27 & Male & $\begin{array}{l}6 \text { months nursing } \\
\text { home care }\end{array}$ & $\begin{array}{l}\text { Rural, } \\
\text { Group }\end{array}$ & $\begin{array}{l}\text { Dutch Antilles } \\
\text { (Aruba) }\end{array}$ & 1 \\
\hline 6 & 26 & Female & $\begin{array}{l}7 \text { months } \\
\text { emergency room }\end{array}$ & $\begin{array}{l}\text { Rural, } \\
\text { Solo }\end{array}$ & $\begin{array}{l}\text { The } \\
\text { Netherlands }\end{array}$ & 1 \\
\hline 7 & 31 & Female & None & $\begin{array}{l}\text { Rural, } \\
\text { Solo }\end{array}$ & Germany & 1 \\
\hline 8 & 31 & Male & $\begin{array}{l}2 \text { years mental } \\
\text { health care }\end{array}$ & $\begin{array}{l}\text { Rural, } \\
\text { Solo }\end{array}$ & Morocco & 3 \\
\hline 9 & 29 & Male & 2 years cardiology & $\begin{array}{l}\text { Urban, } \\
\text { Group }\end{array}$ & $\begin{array}{l}\text { The } \\
\text { Netherlands }\end{array}$ & 1 \\
\hline 10 & 31 & Male & $\begin{array}{l}1 \text { year emergency } \\
\text { room }\end{array}$ & $\begin{array}{l}\text { Urban, } \\
\text { Group }\end{array}$ & $\begin{array}{l}\text { The } \\
\text { Netherlands }\end{array}$ & 3 \\
\hline 11 & 32 & Female & 3 years gynaecology & $\begin{array}{l}\text { Urban, } \\
\text { Solo }\end{array}$ & $\begin{array}{l}\text { The } \\
\text { Netherlands }\end{array}$ & 1 \\
\hline 12 & 36 & Female & $\begin{array}{l}6 \text { months nursing } \\
\text { home care }\end{array}$ & $\begin{array}{l}\text { Urban, } \\
\text { Solo }\end{array}$ & Romania & 3 \\
\hline 13 & 29 & Male & $\begin{array}{l}1 \text { year emergency } \\
\text { room }\end{array}$ & Rural & $\begin{array}{l}\text { The } \\
\text { Netherlands }\end{array}$ & 3 \\
\hline 14 & 31 & Female & $\begin{array}{l}1 \text { year internal } \\
\text { medicine }\end{array}$ & $\begin{array}{l}\text { Urban, } \\
\text { Group }\end{array}$ & $\begin{array}{l}\text { The } \\
\text { Netherlands }\end{array}$ & 3 \\
\hline 15 & 44 & Female & $\begin{array}{l}19 \text { years emergency } \\
\text { room }\end{array}$ & $\begin{array}{l}\text { Rural, } \\
\text { group }\end{array}$ & Belgium & 3 \\
\hline
\end{tabular}

\section{Difficulties encountered during information-gathering}

The trainees in our study experienced difficulties during information-gathering in most of the consultations. Trainees experienced problems when gathering biomedical and contextual information, but most often when exploring the patients' perspective (i.e. patients' ideas, concerns and expectations). Most trainees seemed to view information as extant within patients and which can be tapped by using the right tools. A few trainees seemed to feel that information is not yet always present, and 
that information-gathering sometimes involves a longer-term process during which meaning is created by both doctor and patient.

From trainees' reflections, we could extract five main difficulties that could co-occur in one consultation. Each of the difficulties is described in a narrative form using illustrative quotations in which the following punctuation marks are used:

... =long pause

(...) =omitted text

$!=$ raised voice

[] $=$ word(s) added for clarification

\section{Goal conflicts}

Trainees struggle when they feel that information-gathering conflicts with other goals. Trainees feel that information-gathering may conflict with relationship goals as some questions may seem too intrusive or private, especially given that, usually, a longlasting, doctor-patient relationship has not yet been established. This feeling may arise when exploring patients' beliefs or preferences or when discussing intimate or sensitive subjects, in particular when the patients' actual (non-)verbal behaviour is dismissive: "I sense that he really doesn't want to talk about it and that's difficult, because you don't want to upset people" (T5). They may then refrain from gathering information to prevent seeming intrusive or upsetting patients. A barrier to asking questions also arises in the presence of someone accompanying the patient with whom the patient may not have been completely open: "those were very intimate things, so it was very awkward that the father was there because you don't know what the girl wants her father to know" (T5).

Trainees want to show interest in their patients and therefore want to give them the opportunity to tell their story. This can become problematic when they receive an overload of detailed information which, to them, seems unrelated to the patient's problem, whilst incidentally receiving important information such as emotional cues and alarming symptoms: "She describes everything she believes to be useful, without having any insight into which complaints are related to what organs and so forth. So she provides a great deal of information that you have to sift through because half of it's irrelevant. However, incidentally, she can let things drop in passing that are relevant so it's important to pay attention" (T3). Talkative patients often keep 
swerving off-topic, making it hard to keep up with them. However, trainees feel that interrupting is disrespectful and could risk patients' sense of being heard: "Then you are a lousy doctor who doesn't listen at all" (T11). Information-gathering does then not only conflict with relationship-building, but also with time-management.

\section{Ineffectiveness of trained communication skills in specific situations}

Trainees sometimes consider the communication skills that they have learned during their medical training to be ineffective or even counter-productive. With talkative patients, for example, it is difficult to retrieve the lead in the conversation with closedended questions if the patient: "gives an answer like, 'Yes, the other day I had pain when I was in the supermarket and the endive was cheap, that's because it's in season (...) and then you find that you are completely not where you want to be" (T6). Other attempts to structure the consultation, such as summarising, are experienced as counter-productive: "She interrupts me after one sentence and then she's off again" (T2). In contrast, trainees also often reflected upon the ineffectiveness of skills in cases where patients do not want to share information, e.g. due to the nature of the topic; a lack of trust in the doctor; the presence of a third person or because the initiative to contact the doctor has been taken by someone else: "You can't ask openended questions. They give very short answers and then it's all over" (T9). When in these situations, trainees are forced to ask closed-ended questions or make assumptions, they feel they might miss important information. The ineffectiveness of asking open-ended questions was experienced as particularly problematic when exploring the patients' ideas, concerns and expectations: "they often haven't yet thought about what it is they want, what they think might be going on and what they are afraid of" (T3). Trainees then do not always receive the response they had hoped for: "well, you are the doctor?" (T10).

When paying close attention to the nature of the trainees' reflections, we noticed that their tone of voice became more emotional and that they used more expressions indicating frustration or disempowerment regarding consultations in which a lack of effective skills is accompanied by goal conflicts. An example illustrating this clearly is a consultation with a talkative patient in which the trainee lacks the tools to take back the lead in the conversation, while also worrying about coming across as indifferent: "Then he really got going! A massive problem. How do you get someone back on track (...), back to the complaint? You don't want to seem rude and yet [you want] to let him 
get his story off his chest. But that's not always possible because you run tremendously over time. Then you get so much information that's completely useless!" (T11). Trainees seem to be actively searching for effective communication strategies to handle their goal conflicts: "I find it difficult to interrupt or even to restructure. I feel I have too few tools" (T13).

\section{Trainees' distress hampers open communication}

Trainees' feel distressed when they have to deal with sensitive topics or when they anticipate a strong emotional reaction of a patient. This unease may lead them to evade asking certain questions, although this diminishes with experience: "sexual anamneses demands very explicit questions which you have to get used to asking" (T10). Uncertainty about their medical knowledge causes some trainees to be reluctant to explore concerns or expectations since patients might "expect an answer or want you to come up with a solution which you can't do, given your own experience" (T6).

Trainees' distress may also hamper patients in being open. Trainees recognized that they may transfer their own unease to the patient: "I sense that the more emotionally charged I approach things, the more difficult it becomes for patients to discuss things with me" (T10). Diagnostic uncertainty may distress trainees to the extent that they have trouble focusing on the medical content and the relationship at the same time, which may ultimately hamper information-gathering: "I fall back on my medical knowledge, very structured taking history of every problem, looking at my computer. Then I may lose the connection with the patient, which is a big disadvantage in the long-term, because if you don't have a good connection, they will not discuss certain things (T7).

\section{Untrustworthy information}

Trainees feel that some patients with particular demands attempt to influence trainees' management decisions with misinformation. Consequently, trainees have doubts about the reliability of the information given and also feel that their own expertise is being questioned: "People who come here and want a referral at any cost, they just don't give honest answers; they respond with $a$, "Yes," to every question just to get their referral. You are then left without a single direction to follow. You also get 
the feeling that they don't trust you, that they don't trust me to come to a correct diagnosis" (T2).

While trainees sometimes perceive the provision of incorrect information to be deliberate by some patients, other patients may unconsciously present their information in a way that may cause misinterpretations: "When dealing with theatrical characters, I find it very difficult to assess the seriousness of the complaint, because they always present themselves very dramatically" (T1). On the other hand, trainees experience problems when patients "trivialize everything; then it's difficult to sense whether there's something the matter, whether or not it's serious. Sometimes that's hard to assess. Should I take it seriously or not?" (T4).

\section{Tunnel vision}

When patients directly communicate the diagnosis they have in mind, trainees can suffer from tunnel vision: "When they say, 'Doctor I have gallstones', you completely focus on that piece of information with your questions, while perhaps something completely different is really going on" (T4). Trainees believe that falling into this pitfall is often the result of inexperience and diagnostic uncertainty.

Although trainees often find exploring patients' request for help challenging, its immediate expression can also limit the trainees' perception as they are "too quickly satisfied with the answer" (T1). Trainees let themselves be guided by the doctor's assistants' triage of patients' complaints or requests for help. Sometimes, this information is so intrusive that they may forget to explore whether there are other complaints or questions.

Trainees view a long-lasting relationship with patients as an important facilitator of successful information-gathering. Nevertheless, knowing your patients well can also lead to misconceptions: "The pitfall with these patients is that you think, 'Here she comes again with her headache', always very theatrical, and, after five visits, nothing serious, but the tenth time it could well be significant" (T12).

\section{Differences between trainees}

Some trainees experienced fewer difficulties or experienced difficulties to a lesser extent than others. Although we did not specifically explore solutions, these trainees 
often spontaneously reflected on how they overcame some of their difficulties. Clinical experience seemed helpful, as this enables trainees to try out alternative communication strategies; get used to discussing sensitive topics; develop a relationship with their patients and develop more diagnostic certainty. Trainees that experience fewer difficulties also seemed to have developed a different mind-set regarding the consultation, e.g. that interrupting patients is not necessarily disrespectful, or that information-gathering may sometimes require a more long-term process during which both parties together create meaning by sharing information. These trainees seemed more comfortable with deviating from the consultation structure in which they had been trained and with spreading out informationgathering over more than one consultation. These types of reflections were made more by third year trainees than first year trainees.

\section{DISCUSSION AND CONCLUSION}

\section{Main Findings}

Information-gathering is often difficult for GP trainees. Trainees struggle when: information-gathering conflicts with relationship goals or with time-management goals; the communication skills they have learned during medical training are ineffective or counterproductive; their own emotions get in the way; the trustworthiness of the information is difficult to determine; or when information points so strongly in a specific direction that trainees develop tunnel vision. Consultations during which more of these difficulties are present are experienced as particularly challenging and may lead to frustrations and feelings of disempowerment.

\section{Main findings in relation to the literature}

Patient-centred communication guidelines for information-gathering are focused on stimulating patients to share their perspective (15-18). While previous studies have highlighted that physicians insufficiently explore the patients' perspective, (4-7) this study demonstrates that trainees value the patients' perspective and actively try to explore it. Trainees' notion of patient-centeredness also involves relational aspects such as being respectful, not upsetting and interrupting patients and not making them feel uncomfortable. This notion, however, can be in tension with exploring the patients' perspective. While it is often stressed that a trusting doctor-patient relationship facilitates successful information-gathering (17), this study showed that these two goals can be experienced as conflicting. Communication guidelines 
advocate the exploration of patients' perspective early on in the encounter (15-18), whereas trainees feel that this may also cause a patient to shut down. The literature supports trainees' notion that interrupting patients harms a patient-centred understanding and the relationship (25), but does not seem to offer solutions for gathering and organizing information from talkative patients. Previous research has already shown how physicians pursue multiple communication goals that often compete and may even be incongruent $(15,26)$. Also the need to address goal conflicts in medical communication training has been mentioned earlier (26).

Our results are also relevant to the current debate between the 'communications skills' and 'skilled communication' approaches (27). Trainees' reflections on situations during which the skills they have learned during medical training are ineffective, again underline that the context-specific nature of medical communication in daily practice should not be ignored (27-30). In line with previous studies, there seems to be a need for more tailored, context-specific communication strategies that are adaptable to specific situations $(31,32)$. However, the nature of problems that trainees encounter seems to ask for more than a skills approach. Studies on transfer of communication skills found that trainees plead for more holistic training instead of current reductionist training approaches in which the communicative behaviours trainees need to perform are predetermined and assessed with behavioural checklists $(33,34)$. These studies also advocate promoting changes in the learner's frame of reference in line with Transformative Learning Theory (35). This also seems a good fit with the difficulties identified in this study, such as trainees' goal conflicts and feelings that hamper information-gathering. Discussing the learner's frame of reference may also involve reflections on how information is viewed. Trainees view information mainly from a 'mining' perspective. This perspective is considered useful when exploring causal relations (22) and therefore seems suitable when gathering technical, biomedical information. For constructing a patient-centred understanding of illness and appropriate actions, it seems more suitable to construct meaning during a process of 'shared mind', i.e." "situations in which new ideas and perspectives emerge through the sharing of thoughts, feelings, perceptions, meanings and intentions among 2 or more people" (36). Switching between these two perspectives seems to be challenging for trainees. 


\section{Strengths and limitations}

We combined brief interviews immediately after every consultation, with lengthier interviews later, during which trainees could elaborate. This ensured that we stayed as close as possible to trainees' actual experiences while also obtaining in-depth reflections. Although we used 108 consultations as stimuli for discussion and created space for broader reflections, we may still have missed experiences. Voluntary participation possibly led to under-representation of trainees who feel insecure about their medical and/or communication skills. Trainees also might have felt uncomfortable elaborating on their difficulties. However, we have tried to minimize status differences and role conflicts (19) by selecting interviewers who were less experienced in medical practice than the trainee and who were not involved in their medical training.

All data were analysed by a researcher with an insider perspective and a researcher with an outsider perspective, enriching our understanding of the data and consequently enhancing the credibility of our results and conclusions (37).

\section{Conclusions}

Gathering relevant information on patients' problems is difficult for GP trainees. Difficulties are related to trainees' frames of reference, the communication skills they are trained in, as well as the perspective on information and meaning making that is used. Current generic communication skills training does not seem to support trainees sufficiently in handling effectively these communication difficulties.

\section{Implications for practice and research}

Medical communication training needs to support trainees with overcoming information-gathering problems that hamper appropriate diagnostics and treatment. This requires a holistic approach that, in addition to training skills, stimulates trainees to reflect on and change their frames of reference. Thereby it is important that effectively handling goal conflicts becomes an educational target; in particular, how successful information-gathering can be achieved whilst building and preserving a trusting doctor-patient relationship. With regards to topics such as patient preferences and shared decision-making, it may be useful to shift the emphasis away from collecting information and towards creating meaning together. This may prevent patients from feeling that the doctor tries to shift responsibility for decision making onto the patient when exploring ideas and expectations, and thereby prevent a 
patient response such as "well, you are the doctor". When handling difficult situations, trainees could also benefit from communication strategies that are tailored to specific circumstances. It is therefore desirable that more empirical evidence is obtained on how to gather information successfully in specific challenging situations. 


\section{REFERENCES}

1. Deveugele M, Derese A, De Bacquer D, van den Brink-Muinen A, Bensing J, De Maeseneer J. Is the communicative behavior of GPs during the consultation related to the diagnosis? A cross-sectional study in six European countries. Patient Educ Couns. 2004;54:283-9.

2. Hampton JR, Harrison MJ, Mitchell JR, Prichard JS, Seymour C. Relative contributions of historytaking, physical examination, and laboratory investigation to diagnosis and management of medical outpatients. Br Med J. 1975;2:486-9.

3. Peterson MC, Holbrook JH, Von Hales D, Smith NL, Staker LV. Contributions of the history, physical examination, and laboratory investigation in making medical diagnoses. West J Med. 1992;156:163-5.

4. Beckman HB, Frankel RM. The effect of physician behavior on the collection of data. Ann Intern Med. 1984;101:692-6.

5. Marvel MK, Epstein RM, Flowers K, Beckman HB. Soliciting the Patient's Agenda: Have We Improved? JAMA. 1999;281:283-7.

6. Levinson W, Gorawara-Bhat R, Lamb J. A study of patient clues and physician responses in primary care and surgical settings. JAMA. 2000;284(8):1021-7.

7. Mjaaland Ta, Finset A, Jensen BF, Gulbrandsen P. Physicians' responses to patients' expressions of negative emotions in hospital consultations: a video-based observational study. Patient Educ Couns. 2011;84:332-7.

8. Schouten BC, Meeuwesen L. Cultural differences in medical communication: a review of the literature. Patient Educ Couns. 2006;64:21-34.

9. Meeuwesen L, Harmsen JAM, Bernsen RMD, Bruijnzeels MA. Do Dutch doctors communicate differently with immigrant patients than with Dutch patients? Soc Sci Med. 2006;63:2407-17.

10. Cahill P, Papageorgiou A. Triadic communication in the primary care paediatric consultation: a review of the literature. Br J Gen Pract. 2007;57:904-11.

11. Nova C, Vegni E, Moja EA. The physician-patient-parent communication: a qualitative perspective on the child's contribution. Patient Educ Couns. 2005;58:327-33.

12. Tates K, Meeuwesen L. Doctor-parent-child communication. A (re)view of the literature. Soc Sci Med. 2001;52(6):839-51.

13. Ring A, Dowrick C, Humphris G, Salmon P. Do patients with unexplained physical symptoms pressurise general practitioners for somatic treatment? A qualitative study. BMJ. 2004;328:1057.

14. Salmon P, Ring A, Humphris GM, Davies JC, Dowrick CF. Primary care consultations about medically unexplained symptoms: how do patients indicate what they want? J Gen Intern Med. 2009;24:450-6.

15. de Haes $\mathrm{H}$, Bensing J. Endpoints in medical communication research, proposing a framework of functions and outcomes. Patient Educ Couns. 2009;74(3):287-94.

16. Makoul G. Essential elements of communication in medical encounters: the Kalamazoo consensus statement. Acad Med. 2001;76:390-3.

17. Silverman J, Kurtz S, Draper J. Skills for communicating with patients. Second ed. Oxford: Radcliffe Publishing; 2005. 58-105 p.

18. Thiel JV, Ram P, Dalen Jv. MAAS-Global Manual. Maastricht Maastricht University Press; 2000

19. King N, Horrocks C. Interviews in Qualitative Research. London: SAGE Publications; 2010. p. 175212.

20. van Manen M. Researching lived experience, human science for an action sensitive pedagogy. Albany State University of New York Press.; 1990.

21. King N. Template Analysis. Available from: http://www.hud.ac.uk/hhs/research/template-analysis/ [29-07-2014].

22. Kvale S. Interviews: an introduction to qualitative research interviewing. Thousand Oaks, CA: Sage 1996.

23. Starks H, Trinidad SB. Choose your method: a comparison of phenomenology, discourse analysis, and grounded theory. Qual Health Res. 2007;17:1372-80.

24. McLachlan E, King N, Wenger E, Dornan T. Phenomenological analysis of patient experiences of medical student teaching encounters. Med Educ. 2012;46(10):963-73.

25. Rhoades DR, McFarland KF, Finch WH, Johnson AO. Speaking and interruptions during primary care office visits. Fam Med. 2001;33:528-32. 
26. Veldhuijzen W, Portegijs P, van der Weijden T, Ram P, Kruisifix L, Elwyn G, et al. An exploration of the extent to which doctors modify their goals to those of their patients and its effect on goal achievement by patients. Challenging the patient-centred paradigm Designing feasible guidelines for doctor-patient communication. Maastricht: Universitaire pers Maastricht; 2011. p. 153-68.

27. Salmon P, Young B. Creativity in clinical communication: from communication skills to skilled communication. Med Educ. 2011;45:217-26.

28. Veldhuijzen W, Ram P, van der Weijden $T$, Wassink M, van der Vleuten C. Much variety and little evidence: a description of guidelines for doctor-patient communication. Med Educ. 2007;41(2):13845.

29. Essers G, Kramer A, Andriesse B, van Weel C, van der Vleuten C, van Dulmen S. Context factors in general practitioner-patient encounters and their impact on assessing communication skills--an exploratory study. BMC Fam Prac. 2013;14:65.

30. Essers G, van Dulmen S, van Weel C, van der Vleuten C, Kramer A. Identifying context factors explaining physician's low performance in communication assessment: an explorative study in general practice. BMC Fam Prac. 2011;12:138.

31. Veldhuijzen W, Ram PM, van der Weijden T, van der Vleuten CPM. Communication guidelines as a learning tool: an exploration of user preferences in general practice. Patient Educ Couns. 2013;90:213-9.

32. Veldhuijzen W. Challenging the patient-centred paradigm: Designing feasible guidelines for doctorpatient communication. Maastricht: Datawyse; 2011.

33. Veldhuijzen W, Ram PM, van der Weijden T, Niemantsverdriet S, van der Vleuten CP. Characteristics of communication guidelines that facilitate or impede guideline use: a focus group study. BMC Fam Pract. 2007;8:31.

34. van den Eertwegh V, van Dalen J, van Dulmen S, van der Vleuten C, Scherpbier A. Residents' perceived barriers to communication skills learning: Comparing two medical working contexts in postgraduate training. Patient Educ Couns. 2014.

35. Mezirow J. Transformative learning: Theory to practice. New Directions for Adult and Continuing Education. 1997;1997(74):5-12.

36. Epstein RM. Whole mind and shared mind in clinical decision-making. Patient Educ Couns. 2013;90(2):200-6.

37. Tracy SJ. Qualitative Quality: Eight Big-Tent Criteria for Excellent Qualitative Research. Qual Inq. 2010;16(10):837-51. 



\section{CHAPTER}

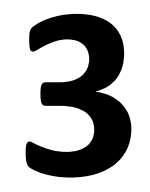

\section{How to gather information from talkative patients in a respectful and efficient manner: a qualitative study of GPs' communication strategies}

Esther Giroldi, Wemke Veldhuijzen, Annika Dijkman, Maxime Rozestraten, Jean Muris, Cees van der Vleuten, Trudy van der Weijden

Family Practice. 2016, 33:100-6.

(An adjusted version of this article has been published as: Consultvoering bij breedsprakige patiënten: 10 tips. Nederlands Tijdschrift voor de Geneeskunde. 2016;160: D184) 


\section{ABSTRACT}

\section{Objectives}

Gathering information from talkative patients presents a challenge to clinicians. Empirical evidence on how to effectively deal with this challenge is scant. This study explores communication strategies and their underlying mechanisms that general practitioners (GPs) consider effective when gathering information from talkative patients in order to inform the development of best practices.

\section{Methods}

We conducted a qualitative study with experienced GPs. We held individual stimulated-recall interviews (SRIs) with 6 GPs using their videotaped consultations as a stimulus. The transcripts that ensued were triangulated with data from 3 focus-group discussions (FGs). We performed a thematic network analysis during an iterative process of data collection and analysis.

\section{Results}

To deal with talkative patients during consultations, GPs first try to pinpoint the cause of patients' talkativeness before deciding on the approach to take. Moreover, they resort to the familiar communication strategies, however, in doing so adopt a more directive attitude. To prevent such attitude from damaging the relationship, GPs take a stepped approach in which they try not to be overly directive, make the patient coresponsible for efficient time management, and they make use of empathic interrupting.

\section{Conclusions}

In the absence of evidence, this description of GPs' communication strategies can guide clinicians, residents, and students in gathering information from talkative patients in an efficient, yet empathic and respectful manner. When developing best practices, heed should be paid to the causes of patients' talkativeness and the tension between taking a directive approach and building a doctor-patient relationship. 


\section{BACKGROUND}

Gathering information from a talkative patient is challenging for doctors. Seeing the name of a talkative patient on the schedule may even to lead to a "heartsink feeling" $(1,2)$. Talkativeness, also referred to as "off-target verbosity", is defined as speech that is excessive, lacks focus, and contains irrelevant information (3). Not being able to collect the relevant information about the patient's symptoms, context, ideas, concerns, and preferences may lead to improper diagnostics and treatment and inhibit the delivery of patient-centred care (4-6).

The traditional recommendations for patient-centred communication may not work on talkative patients (2). These recommendations mainly propose the use of skills that invite patients to talk, such as active listening, the open-to-closed cone, not interrupting the patient, facilitative responses, and clarifying statements $(7,8)$. When seeing talkative patients, doctors sense that their quest for information potentially conflicts with other goals, such as relationship-building and time management $(1,2)$. Interrupting a talkative patient on repeated occasions, for example, may be necessary to keep the patient on-topic, yet may jeopardize patients' feeling of being heard and thereby the doctor-patient relationship (9). Dealing with such goal conflicts is challenging for doctors $(10,11)$.

Research has focused on effective information-gathering skills in general patient populations (12-14), which has resulted in generic advices for information-gathering that do not take the context of the patient into account $(7,8)$. What we have not yet encountered, however, are empirical studies into the specific question of how information from talkative patients can be gathered in an efficient way. The present study investigates which communication strategies experienced general practitioners (GPs) consider effective and why in order to assist clinicians, medical students, and residents in handling this challenging situation. We chose to interview GPs as we assume that they are part of a community of professionals facing the same problems, exchanging information and learning from each other, while becoming increasingly adept at finding solutions to their problems $(15,16)$. Moreover, we assume that during their years of clinical experience, GPs have developed feasible and contextspecific communication strategies and have found ways to handle goal conflicts. As such, their input can serve as a starting point for the development of best practices in gathering information from talkative patients. 


\section{METHODS}

\section{Design}

In this qualitative study that explores GPs' communication strategies, we triangulated stimulated-recall interviews (SRIs) based on videotaped consultations with focusgroup discussions (FGs) (Figure 3.1). We performed a thematic network analysis during iterative data collection and analysis (17-19).

Iterative data collection \& analysis

Each SRI and FG interview was

analysed before proceeding with

data collection, thereby informing

the following SRI/FG

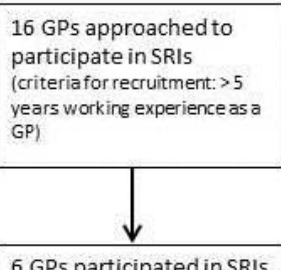

6 GPs participated in SRIs discussing 9 consultations

60 GPs approached to participate in FGs

(criteria for recruitment: being

a GP supervisor, $>5$ years

working experience as a GP)

25 GPs participated in

three $F G s(N=8, N=7, N=10)$

Figure 3.1 Flow chart of data collection and analysis

\section{Study Context}

The study was conducted in a Dutch general practice setting. In the Netherlands, GPs see enlisted patients who are allowed to register in one practice only. Thus as a general rule, GPs see their own patients with whom they have a continuous and longstanding relationship. Usually, ten minutes of consultation time are scheduled per patient, while this time may be doubled in case of multiple and/or complex problems. GPs in the Netherlands have all completed a three-year post-graduate training, followed by obligatory re-registrations and extra trainings. 
Table 3.1 Characteristics of the participating GPs and the conducted interviews

\begin{tabular}{lllll}
\hline $\begin{array}{l}\text { Dataset } \\
\text { (N GPs) }\end{array}$ & $\begin{array}{l}\text { Sex } \\
\text { male:female (N) }\end{array}$ & $\begin{array}{l}\text { Age } \\
\text { range (mean) }\end{array}$ & $\begin{array}{l}\text { Years of experience } \\
\text { as GP range (mean) }\end{array}$ & $\begin{array}{l}\text { Interview time } \\
\text { in minutes range }\end{array}$ \\
\hline SRI (6) & $5: 1$ & $36-59(46,3)$ & $5-32(15,8)$ & $60-90$ \\
FG (25) & $14: 11$ & $36-61(49,9)$ & $6-35(19)$ & $70-90$ \\
\hline
\end{tabular}

\section{Stimulated-recall interviews}

We recruited 16 GPs from the region who had at least five years of work experience as a GP, informed them of the study, and invited them to participate. Six GPs participated in the SRIs (Table 3.1). For each partaking GP, the consulting hours of one full day were observed and video recorded by the researcher. Subsequently, the researcher listed characteristics of talkativeness derived from the literature (Figure 3.1) and invited the GP to select one or two consultations that in their experience fitted these characteristics. A total of 9 consultations were discussed, including a mixture of first and follow-up visits and a variation in terms of the reason for visit (Table 3.2). To stay as close to daily practice as possible, the researcher watched the selected consultation(s) with the GPs and asked them to stop the video each time they wanted to share thoughts, intentions, and actions regarding informationgathering. When a moment deemed relevant by the researcher presented itself, and the GPs did not stop the video, the researcher did so. If necessary, the researcher prompted the GPs by asking them what complicated the information-gathering process at that particular moment, how they tackled this, and why they deemed this effective.

\section{Focus groups}

In order to obtain a more in-depth understanding of the underlying mechanisms of communicative actions, we organized focus-group discussions with GPs: we expected that such an interactive setting in which GPs were distanced from actual practice, would invoke deeper reflection on how they believed their actions were effective. We purposively sampled GP supervisors (practicing GPs supervising a GP trainee in their own practice) who as a coach and role model for their trainees are well capable of explicating the reasons for their behaviour. GP supervisors have at least five years of work experience and regularly meet at educational meetings of the GP specialty training programme. Sixty GP supervisors from two different specialty training centres were informed about the study of which 25 GPs participated in the FGs. Three FGs 
were held with eight, seven, and ten GPs respectively, all three groups meeting once for a FG discussion. These GPs differed from the GPs participating in the SRIs.

Table 3.2 Characteristics of the consultations selected for the stimulated recall interviews

\begin{tabular}{llllll}
\hline Patient & $\begin{array}{l}\text { Sex } \\
(\mathrm{m} / \mathrm{f})\end{array}$ & $\begin{array}{l}\text { Age } \\
\text { (yrs.) }\end{array}$ & Reason for visit & $\begin{array}{l}\text { First / follow- } \\
\text { up visit }\end{array}$ & $\begin{array}{l}\text { Duration of } \\
\text { consultation (min) }\end{array}$ \\
\hline 1 & $\mathrm{f}$ & 73 & Diarrhoea & First & 17 \\
2 & $\mathrm{~m}$ & 79 & Incontinence & First & 15 \\
3 & $\mathrm{~m}$ & 92 & Coughing, headache, fever & First & 11 \\
4 & $\mathrm{~m}$ & 60 & Pneumonia & Follow-up & 9 \\
5 & $\mathrm{f}$ & 73 & Knee problems & First & 12 \\
6 & $\mathrm{~m}$ & 62 & Cholesterol check, COPD & Follow-up & 11 \\
7 & $\mathrm{~m}$ & 49 & Psychosocial problems & Follow-up & 42 \\
8 & $\mathrm{f}$ & 75 & Blood pressure check & Follow-up & 20 \\
9 & $\mathrm{f}$ & 70 & Infected toe (diabetes) & Follow-up & 14 \\
\hline
\end{tabular}

An experienced chair moderated the FGs. The primary researcher (EG) took field notes. To trigger authentic solutions, the topic was introduced by using several quotes from GP trainees struggling to gather information from talkative patients that originated from a previous study (2). Participants were then prompted to share with each other how they handled these situations and which mechanisms rendered these actions effective in their view. Within two weeks after the discussion, we performed a member check by sending every participant a summary of the discussion and inviting them to comment on its accuracy, which did only lead to confirmations without any revisions.

\section{Analysis}

All interviews were audiotaped and transcribed verbatim. First, the individual interviews were analysed by coding relevant fragments using specialized software (Atlas-ti). Memo-writing guided the interpretation of patterns that emerged from the data (17). The codes were then organized into a thematic network visualizing the relationships between themes (18). This network and its codes derived from the SRIs were used as a starting point for the FG-analysis, during which the coding and memowriting continued and the network was extended and refined.

Each SRI and FG interview was analysed before proceeding with data-collection, allowing us to adjust the focus in the following interview. All transcripts were analysed independently by two researchers with different backgrounds (medical vs. nonmedical). Coding discrepancies were discussed until consensus was reached. 
Although the type of strategies described in the SRIs and FGs largely overlapped, the FGs resulted in a deeper understanding of the mechanisms underlying the specific actions identified in the SRIs. In addition, the FGS brought to light some new communication strategies that were not identified in the SRIs, in particular in relation to understanding the underlying cause of the patient's talkativeness. Although the third FG did contain new examples of specific communicative actions, it did not contribute to a new or deeper understanding of the underlying mechanisms of GPs' strategies compared to the previous FGs and SRIs. Therefore, data saturation was considered to have been reached.

\section{RESULTS}

\section{GPs' approach to dealing with talkative patients}

Figure 3.2 showcases the approach taken by GPs when seeing talkative patients. The approach is guided by the underlying cause of patients' talkativeness: if it is inherent in the patient's personal communication style, GPs tend to adopt a more directive approach, but only to the extent that their doctor-patient relationship is not jeopardized. The next paragraphs will elaborate more on this process and GPs' specific communication strategies (Table 3.3).

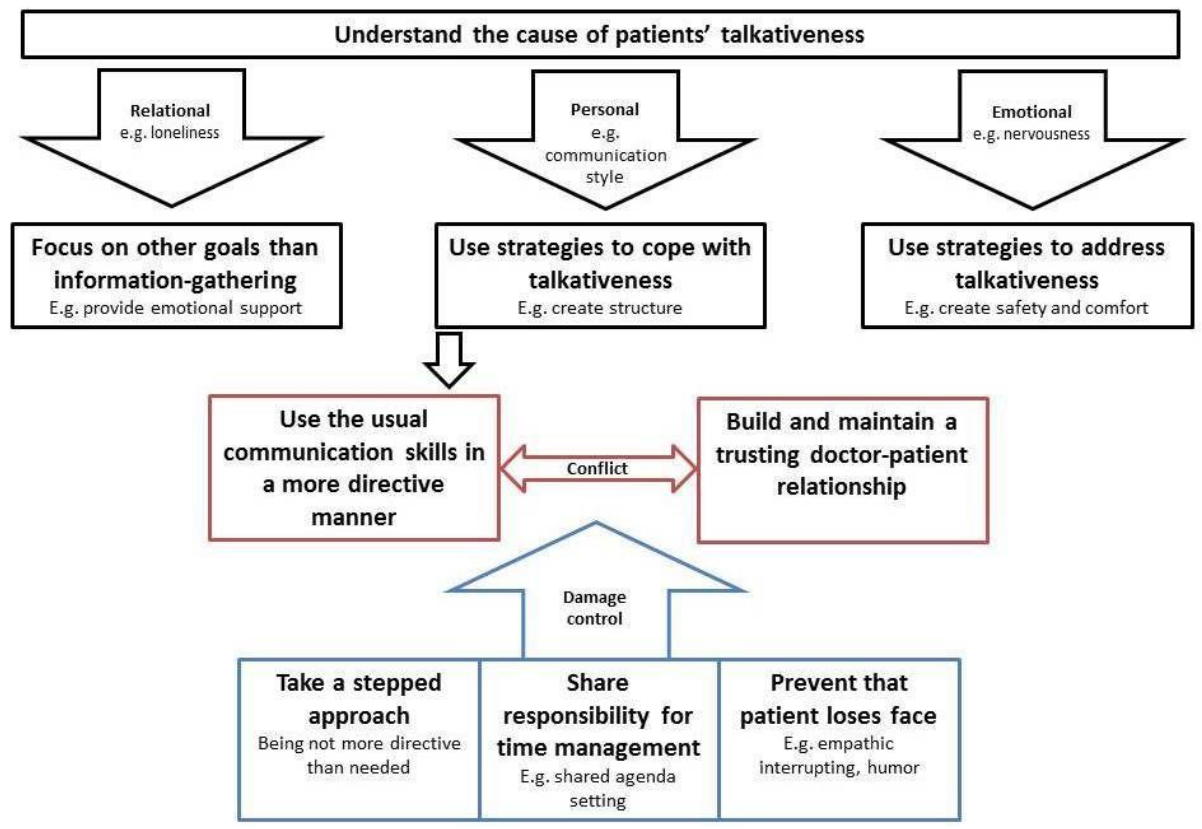

Figure 3.2 GPs' approach to dealing with talkative patients 


\section{Understanding patients' talkativeness}

GPs seek to understand the underlying cause of patients' talkativeness as this helps them to determine their communication strategy. The cause could be an underlying emotion which the GPs may help resolve. When a patient is nervous, for instance, the GP can try to make the patient feel more at ease. It may also happen that GPs discover a relational cause: in case of loneliness, for example, the patient's talkativeness could be an expression of his/her need for contact and support. In such cases specific information may not need to be obtained, as in the absence of a medical goal other goals such as the provision of emotional support take precedence. When the cause of patients' talkativeness cannot be abated, for instance when being talkative and unstructured is inherent in patients' communication style, GPs try to cope with this by creating structure, for example.

I think it is important to know what causes the talkativeness in the first place. Nervousness is concealing the request for help. Some people are visiting you just to complain, while actually they do not ask for a solution. They are done when they have told you everything, so virtually at the end you might just as well add a simple "okay", and then: "see you next week." There's no need to deduce anything from that. And some people put on a masquerade, which I think you need to be really careful about. These people tell you a lot, just because they don't have the courage to reveal their fear of cancer, because they found blood, name it, or have chest pain or something. And then they tell you that somewhere in a tiny phrase, which, yeah, I believe a professional should be able to catch, like: what type of talkativeness am I dealing with right now? - FG 1, GP 2

To understand which type of talkativeness they are dealing with, GPs explore the patients' background, for example by discussing their medical history during an initial consultation, asking them to list important life events, and exploring psychosocial problems. GPs may also be aided by behavioural cues that point to a certain cause, which they consequently try to pick up and explore further.

And also by being sensitive, so to speak, starting by acknowledging the way the patient is sitting in front of you, like: 'Gee, you look tensed, what is going on?' FG 1, GP 3 
Table 3.3 GPs' communication strategies to deal with talkative patients

\begin{tabular}{|c|c|}
\hline Communication strategy & $\begin{array}{l}\text { Dataset: } \\
\text { SRI/FG }\end{array}$ \\
\hline \multicolumn{2}{|l|}{ Understand the cause of patients' talkativeness } \\
\hline Gather (biomedical) background information & FG \\
\hline Explore psychosocial problems & FG \\
\hline Pick up cues/concerns & FG \\
\hline \multicolumn{2}{|l|}{ Relational cause: focus on other goals than information gathering } \\
\hline Provide emotional support: give space, active listening & SRI, FG \\
\hline Provide emotional support: show empathy, explore/name emotions & SRI, FG \\
\hline \multicolumn{2}{|l|}{ Personal cause: use strategies to cope with talkativeness } \\
\hline Create structure: signposting & SRI, FG \\
\hline Create structure: (closed-ended) summary & SRI, FG \\
\hline Create structure: (focused) evaluation of the consultation & SRI, FG \\
\hline Create structure: discuss available consultation time, type of complaints & SRI, FG \\
\hline \multicolumn{2}{|l|}{ Emotional cause: use strategies to address talkativeness } \\
\hline Create safety and comfort: acknowledge anxiety/nervousness & SRI, FG \\
\hline \multicolumn{2}{|l|}{ Damage control: take a stepped approach } \\
\hline Open exploration of reason for visit / complaints & SRI, FG \\
\hline Subtly redirection: reformulate/clarify question, multiple-choice & SRI, FG \\
\hline Straightforward redirection: strict instructions & SRI, FG \\
\hline \multicolumn{2}{|l|}{ Damage control: share responsibility for efficient time management } \\
\hline Phrase talkativeness as a shared problem & FG \\
\hline Shared agenda setting / prioritization & SRI, FG \\
\hline Ask patient to think about and write down complaints/questions beforehand & FG \\
\hline \multicolumn{2}{|l|}{ Damage control: ensure that patient doesn't lose face } \\
\hline Build-up credit & SRI, FG \\
\hline Empathic interrupting & SRI, FG \\
\hline Humour & FG \\
\hline
\end{tabular}

\section{A directive approach}

GPs try to cope with patients' talkativeness by encouraging them to give information in a more structured fashion. By making subtle adjustments to the communication skills they usually apply, such as summarising, and signposting, they take a more directive approach. More specifically, they take the lead more explicitly, giving patients less opportunity to talk, and setting clear boundaries, for example by explaining the type and number of problems that can be discussed during a visit. As talkative patients may stray off topic during a general evaluation of the consultation, some GPs try to refocus on the patients' specific request for help. Another example of 
a subtle adjustment is to make a summary "closed-ended", which prevents the patient from interrupting the GP.

I also believe it is about the art of summary. You can provide a summary in two ways: one way is to allow the patient to join in, whereas the other evokes the message: 'And now it is my turn to speak.' This is also influenced by your posture, intonation, and sentence structure. When I am observing residents, I often see them go astray by providing a summary that is very open, leaving the patient little other choice but to join in. - FG1, GP 1

\section{Damage control}

Being aware that a directive approach may damage the doctor-patient relationship, GPs wielded a host of strategies to prevent this from happening. They reported three mechanisms that rendered such strategies effective in their view: "taking a stepped approach," "sharing responsibility," and "ensuring that the patient does not lose face."

\section{Stepped approach}

Most GPs take a stepped approach toward being directive, trying not to be more directive than needed. They usually start with an open exploration, giving patients ample opportunity to tell their story. This helps them gain a general understanding of the patient's problem so that they can purposefully go into the specifics during the remainder of the consultation.

In my experience, it is often conveyed during the first minutes of the consultation, the story's essence. When you give people the chance to talk for a while and you're not right on the ball, so when you lean back for a moment, you often find the crux in the first few minutes already. So it will save you time which you can use for exploring the specifics. - FG1, GP 3

When patients give ambiguous answers or deviate from the topic, GPs first try to obtain the information they seek by using subtle strategies, such as reformulating the question, listing several options, specifying the type of answer needed, or clarifying the purpose of a question. If this does not work and patients keep straying off topic, 
GPs become more strict and explicit, given that they have already invested in the relationship and/or the seriousness of the symptoms demands such an approach.

Well, I also have a patient who does not respond to these subtleties. "And now give me a yes or no!" She is someone I have to approach in a very directive manner. Sometimes you really need to be a bit strict; take the lead. Often you start with this (subtle strategies), which may work out for a certain group, but not for this particular patient. I do not think this is the way to act at the first consultation. You first need to build-up credit. - FG 1, GP 6

\section{Sharing responsibility}

GPs explained that when patients are made co-responsible for effective time management, they realize the importance of an efficient use of the available consultation time. When GPs know beforehand that a patient is talkative, they sometimes address this matter and its consequences right in the beginning of the consultation. They typically do so by presenting it as a shared problem: both doctor and patient are held accountable for efficient time management.

Yes, what I often do is to make it a "we problem". Then you focus on your collective aim, by explicitly saying: 'Today we have ten minutes scheduled. I know from experience that "we" tend to end up chatting, so it would be a pity if "we" spend too much time on that at the expense of the real reason for your visit'. - FG 2, GP 10

At the start of the consultation, GPs try to reach consensus about the symptoms that will be discussed during the consultation and the time allocated to do so. GPs felt that actively involving the patient in the agenda-setting made it less likely that they would stray off topic later on in the consultation. Should they still deviate from the topic, then it would be easier to redirect them to an agenda on which both parties have previously agreed.

I do that [doctor suggests to make a list of symptoms] so that I can satisfy him eventually. Otherwise it would be my choice to decide what's important and what's not. This would only result in a struggle for power. I want him to name it, to set the agenda and decide on what's important, allowing me, in fact, to zoom in on the territory over which he let me rule. - SRI, GP 4 
GPs mentioned that joint responsibility also helps prevent talkativeness in future encounters; they teach patients how to prioritize problems and structure their information, for instance by asking patients to actively think about or write down their questions and symptoms before the consultation.

\section{Ensure that the patient does not lose face}

GPs recognized that their directive approach and interruptions could give the false impression that the doctor was disinterested in the patient's story and found the patient's information irrelevant. To show that they did value the patient's information and did take the patient seriously, they employed various strategies, which are spelt out below.

\section{Build-up credit}

A way to demonstrate their appreciation of the patients' information was to first give patients the opportunity to tell their story. GPs then listened actively without interruptions as a way to "build-up credit." Such experience of feeling heard and understood was expected to reduce chances of a future interruption being experienced as insulting or disrespectful.

No, when you give space, you are entitled to take it back. That is reciprocity. FG 1, GP 4

\section{Empathic interrupting}

An oft-employed strategy to smoothen interruptions is to acknowledge the importance of what the patient has to say. Knowing that the doctor takes the problem seriously enables patients to refocus their attention on the current problem. GPs, for example, acknowledge the importance of a newly mentioned problem before transferring it to later on in the consultation, to a follow-up consultation, or to another health care professional.

Then you say 'that is so important, shall we get back to that next week?'. In such case the patient is less troubled, as the doctor 'already knows,' which releases the pressure. - SRI, GP 3 
Empathic interrupting also requires GPs to demonstrate that they too are uncomfortable interrupting the patient. This is achieved by emphasising that such interruption serves a legitimate purpose, for example by mentioning the effect of the patient's talkativeness on the GP's ability to solve the problem.

Well, by naming it. 'You mention many issues at once, which confuses me. I would like to go back to the real reason for your visit.' Then they often reply that it is related to it, or yes, indeed, it is a digression. - FG 3, GP 17

Then I just say: 'Stop!' And so it stops. Then they look at me and I say: 'Listen, you want to tell me a lot and I understand this is important to you, but I won't be able to find a solution like this. So I am going to ask you my question now.' - FG 3, GP 21

While stating the consequences of the talkativeness, the GP may explicitly ask the patient for help, without blaming and insulting him or her.

Then I say: 'This is too difficult for me, I need some help with that, I need you to help me. We only have ten minutes, so it is also important I get a clear understanding of the purpose of your visit.' - FG 1, GP 7

You cannot tone down a talkative lady in ten minutes, but you can indeed try to make it your problem so as not to offend her by saying: 'Oh, wait a minute, this is a lot of information here, say it again, what exactly was the reason you called?' The fact that it is not her or his problem, I think, will do good to the patient's dignity. FG 1, GP 3

Another expression of empathic interrupting is to connect to the patient's story, and consequently take over the initiative without the patient noticing it. Specific strategies that were mentioned include linking new symptoms to the current one or asking a specific question about the current symptom.

Very subtly, I try to be really kind and to join in with something, so that I can interrupt. What I do is, I take a detail and then I interrupt him with a question about that detail, which allows me to get the floor. Once I have the floor I start to direct 
more, like 'yes, I understand what you're saying, but I would like to know more about...' and then I try to focus on something that is relevant. - SRI, GP 4

\section{Humour}

When GPs already have a long-standing relationship with a patient, they sometimes accompany their interruption with humour. This way they can make the patients aware of their talkativeness, without blaming or accusing them.

Sometimes humour works, but in these cases you should be a little familiar with your people. I have two patients whom I sometimes ask: 'Alright, where is the button to switch you off? Be quiet for a change, will you.' Yes, and then they laugh and the laughing causes them to be quiet for a little while, which allows me to seize my opportunity. - FG 1, GP 7

\section{DISCUSSION}

\section{Summary}

GPs accommodate their communication strategy to the cause of patients' talkativeness: if it is inherent in patients' personal communication style, GPs help them convey the information in a structured manner. To deal with talkative patients, GPs resort to the familiar patient-centred skills promoted in medical communication skills trainings, however, in doing so they take a more directive approach. As a directive attitude might damage the relationship, GPs use a stepped approach in which they try not to be overly directive, they share responsibility for efficient time management, and they acknowledge the importance of the patient's story, for example by employing empathic interrupting.

\section{Comparison with existing literature}

The communication strategies identified in this study find resonance in previous literature. By using strategies such as empathic interrupting and sharing responsibility, GPs manage to handle the conflict between information-gathering and relationshipbuilding that GP trainees experience (2). The GPs in this study have demonstrated how these two goals can go together in harmony. Empathic interrupting has been suggested to be instrumental in doctor-patient communication for its potential to furnish the doctor with the necessary information while meeting patients' need for social closeness (20). Sharing responsibility for agenda-setting has been shown to 
improve efficiency and patient satisfaction $(21,22)$. GPs also stressed the importance of investing in the relationship first before taking a directive approach. It has been well recognized that relationship-building facilitates more effective communication ( 7 , 8, 23-25).

GPs' directive approach could be associated with the traditional paternalistic model $(26,27)$. Despite GPs' directive attitude however, acknowledging the importance of patients' story and focusing on the patients' request for help remains key. The extent to which GPs adopt a directive approach very much depends on the cause of talkativeness, the symptom's severity, and on patients' response to their attempt to structure the consultation. This confirms once again that in medical communication in general, and in consultations with talkative patients in particular, there is no one-sizefits-all approach $(23,28-31)$.

\section{Strengths and limitations}

The use of several techniques has bolstered the trustworthiness of our findings (19). First, we triangulated stimulated-recall interviews in which we stayed close to daily practice with focus-group discussions detached from daily practice, which allowed us to obtain an in-depth understanding of GPs' actual behaviour and its underlying mechanisms. Second, all interviews were independently coded by a researcher with an insider and one with an outsider perspective. Last, we performed a member check. The fact that we collected and analysed data during an iterative process, used a method of constant comparison, and data saturation was achieved, has ensured consistency of our findings in a context of general practice. However, the transferability of the identified strategies to settings other than general practice remains to be investigated, particularly those strategies that require a longitudinal relationship.

Our findings do not allow us to make inferences regarding the actual effectiveness of the described strategies, for example in terms of the duration of the consultation or volume of information collected. Neither did we explore how patients experienced GPs' communication strategies and their effects on patient outcomes, such as satisfaction and anxiety. These issues merit attention in future studies with larger populations using both qualitative and quantitative methods. In contrast to the subjective operationalization of talkativeness employed in this qualitative study, future quantitative studies evaluating the effectiveness of specific interventions may 
develop a more objective definition of talkativeness, e.g. in terms of duration of the consultation, duration of the history taking, number of interruptions etc.

\section{Conclusions}

Our detailed descriptions of GPs' strategies to gather information from talkative patients efficiently without damaging the relationship are a first step towards defining explicit interventions for evaluation. We also believe that, in the absence of evidence, this description can guide doctors, residents, and medical students. Once the effectiveness of these strategies has been studied, they could be incorporated into medical communication skills trainings. The result may be that talkative patients are no longer regarded as "heartsink patients", but rather as a challenge that doctors can confidently overcome. 


\section{REFERENCES}

1. Elder N, Ricer R, Tobias B. How respected family physicians manage difficult patient encounters. J Am Board Fam Med. 2006;19(6):533-41.

2. Giroldi E, de Leve T, Veldhuijzen W, Bueving H, van der Weijden T, van der Vleuten C. 'I still have no idea why this patient was here': an exploration of the challenges GP trainees experience when gathering information. Patient Educ Couns. 98(7):837-42.

3. Arbuckle TY, Gold DP. Aging, inhibition, and verbosity. J Gerontol. 1993;48:P225-32.

4. Hampton JR, Harrison MJ, Mitchell JR, Prichard JS, Seymour C. Relative contributions of historytaking, physical examination, and laboratory investigation to diagnosis and management of medical outpatients. Br Med J. 1975;2:486-9.

5. Peterson MC, Holbrook JH, Von Hales D, Smith NL, Staker LV. Contributions of the history, physical examination, and laboratory investigation in making medical diagnoses. West J Med. 1992;156:163-5.

6. Roshan M, Rao AP. A study on relative contributions of the history, physical examination and investigations in making medical diagnosis. J Assoc Physicians India. 2000;48:771-5.

7. Silverman J. Skills for Communication with Patients. Oxford - San Francisco 2005.

8. Makoul G. The SEGUE Framework for teaching and assessing communication skills. Patient Educ Couns. 2001;45:23-34.

9. Rhoades DR, McFarland KF, Finch $\mathrm{WH}$, Johnson aO. Speaking and interruptions during primary care office visits. Fam Med. 2001;33:528-32.

10. Veldhuijzen W, Portegijs P, van der Weijden T, Ram P, Kruisifix L, Elwyn G, et al. An exploration of the extent to which doctors modify their goals to those of their patients and its effect on goal achievement by patients. Challenging the patient-centred paradigm Designing feasible guidelines for doctor-patient communication. Maastricht: Universitaire pers Maastricht; 2011. p. 153-68.

11. de Haes $\mathrm{H}$, Bensing J. Endpoints in medical communication research, proposing a framework of functions and outcomes. Patient Educ Couns. 2009;74(3):287-94.

12. Henbest RJ, Stewart M. Patient-centredness in the consultation. 2: Does it really make a difference? Fam Pract. 1990;7(1):28-33.

13. Roter DL, Hall JA. Physician's interviewing styles and medical information obtained from patients. J Gen Intern Med. 1987;2(5):325-9.

14. Levinson W GBR, Lamb J. A study of patient clues and physician responses in primary care and surgical settings. 2000:6-7.

15. Egan T, Jaye C. Communities of clinical practice: the social organization of clinical learning. Health (London, England : 1997). 2009;13(1):107-25.

16. Ranmuthugala G, Plumb JJ, Cunningham FC, Georgiou A, Westbrook JI, Braithwaite J. How and why are communities of practice established in the healthcare sector? A systematic review of the literature. BMC health services research. 2011;11:273.

17. Watling CJ, Lingard L. Grounded theory in medical education research: AMEE Guide No. 70. Med Teach. 2012;34:850-61.

18. Attride-Stirling J. Thematic networks: an analytic tool for qualitative research. Qual Res. 2001;1:385405.

19. Frambach JM, van der Vleuten CP, Durning SJ. AM last page. Quality criteria in qualitative and quantitative research. Acad Med. 2013;88(4):552.

20. Černý M. Interruptions and overlaps in doctor-patient communication revised. Linguistica ONLINE. 2010.

21. Baker LH, O'Connell D, Platt FW. "What else?" Setting the agenda for the clinical interview. Ann Intern Med. 2005;143(10):766-70.

22. Brock DM, Mauksch LB, Witteborn S, Hummel J, Nagasawa P, Robins LS. Effectiveness of intensive physician training in upfront agenda setting. J Gen Intern Med. 2011;26:1317-23.

23. Giroldi E, Veldhuijzen W, Leijten C, Welter D, van der Weijden T, Muris J, et al. 'No need to worry': an exploration of general practitioners' reassuring strategies. BMC Fam Prac. 2014;15(1):133.

24. Giroldi E, Veldhuijzen W, Mannaerts A, van der Weijden T, Bareman F, van der Vleuten C. "Doctor, please tell me it's nothing serious": an exploration of patients' worrying and reassuring cognitions using stimulated recall interviews. BMC Fam Prac. 2014;15(1):73. 
25. Mikesell L. Medicinal relationships: caring conversation. Med Educ. 2013;47(5):443-52.

26. Taylor K. Paternalism, participation and partnership - the evolution of patient centeredness in the consultation. Patient Educ Couns. 2009;74:150-5.

27. Joosten EaG, DeFuentes-Merillas L, de Weert GH, Sensky T, van der Staak CPF, de Jong CaJ. Systematic review of the effects of shared decision-making on patient satisfaction, treatment adherence and health status. Psychother Psychosom. 2008;77:219-26.

28. Veldhuijzen W, Mogendorff K, Ram P, van der Weijden T, Elwyn G, van der Vleuten C. How doctors move from generic goals to specific communicative behavior in real practice consultations. Patient Educ Couns. 2013;90(2):170-6.

29. Essers G DS, Weel CV, Vleuten CVD, Kramer A. Identifying context factors explaining physician's low performance in communication assessment: an explorative study in general practice. BMC Fam Pract. $2011 ; 12: 138$.

30. Essers G KA, Andriesse B, van Weel C, van der Vleuten C, van Dulmen S. Context factors in general practitioner-patient encounters and their impact on assessing communication skills--an exploratory study. BMC Fam Pract 2013. 2013;14(65).

31. Swenson SL, Buell S, Zettler P, White M, Ruston DC, Lo B. Patient-centered communication: do patients really prefer it? J Gen Intern Med. 2004;19:1069-79. 


\section{CHAPTER}

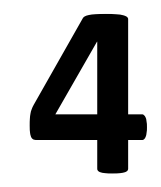

\section{"Doctor, please tell me it's nothing serious": an exploration of patients' worrying and reassuring cognitions using stimulated recall interviews}

Esther Giroldi, Wemke Veldhuijzen, Alexandra Mannaerts, Trudy van der Weijden, Frits Bareman, Cees van der Vleuten

BMC Family Practice. 2014, 15:73. 


\section{ABSTRACT}

\section{Background}

Many patients who consult their GP are worried about their health, but there is little empirical data on strategies for effective reassurance. To gain a better understanding of mechanisms for effective patient reassurance, we explored cognitions underlying patients' worries, cognitions underlying reassurance and factors supporting patients' reassuring cognitions.

\section{Methods}

In a qualitative study, we conducted stimulated recall interviews with 21 patients of 12 different GPs shortly after their consultation. We selected consultations in which the GPs aimed to reassure worried patients and used their videotaped consultation as a stimulus for the interview. The interviews were analysed with thematic coding and by writing interpretive summaries.

\section{Results}

Patients expressed four different core cognitions underlying their concerns: 'I have a serious illness', 'my health problem will have adverse physical effects', 'my treatment will have adverse effects' and 'my health problem will negatively impact my life'. Patients mentioned a range of person-specific and context-specific cognitions as reasons for these core cognitions. Patients described five core reassuring cognitions: 'I trust my doctor's expertise', 'I have a trusting and supporting relationship with my doctor', 'I do not have a serious disease', 'my health problem is harmless' and 'my health problem will disappear.' Factors expressed as reasons for these reassuring cognitions were GPs' actions during the consultation as well as patients' pre-existing cognitions about their GP, the doctor-patient relationship and previous events. Patients' worrying cognitions were counterbalanced by specific reassuring cognitions, i.e. worrying and reassuring cognitions seemed to be interrelated.

\section{Conclusions}

Patients described a wide range of worrying cognitions, some of which were not expressed during the consultation. Gaining a thorough understanding of the specific cognitions and tailoring reassuring strategies to them should be an effective way of achieving reassurance. The identified reassuring cognitions can guide doctors in applying these strategies in their daily practice. 


\section{BACKGROUND}

Many patients consult their general practitioner (GP) because they experience certain symptoms and are worried that these may be indicative of serious illness (1-3). Patients with a chronic or progressive condition often worry about the potential impact of disease on their daily life, such as becoming dependent on others (4). Anxiety about illness causes psychological distress, posing a major burden to patients $(5,6)$. Understanding how to reassure patients effectively is important because reassurance can improve patients' health status and well-being (7-11). It has also been suggested that effective reduction of anxiety helps patients to better understand information given by the doctor and strengthens the doctor-patient relationship (8, 10).

As general practitioners are generally aware of the importance of effective reassurance, they use various strategies to reassure their patients, such as enhancing patients' insight into the benign cause of the complaint (12). However, evidence for the effectiveness of these strategies is limited. Previous studies have shown that attempts to reassure patients are often ineffective (13-16). Clinicians and textbooks may attribute unsuccessful reassurance to patients' abnormal illness behaviour, i.e. persistence of illness behaviour despite medical reassurance (13, 17-19). However, an alternative explanation placing less blame on the patient is that ineffective reassurance may be due to the fact that patients and doctors perceive clinical encounters in different ways (20-22). Patients might understand and interpret the doctor's reassuring statements quite differently than expected by the doctor. For example, the doctor stating that the complaints are not serious fails to achieve the intended effect when these complaints severely impact the patient's everyday life (17). This suggests that a thorough understanding of patients' concerns is a key factor for successful reassurance. Patients do indeed feel more reassured when their doctor explores their concerns using screening questions such as 'have you any other concerns or questions?' (10).

The "common sense model of illness representations" describes how patients facing a health problem construct disease cognitions related to symptoms, causes, duration, controllability and consequences (23-26). The emotional component of illness comprises how patients feel in response to these cognitions, e.g. their being anxious 
or worried (24). Effective reassurance is likely to depend on doctors being aware of and addressing these cognitions and worries. This supports the relevance of studies aimed at enhancing insight into mechanisms that determine effective reassurance of patients. Therefore we firstly aim to understand what cognitions underlie patients' worries, what cognitions underlie patients' feeling of being reassured and what factors (GP factors, communication factors and other contextual factors) support patients' reassuring cognitions.

\section{METHODS}

\section{Design}

In order to explore patients' experiences and cognitions related to concerns and reassurance, we conducted a qualitative study in which we used recent, videotaped consultations of the participating patients with their GP as stimulus for stimulated recall interviews with the patients (27). A thematic analysis of the interviews was performed to identify common themes. Drawing upon principles of grounded theory, we conducted an iterative process of data collection and analysis to facilitate further exploration of themes in subsequent interviews and the method of constant comparison (28).

\section{Ethical approval and informed consent}

The Medical Ethical Commission of Maastricht University Medical Centre granted ethical approval for the study protocol. All participating patients gave informed consent. Codes were used to anonymize the verbatim transcriptions of the recorded interviews.

\section{Study context}

The study was conducted in Dutch general practices. The Netherlands has general practices with enlisted patients, with each patient allowed to register in and attend one practice only. Thus as a general rule, GPs have a continuous and longstanding relation with their patients. In the visited practices, patients' appointments are booked in advance.

\section{Selection procedures}

GPs were recruited and informed of a study on reassurance with an invitation letter and a follow-up telephone call. Twelve GPs agreed to participate and were visited 
during a morning clinic. A total of 134 patients were informed of a study on doctorpatient communication. One of the researchers informed patients in the waiting room, both verbally and with an information letter. Before and after their consultation with their GP, the 68 participating patients $(50.7 \%)$ rated the level of their concern (i.e. how worried about your health problem are you at this moment?) on a scale ranging from 0 (not worried at all) to 10 (very worried). After the consultation, the GPs rated for each patient how important achieving the goal of reassurance was in this particular consultation, also on a scale ranging from 0 to 10 . Consultations were observed and recorded on video to enable patients to reflect upon non-verbal communication. From this sample we aimed to select two consultations at each visit that combined a high rating by the GP on the importance of reassurance with a high rating by the patient on their level of concern before the consultation. In case we were unable to identify two of such consultations, we prioritized the GP rating. Reassurance needed to be an explicit goal of the GP since the selected consultations were to be used for interviews with GPs about the way they reassured patients (12) and with patients about how they experienced their GP's reassuring efforts.

\section{The interviews}

The selected patients were interviewed by trained interviewers, preferably on the day of the consultation or shortly thereafter. To guarantee that patients felt comfortable, they were interviewed in their own homes. To ensure consistency in the approach of the three interviewers, they thoroughly discussed the interview procedure before and during the period of data collection. Moreover, a rehearsal session with simulated patients was organised to practice, discuss and receive feedback on the stimulated recall procedure.

At the start of the interview the patients were invited to elaborate on their health concerns in relation to their GP visit. Next, the researcher and the patient watched the recording of the patient's consultation. The patients were invited to stop the tape whenever they felt that something occurred that had influenced their level of concern during the consultation and to recall their thoughts regarding this moment. The researcher could stop the tape too at moments she considered relevant and ask patients how they experienced these moments. The researchers made this decision based on their literature study and clinical experience and by paying close attention to (non)-verbal expressions of cues and concerns. The researcher prompted patients to 
elaborate on their experiences and thoughts (e.g. why was that reassuring; what were your thoughts at that moment?).

\section{Data analysis}

The interviews were transcribed verbatim. After carefully reading the transcripts, the researchers used specialized software (Atlas-ti) to identify and code relevant fragments. Open coding was used to identify themes and axial coding was performed to understand how themes related to each other. Transcripts were compared with those that had already been analysed to revise and refine themes. Memo writing guided the identification and interpretation of patterns that emerged from the data (28). The coded sections and memo's formed the basis for writing interpretive summaries of every patient. These summaries helped to understand how different worrying cognitions were counterbalanced by reassuring cognitions and which factors facilitated that process. To increase the credibility of the results, the transcripts were coded independently by at least two researchers with different backgrounds, i.e. health sciences (EG) or medicine (WV/AM), increasing scope and deepening understanding of the data (29). Discrepancies in coding were discussed until consensus was reached. All the authors discussed the themes that were identified during the analysis.

\section{RESULTS}

\section{Data characteristics}

A total of 21 patients were interviewed (Table 4.1), of which nine were female. Patients' age ranged from 19 to 89 years (mean: 53.8 years). The twelve GPs came from ten different practices, representing a range of practice settings (rural, urban, solo, duo and group practices). The sample represented a mixture of follow-up and stand-alone appointments, with a mean consultation time of 12 minutes (Table 4.1). The analysis of the GP interviews (12) indicated that GPs did not expect serious pathology to be present in any of the selected consultations, based upon their findings of the history taking, physical examination and, if applicable, additional investigations.

As the analysis of the last five interviews did not yield any new themes and confirmed the results, saturation was reached. 


\begin{tabular}{|c|c|c|c|c|c|}
\hline Patient & $\begin{array}{l}\text { Patients' rating: } \\
\text { concern pre- } \\
\text { consultation } \\
(0-10)\end{array}$ & $\begin{array}{l}\text { GPs' rating: } \\
\text { importance } \\
\text { reassurance } \\
(0-10)\end{array}$ & Complaint(s) & $\begin{array}{l}\text { Stand-alone / } \\
\text { follow-up } \\
\text { appointment }\end{array}$ & $\begin{array}{c}\text { Duration } \\
\text { consultation } \\
\text { (minutes) }\end{array}$ \\
\hline 1 & 10 & 8 & Chest pain & Stand-alone & 16 \\
\hline 2 & 6 & 8 & $\begin{array}{l}\text { Abdominal pain, } \\
\text { lower back pain }\end{array}$ & Follow-up & 9 \\
\hline 3 & 0 & 8 & $\begin{array}{l}\text { Reduced kidney } \\
\text { function }\end{array}$ & Stand alone & 9 \\
\hline 4 & 6 & 10 & $\begin{array}{l}\text { Hypertension, } \\
\text { lower back pain }\end{array}$ & Follow-up & 15 \\
\hline 5 & 3 & 10 & Stool problems & Follow-up & 8 \\
\hline 6 & 10 & 10 & $\begin{array}{l}\text { Accelerated } \\
\text { heartbeat, } \\
\text { headache }\end{array}$ & Follow-up & 19 \\
\hline 7 & 10 & 10 & $\begin{array}{l}\text { Chest pain, } \\
\text { headache, } \\
\text { hypertension }\end{array}$ & Stand-alone & 15 \\
\hline 8 & 0 & 3 & Burn & Stand-alone & 7 \\
\hline 9 & 1 & 4 & Sore throat & Stand-alone & 7 \\
\hline 10 & 4 & 7 & $\begin{array}{l}\text { Sudden shaking } \\
\text { attack, furuncle }\end{array}$ & Follow-up & 7 \\
\hline 11 & 7 & 7 & $\begin{array}{l}\text { Hypertension, } \\
\text { headache, nausea }\end{array}$ & Stand-alone & 14 \\
\hline 12 & 2 & 8 & Chest pain & Stand-alone & 13 \\
\hline 13 & 8 & 7 & Skin mark & Follow-up & 10 \\
\hline 14 & 4 & 7 & Ankle pain & Stand-alone & 9 \\
\hline 15 & 10 & 10 & $\begin{array}{l}\text { Breast lump, joint } \\
\text { pain }\end{array}$ & Stand-alone & 17 \\
\hline 16 & 6 & 8 & $\begin{array}{l}\text { Burn out, } \\
\text { hypertension }\end{array}$ & Follow-up & 21 \\
\hline 17 & 1 & 7 & $\begin{array}{l}\text { Wrist pain, } \\
\text { excessive } \\
\text { sweating }\end{array}$ & Stand-alone & 8 \\
\hline 18 & 7 & 10 & $\begin{array}{l}\text { Hypertension, } \\
\text { weight gain }\end{array}$ & Follow-up & 12 \\
\hline 19 & 7 & 9 & Hip complaints & Stand-alone & 11 \\
\hline 20 & 1 & 9 & Urinary problems & Stand-alone & 11 \\
\hline 21 & 0 & 9 & Leg pain & Stand-alone & 15 \\
\hline
\end{tabular}

\section{The interviews}

Twenty patients were interviewed on the day of the consultation and one patient was interviewed seven days later. The interviews lasted between thirty and sixty minutes. In most cases patients spontaneously shared cognitions related to their concerns. Even patients with a low level of concern spontaneously expressed concerns and 
underlying worrying cognitions during the interview. Not all worrying cognitions discussed in the interview had been mentioned in the consultation. Specifically cognitions regarding the adverse effects of medication were expressed in several interviews but were never mentioned during consultations. Patients easily described the GPs' actions they experienced as reassuring, but did not often express spontaneously how these actions supported reassuring cognitions. This was explored by further probing by the researcher.

\section{Worrying cognitions and how reassuring cognitions counterbalance them}

Patients described four worrying core cognitions. As explanations for why they had these core cognitions, patients expressed person-specific cognitions (concerns related to their complaints, their body and self-image) and context-specific cognitions (concerns related to their social environment) (Table 4.2). While person-specific cognitions were often expressed in relation to context-specific cognitions, they were sometimes expressed individually.

In addition, patients mentioned five reassuring core cognitions. As explanations for why they had these core cognitions, patients mentioned consultation-specific factors (GPs' actions during the consultation) and context-specific factors (patients' preexisting cognitions based on experiences that had occurred before the consultation, e.g. regarding their GP, the doctor-patient relationship and prior events) (Table 4.3).

The analysis of the data revealed possible relationships between worrying and reassuring core cognitions, as three reassuring cognitions seemed to directly counterbalance either one or two specific worrying cognitions (Figure 4.1). However the two reassuring cognitions 'I trust my doctors' expertise' and 'I have a trusting and supporting relationship with my doctor' appeared to mainly have an indirect reassuring effect in terms of supporting the other three reassuring cognitions. Patients mentioned these trust-related factors to be reassuring because they created an environment in which the patient felt safe and supported and accepted what the GP was saying, however they did not seem to directly counterbalance patients' specific worrying cognitions. One exception was that the reassuring cognition 'I have a trusting and supporting relationship with my doctor' seemed to directly counterbalance the worrying cognition 'My health problem will negatively impact my life. Patients mentioned no reassuring cognitions that directly counterbalanced the worrying core cognition 'my treatment will have adverse effects'. 
Table 4.2 Worrying core cognitions and underlying cognitions

\begin{tabular}{l} 
Worrying core \\
cognitions \\
\hline $\begin{array}{l}\text { I have a serious } \\
\text { disease }\end{array}$ \\
\\
My health \\
problem will \\
have adverse \\
physical effects
\end{tabular}

My treatment will have adverse effects

My health
problem will
negatively
impact my life

Underlying Cognitions

Person-specific cognitions

- I have alarming symptoms / abnormal test results which indicate serious disease.

- The symptoms I have are not normal.

- Now that I am getting older the chance of having a serious disease is increasing.

- My symptoms have not disappeared after the treatment so something must be wrong.

- I have a health problem that will lead to serious illness causing disability / additional conditions / death.

- My symptoms are getting worse.

- I do not know how the symptoms can be treated since I do not know what causes them.

- The treatment I received was incorrect, so my health problem will persist.

- If I take medication, I will have to continue to take it indefinitely / there will be side effects / I will have difficulty sticking to my drug regimen.

- Having health problems does not fit with how I see myself and my future.

- I have so many health problems at the same time / my health problems are getting worse / my treatment is no longer effective.

- My health problems will make me dependent on others / limit my daily functioning.
Context-specific cognitions

- This is a common disease according to the media/in my family/among my friends and acquaintances.

- The media/my friends say that my symptoms are indicative of a serious disease.

- The symptoms I have must be abnormal as I know of no people in my social environment and with a similar background to mine that have such symptoms.

- These adverse effects happen all the time according to the media / in my family / among people I know.

- In my social environment I have seen many cases of incorrect treatment of this problem with bad outcomes.

- In my social environment I have often seen adverse effects of medication.

- My social environment is not supportive when I have problems and concerns / does not allow me to deal with the problem in my own way. 
Table 4.3 Reassuring core cognitions and supporting factors

\begin{tabular}{|c|c|c|}
\hline \multirow{2}{*}{$\begin{array}{l}\text { Reassuring core } \\
\text { cognitions }\end{array}$} & \multicolumn{2}{|c|}{ Factors supporting reassuring core cognitions } \\
\hline & $\begin{array}{l}\text { Consultation-specific factors. } \\
\text { My doctor: }\end{array}$ & $\begin{array}{l}\text { Context-specific factors. } \\
\text { There is: }\end{array}$ \\
\hline $\begin{array}{l}\text { I feel safe and } \\
\text { supported } \\
\text { because I have a } \\
\text { trusting } \\
\text { relationship with } \\
\text { my doctor. }\end{array}$ & $\begin{array}{l}\text { emphasises the equality of our } \\
\text { relationship by: } \\
\text { approaching me in a friendly manner; } \\
\text { using humour. } \\
\text { shows that he/she is interested in me } \\
\text { as a person by: } \\
\text { allowing me to tell my story, listening } \\
\text { attentively, exploring and } \\
\text { understanding my feelings and } \\
\text { personal situation. } \\
\text { shows involvement by: } \\
\text { showing empathy; monitoring my } \\
\text { condition }\end{array}$ & $\begin{array}{l}\text { an existing trusting doctor-patient } \\
\text { relationship based on: } \\
\text { the duration of the relationship; I } \\
\text { know I can always ask the doctor } \\
\text { any question I have; the doctor } \\
\text { being always open and honest. }\end{array}$ \\
\hline $\begin{array}{l}\text { I trust my } \\
\text { doctor's } \\
\text { judgment since I } \\
\text { trust his/her } \\
\text { expertise. }\end{array}$ & $\begin{array}{l}\text { obtains a good understanding of my } \\
\text { problems and symptoms by: } \\
\text { allowing me to tell my story; listening } \\
\text { attentively; exploring and summarising } \\
\text { my symptoms/feelings/context; } \\
\text { showing/telling me what he/she is } \\
\text { typing; referring to the previous } \\
\text { consultation. } \\
\text { takes the necessary actions to } \\
\text { adequately investigate my symptoms } \\
\text { by: } \\
\text { exploring alarming symptoms; } \\
\text { performing a physical examination and } \\
\text { other investigations; referring me to a } \\
\text { specialist. } \\
\text { explains the reasons for his/her } \\
\text { actions by: } \\
\text { announcing and explaining what } \\
\text { he/she will do during the physical } \\
\text { examination and which further } \\
\text { investigations will be done. } \\
\text { takes care to perform actions properly } \\
\text { and thoroughly by: } \\
\text { making sure that he/she does not } \\
\text { forget anything by sharing findings with } \\
\text { me during the examination/when } \\
\text { typing during the consultation; } \\
\text { discussing test results with me; } \\
\text { proposing a good specialist. }\end{array}$ & $\begin{array}{l}\text { an experienced doctor who: } \\
\text { has had many years of experience; } \\
\text { sees many patients with problems } \\
\text { that are similar to mine; has a good } \\
\text { reputation in my neighbourhood. } \\
\text { a familiar doctor who: } \\
\text { knows my whole history. } \\
\text { a careful doctor who: } \\
\text { has never made a mistake; has } \\
\text { always been quick and effective; } \\
\text { has always referred me when it } \\
\text { was necessary. }\end{array}$ \\
\hline
\end{tabular}


Table 4.3 Continued

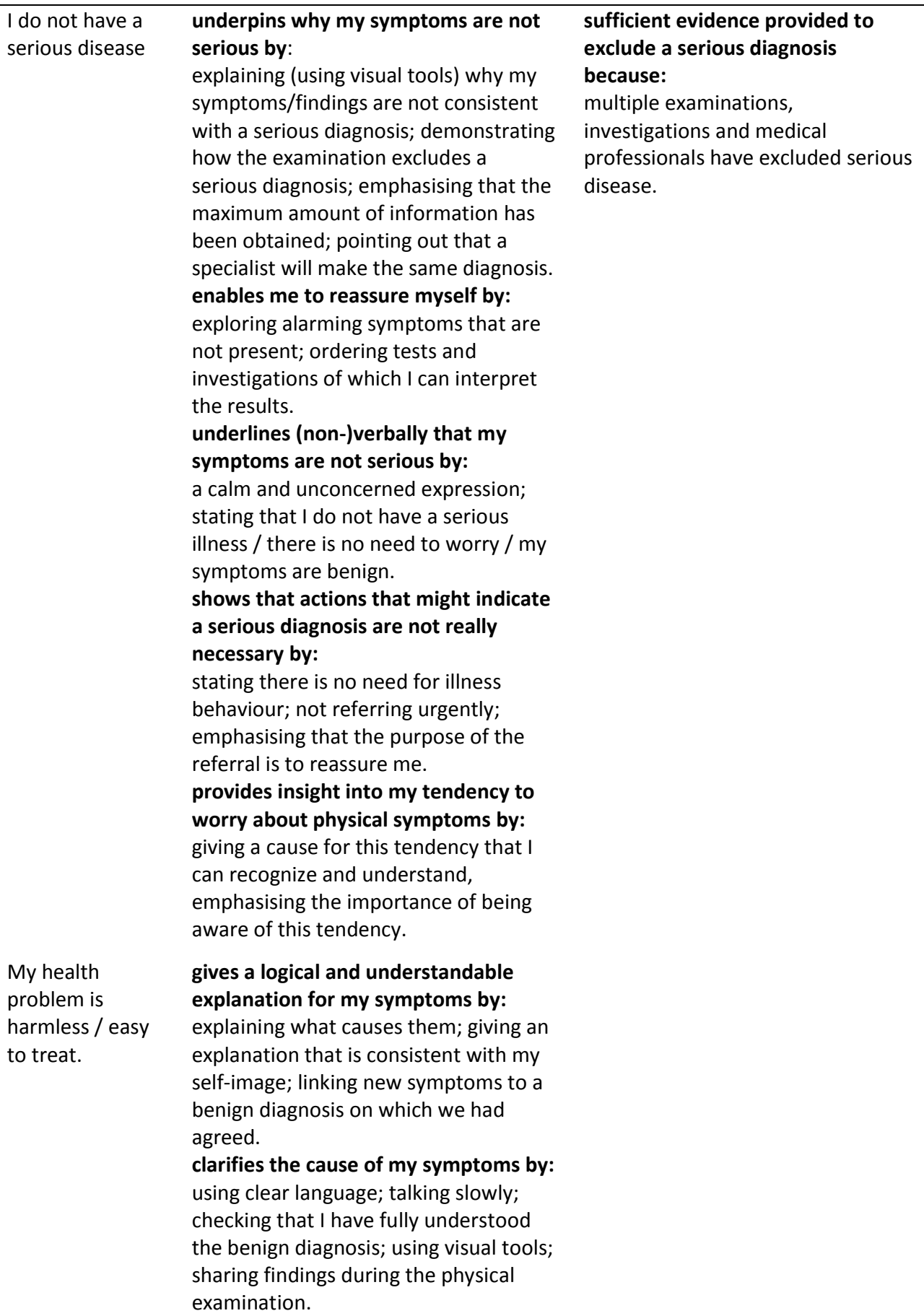


Table 4.3 Continued

\begin{tabular}{|c|c|c|}
\hline $\begin{array}{l}\text { My health } \\
\text { problem will: } \\
\text { disappear / not } \\
\text { return / not } \\
\text { deteriorate }\end{array}$ & $\begin{array}{l}\text { ensures I receive adequate treatment } \\
\text { by: } \\
\text { tailoring the treatment to my wishes } \\
\text { and expectations; proposing treatment } \\
\text { that I can execute myself; treating the } \\
\text { cause of my symptoms; referring me to } \\
\text { (a team of) specialists for treatment. } \\
\text { adequately monitors my condition by: } \\
\text { indicating when he/she wants to } \\
\text { schedule a follow-up visit/check-up; } \\
\text { monitoring my condition him/herself. } \\
\text { gives a positive vision of my future by: } \\
\text { outlining the natural course of the } \\
\text { disease; emphasising that everything } \\
\text { will be done to ensure a full recovery. }\end{array}$ & $\begin{array}{l}\text { evidence that I am getting better } \\
\text { because: } \\
\text { the symptoms are diminishing, the } \\
\text { treatment is effective. } \\
\text { a doctor who always carefully } \\
\text { monitors my condition by: } \\
\text { scheduling regular follow-up visits; } \\
\text { being available in case of problems } \\
\text { between appointments. }\end{array}$ \\
\hline
\end{tabular}

Following the structure of Table 4.2 and using illustrative quotations, we describe in some detail patients' worrying cognitions. For every worrying cognition, we describe how these seemed to be counterbalanced by patients' reassuring cognitions, using some specific examples from Table 4.3. For a complete list of cognitions see Tables 4.2 and 4.3 .

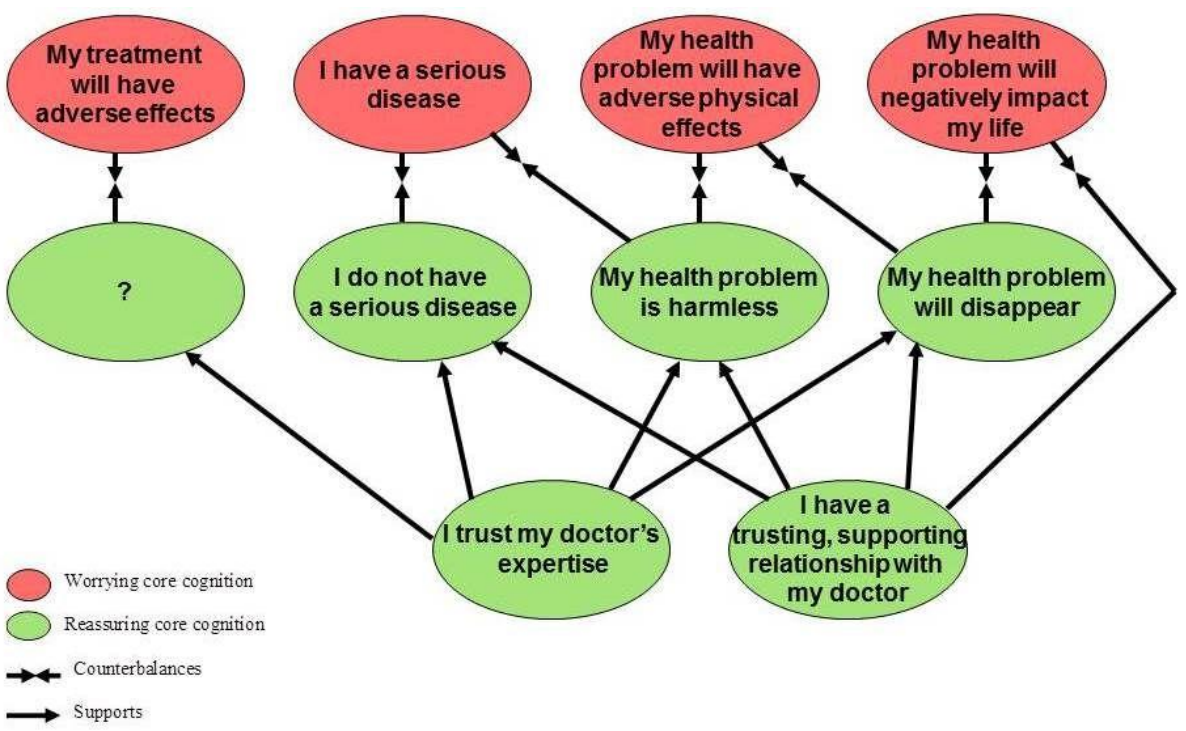

Figure 4.1 Reassuring cognitions to counterbalance worrying cognitions 


\section{Worrying core cognition: I have a serious disease}

Most of the participating patients expressed concerns that they might have a specific serious disease, such as cancer or a heart condition, often triggered by an alarming symptom, such as chest pain. Some patients said they felt that having a symptom in itself is abnormal and therefore indicative of serious disease, without having a specific disease in mind. These person-specific cognitions were often mentioned alongside context-specific cognitions, such as worrying they might have a specific severe illness because it runs in the family.

This pain persisted here and then I thought: 'Couldn't it be my heart?' I wanted to know what it is actually, as there are a few in my family who died of heart disease. - Patient 12

I had a blood test showing reduced kidney function, and because my mother died from renal disease I wanted to ask the doctor what might be the matter and if this could cause problems. I was worried that it might be hereditary. - Patient 3

Patients often mentioned that they trusted their doctor's judgement. This trust was partly based on pre-existing cognitions, i.e. cognitions arisen from previous encounters with the GP, for example about the presence of a long-lasting doctorpatient relationship.

I trust him, he has never been wrong in treating me, my husband, and my whole family. I have known him for years. - Patient 15

Often such pre-existing cognitions appeared to be triggered by what happened in the current consultation.

Here we are making jokes. You can see that we can get along very well. Therefore I trust him. I value that he knows who I am and that he is attuned to me. - Patient 10

Patients seemed to trust their doctor's expertise when they felt the doctor had obtained a good understanding of their problem, e.g. by listening attentively to their story. Patients mentioned that the doctor needed to understand what they were worried about to be able to conduct appropriate examinations. Patients expressed 
that taking the necessary steps to thoroughly investigate their complaint, e.g. by performing a proper physical examination, enabled the doctor to come to an accurate diagnosis.

I was able to properly talk with him and I gave him various signs, that I was thinking 'maybe it is the thyroid gland?' Well, he reassured me about that. He paid attention to that and he made the effort to have a look. I thought there might be a cause, and when he said that is not the case, well, I was satisfied with that. - Patient 9

Well, it seems to me that it [physical examination] is a part of the consultation, for without it the doctor cannot find out what is going on. She also explained things to me, but I think that without a proper physical examination it is impossible to determine what the matter is. - Patient 17

Patients also expressed that they needed to be convinced that their complaint was not serious by evidence or signs that denied the presence of severe illness. Some patients said they were already able to reassure themselves by being able to answer negatively to the doctor's questions about alarming symptoms.

As I do not have it [sweating, nausea], because I could answer negatively, I found that reassuring. - Patient 1

In addition, patients stressed the importance of the doctor explaining how test results or findings of the history taking and physical examination excluded a harmful diagnosis. Different types of explanations were mentioned. Some patients preferred such an explanation to take place during the physical examination.

In that way [describing findings during the physical examination] he won't forget anything and I know immediately how things stand. That is quite a relief. Patient 21

In case of an abnormal test result, patients felt reassured when the doctor used visual tools, such as anatomical models and graphs, to explain why they are reported and that they are no reason for concern. 
For some patients it was sufficient to understand why the complaint was not serious, but others said they also needed an alternative explanation showing that their symptoms were harmless before they felt completely reassured. Patients believed the doctor's explanation that their symptoms were harmless when the doctor gave a clear, logical explanation that the patient could recognize. The doctor could do so, for example, by demonstrating and explaining during physical examination that chest pains can be caused by muscle tension. Several patients mentioned that they did not need any additional investigations after receiving a clear, detailed explanation of their complaints.

When she says it [an X-ray] is not necessary and everything is fine, I trust her and I feel sufficiently reassured. So explaining this and that it is unlikely to be that and it is probably this. And that she explained really well why it was that and not something else. - Patient 14

When he explains it you start to think, obviously when I have pain in my left foot end my right hip, walking is difficult and I distribute it. Then I think, well what he says makes sense, it is quite a logical explanation. - Patient 21

In contrast, a few patients mentioned that in order to feel reassured, they needed additional tests or a referral to a specialist, after which they would obtain absolute certainty. They felt that the GP is limited in his/her diagnostic means and that additional investigations would give a more precise result than a physical examination. Some patients preferred an investigation of which they are able to understand the results.

With an X-ray I can see it myself, it's tangible. Then I feel more reassured than with a blood test. You see I'm no expert, such a result of a blood tests is like Chinese to me. - Patient 4

Despite these investigations or referrals, patients seemed to be aware that the doctor him/herself was not worried. The doctor demonstrated this by not referring the patient urgently or by emphasising that the only purpose of the referral is to reassure the patient. 
He knows that when I don't do it [X-ray] that I keep feeling it, keep worrying and get really nervous. He knows that and therefore he says: ' to reassure you I'll order an $X$ ray'. Once that is done it will all be ok. - Patient 15

\section{Worrying core cognition: My health problem will have adverse physical effects}

Worries about having a serious disease were often accompanied by worries about potential adverse physical consequences of such a disease, such as additional conditions and death.

But well, I am worried about the pressure at the back of my head. Then I think of my heart, for that is the pump and the pump is the main thing, and, to be honest, then I worry that I will not live to an old age. Yes, your heart is in fact the thing of your body and if it is not alright, other things will be wrong as well. For you get a domino effect. - Patient 4

Worries about the adverse effects of a complaint were often due to the experiences of family members and friends or to information on the internet.

I have high blood pressure with symptoms and then you hear all sorts of stories and you know people, some I know personally, who have suffered attacks due to high blood pressure and were partially paralyzed. I have two young children and I do not want that. - Patient 18

Patients who worried that their symptoms might lead to adverse consequences mentioned to feel reassured after the cause of their symptoms was explained to them. In some cases a clear explanation helped patients to understand that the symptoms were easy to treat. Having control over their complaint by being able to treat it themselves was reassuring as well.

I know what causes it. Things are in my own hand now, I know what I can do about it, and that is reassuring. - Patient 18

Patients felt reassured also when they were convinced that their complaint would disappear or when they believed it would not get worse or return. This depended on 
adequate treatment as well as close monitoring, preferably by their GP, who was considered to be the most capable of judging how the complaint would develop.

\section{Worrying core cognition: My treatment will have adverse effects}

Some patients believed that treatment would lead to serious consequences. This could relate to treatment that already had been performed, in this case a hip replacement.

You can read a lot about new hips, metal on metal can cause all sorts of things. My sister still has these complaints, pain in her leg, swollen. I have the same. She already has it [new hip] for 5 years now. Then I rather go back on time. - Patient 19

This cognition however mostly arose when the doctor prescribed medication during the consultation or when the patient thought the doctor might prescribe medication in the future.

I know someone who also has something like that and when he reads the side effects of the medication, then you start to think, do I really have to take that? Then I'm afraid that there will be side effects and they are going to make it worse. - Patient 7

Patients who worried about potential adverse effects of medication use mentioned no reassuring cognitions that counteracted these particular concerns. A few patients with these concerns did derive some reassurance from trust in their doctor's expertise, however this did not seem to influence their specific worrying cognition. The patient worrying about a possible incorrect hip replacement did also not express any reassuring cognitions apart from trust in the doctor's expertise, yet for a different reason. This patient felt partly reassured because her doctor referred her for an additional investigation. Inevitably the results and treatment options had not been discussed yet so the patient's worries remained for the most part.

\section{Worrying core cognition: My health problem will negatively impact my life}

Several patients expressed difficulties in coping with their health problems as they worried about the impact of these problems on their life, e.g. on their everyday functioning. Some of these patients had been experiencing several health problems for a longer period and some mentioned that their problems were getting worse 
and/or that their treatment was no longer effective. A few patients also indicated non-supportive family members, friends and working environment as one of the reasons for their experienced difficulties. Another cognition that patients expressed in relation to this type of concern was the mismatch between living with complaints and the patient's vision of his/her future, for instance when the patient had expected to grow old without experiencing any physical problems.

Well, I find it difficult to deal with that this is the case for several things. It really makes me feel like, hey guys is there anything that is not wrong with me, just put me out with the garbage. I find this very discouraging, like, well you are getting old, shortly you will be written off completely (...). I am 65 years old and I would like to live to 85 without any problems. - Patient 2

While a trusting relationship seemed to have an indirect reassuring function for most patients, patients who struggled with the impact of their complaints on their life, explicitly described the reassurance they obtained from a trusting and supporting relationship. The doctor showing involvement and empathy and listening attentively to the patient's story supported such a relationship. This made patients feel their doctor was interested in them as a person and was genuinely trying to help them. Especially patients who felt that people in their environment did not take them seriously appreciated naming concerns.

It is reassuring to be listened to. If I had talked about this with my boss, he would have listened to me for two seconds and told me to go to bed and see how things were in the morning. And he says, no, you should tell your story properly and I will not interrupt you. One is not afraid to have a proper talk with this man, because you know that everything you say will be heard, that he really listens to you. He gives you time to get it off your chest. He asks some pertinent questions and otherwise he keeps quiet. Well, that is why I am here isn't it? - Patient 16

Several patients mentioned that they felt reassured when they believed their complaints would be resolved and not return. These concerns seemed to be dealt with particularly effectively, when the doctor communicated a treatment plan and a positive vision of a future without complaints. 
It is very much tailored to the person. He says, well you need a little more of this. That is reassuring. Then they start to work on things you might do better in order to prevent this from happening again. - Patient 16

He had this idea, that I can go to that hospital with a team of specialists and try it [treatment] again. And I'll try it. I'm optimistic about it, maybe they can do something positive. - Patient 21

\section{DISCUSSION}

\section{Main findings}

During the interviews, patients mentioned a range of worrying core cognitions underlying their concerns: 'I have a serious illness', 'my health problem will have adverse physical effects', 'my treatment will have adverse effects' and 'I find it difficult to live with my complaints'. Patients related these worrying core cognitions to a range of underlying person-specific and context-specific cognitions. Patients also described different reassuring cognitions: 'I trust my doctor's expertise, 'I have a trusting and supporting relationship with my doctor', 'I do not have a serious disease', 'my health problem is harmless' and 'my health problem will disappear'. As reasons for these cognitions, patients mentioned the doctor's actions during the consultation and preexisting cognitions related to their doctor and previous events. Worrying and reassuring core cognitions appeared to be related, as worrying cognitions were counteracted by specific reassuring cognitions.

\section{Main findings in relation to the literature}

Patients who were concerned about having a serious disease expressed to be reassured when the GP explained why the complaint was not serious and moreover gave insight into the harmless cause of the complaint. These findings are similar to our previous study in which we interviewed GPs about the strategies they used to reassure patients (12). Both studies provide empirical support for Starcevick's view that this is an effective strategy to reassure patients (30). The reassuring cognitions we identified in the present study are in line with the process in which patients with medically unexplained symptoms (MUS) are supported to re-attribute somatic complaints $(31,32)$ and with giving hypochondriac patients insight into the causes of their tendency to worry as an effective component of Cognitive Behavioural Therapy (33). 
Patients also worried about potential serious consequences of complaints, such as disability. The main reassuring cognition for these patients was the belief to being able to influence their health problem. This finding provides empirical support for Buchsbaum's description of the importance of providing patients with information, thereby enabling them to re-establish control and self-confidence (4), and for the results of a qualitative study by Andén et al. showing that 'understanding what I have' was the key consultation outcome for patients and that it was not sufficient to merely cure the complaint (34).

Buchsbaum also described how an empathic doctor showing genuine interest and compassion can provide support during emotionally turbulent times (4). A compassionate doctor and exploration of patients' concerns have been shown to reduce anxiety in cancer survivors (8) and cancer patients, respectively (10). In our study, patients worrying about the impact of health problems on their everyday life explained how a trusting doctor-patient relationship was reassuring for them. With simple actions, the doctor provided emotional support to patients who did not receive this from their social environment (35). Here, a trusting relationship served as the instrument of reassurance while also having an indirect supportive effect on patients with other worrying cognitions. A trusting relationship created an environment in which patients felt comfortable and were more likely to accept the doctor's information and conclusions.

In addition to patient-centred communication skills that have received considerable attention in the literature, such as showing empathy, this study demonstrates the importance of trusting the doctor's expertise in the acceptance of a reassuring diagnosis. Confirming the findings of our previous study, patients experienced it as reassuring when the doctor showed he or she adequately understood the complaint and took what patients believed to be the necessary action to investigate the complaint (12). Besides the reassuring effect of the GPs' actions in the consultation, the present study also highlighted the importance of patients' pre-existing cognitions about their doctors' expertise.

We described earlier in the background that patients and doctors perceived consultations differently (20-22), and hypothesized that this might lead to ineffective reassurance (13-16). A comparison of the results of the present study with those of our earlier study nevertheless showed considerable overlap between strategies GPs believe to be reassuring and patients' reassuring cognitions. However it cannot be concluded that this overlap will be present on the level of individual consultations. 
Furthermore, reassurance may be difficult to achieve in specific patient groups with high anxiety $(14,16)$ and more feasible in the less anxious population we studied. Our findings are consistent with previous research showing that in most patients reassurance is a multifaceted process involving more than just providing normal results of diagnostic tests $(13,15,36)$. Most patients wanted clear explanations to help them understand their complaint, after which they felt no need for any additional diagnostic tests. A few patients, however, did not feel sufficiently reassured by their GP's explanations and needed more investigations or a referral to a specialist. These differences between patients point to the important observation that worrying and reassuring cognitions can vary considerably among patients, requiring doctors to use situation-specific reassurance strategies. This may be challenging considering that training in medical communication skills tends to be of a quite generic nature (37). It might be particularly challenging to address patients' undisclosed or ambiguously expressed concerns, a phenomenon present in this study as well as in previous research (38).

Although we did not aim to explore which sorts of cognitions were or were not expressed during the consultations, we noticed that worries about the effects of medication use were never expressed. Obviously, an in-depth interview gives patient much more opportunity to elaborate on their concerns than a 10-minute consultation. Nevertheless, the reasons for patients' unexpressed concerns in this study seemed to be related to the subject. Patients may feel uncomfortable disclosing concerns about the physician's treatment plan.

\section{Strengths and limitations}

Interestingly, none of the patients, including those who remained worried, expressed worrying cognitions about their own doctor, e.g. regarding the absence of trust. Although we explicitly asked all patients if they could think of anything that would have reassured them more, only one patient described this. The absence of this action was however no cause of increased concern. Patients who mentioned doubts about other GPs and specialists generally remarked that their own doctor did much better. There are several possible explanations for this phenomenon. Firstly, patients may have given socially desirable answers and be reluctant or not used to making negative comments about their doctor. Secondly, expressing only positive views of their doctor may be used as a personal confirmation that the doctor was right. Negative thoughts about their doctor might jeopardize patients' feelings of being reassured. Thirdly, 
since participating GPs were aware of this research project and the video recording and may have had affinity with its subject, GPs may have tried to enhance their reassuring actions, resulting in patients' positive experiences. A positive outcome is that we have captured patients' experiences of many different actions, yet we may have missed some of patients' worrying cognitions.

Since we were not able to select from every practice consultations in which patients gave high ratings of their level of concern, we included several patients who indicated that they were only slightly worried. During the interview, however, these patients spontaneously mentioned several worrying and reassuring cognitions. We therefore think that the data comprise descriptions of worrying and reassuring cognitions given by patients showing a high degree and patients showing a lower degree of concern. This may well be interpreted as a strength of this study given that the current literature focuses mainly on patients with high anxiety, such as patients with hypochondriasis $(30,33)$ and MUS patients $(16,31,32)$. The variety of the consultations is limited with respect to the absence of consultations in which GPs diagnose or suspect serious disease. It is likely that patients have other worrying and reassuring cognitions in case GPs express their concerns about serious pathology.

Another strength is that we interviewed patients about a recent consultation with their GP. This meant that the interviews remained very close to what actually happened during the consultations while the videotaped consultations were an effective stimulus for patients' reflections. This reduced the risk of unreliable and incomplete answers, though the risk of patients constructing answers using hindsight knowledge is always present.

\section{Implications for practice and research}

A good understanding of patients' concerns is crucial for successful reassurance. It is not only reassuring in itself, it also gives doctors a focus for their efforts to reassure patients. Our results show a variety of cognitions underlying patients' concerns. Once physicians are aware of the worrying cognitions patients have, they may be able to recognize patient cues pointing towards these cognitions. This is especially important in light of the finding that patients often did not mention all their concerns during the consultation and that these concerns were not addressed, in particular concerns related to treatment. Doctors should therefore pay attention to cues and concerns throughout the consultation, not solely during the opening phase. Awareness of the 
existence of 'hidden' worrying cognitions is essential for doctors aiming to effectively reassure their patients.

Furthermore, the reassuring core cognitions that were identified can support doctors in applying reassuring strategies. By not only describing reassuring actions but also the core cognitions supported by these actions and the worrying core cognitions counteracted by them, we aim to offer doctors guidance for strategies to reassure patients in a goal-directed manner. We do not recommend to apply all reassurance strategies in every consultation but aim to help doctors select the most appropriate reassurance strategy based on a proper exploration and understanding of the patient's concerns.

In this small scale, qualitative study we were only able to describe patterns on the level of core cognitions. Specific underlying worrying cognitions, however, may require specific types of reassurance. It would therefore be interesting to conduct further experimental, systematic studies of the relationship between specific worrying and reassuring cognitions, in order to obtain additional insights regarding effective situation-specific reassurance. Future studies could explore specifically how different sorts of concerns are expressed during the encounter and factors that influence this expression, such as the presence/absence of a trusting doctor-patient relationship. Less intensive methods of data collection such as questionnaires would also allow the investigation of associations between patient characteristics (e.g. anxiety level) / GP characteristics and worrying/reassuring cognitions.

Using recently videotaped consultations as a stimulus for stimulated recall interviews appears to be an effective method of gaining insight into patients' experiences and thoughts about the interaction with their GP. This method may also be useful for studies of patients' perspectives on other important communicative aspects of doctor-patient consultations, such as patients' feeling of involvement in decisionmaking.

\section{Conclusion}

Both patients' concerns about disease and patients' reassurance are based on a variety of cognitions. What patients experience as reassuring seems to depend on their specific worrying cognitions. Gaining a thorough understanding of these worrying cognitions and tailoring reassuring strategies to them should be an effective way of achieving reassurance. 


\section{REFERENCES}

1. Barry CA, Bradley CP, Britten N, Stevenson FA, Barber N. Patients' unvoiced agendas in general practice consultations: qualitative study. Br Med J (Clin Res Ed). 2000;320(7244):1246-50.

2. McKinley RK, Middleton JF. What do patients want from doctors? Content analysis of written patient agendas for the consultation. Br J Gen Pract. 1999;49:796-800.

3. van Bokhoven MA, Koch H, van der Weijden T, Grol RPTM, Kester AD, Rinkens PELM, et al. Influence of watchful waiting on satisfaction and anxiety among patients seeking care for unexplained complaints. Ann Fam Med. 2009;7:112-20.

4. Buchsbaum DG. Reassurance reconsidered. Soc Sci Med. 1986;23:423-7.

5. Lucock MP, Morley S, White C, Peake MD. Responses of consecutive patients to reassurance after gastroscopy: results of self administered questionnaire survey. Br Med J (Clin Res Ed). 1997;315:5725.

6. Stark D, Kiely M, Smith A, Morley S, Selby $\mathrm{P}$, House A. Reassurance and the anxious cancer patient. $\mathrm{Br}$ J Cancer. 2004;91:893-9.

7. Fassaert T, van Dulmen S, Schellevis F, van der Jagt L, Bensing J. Raising positive expectations helps patients with minor ailments: a cross-sectional study. BMC Fam Prac. 2008;9:38.

8. Fogarty LA, Curbow BA, Wingard JR, McDonnell K, Somerfield MR. Can 40 seconds of compassion reduce patient anxiety? J Clin Oncol. 1999;17:371-9.

9. $\quad$ Kessel N. Reassurance. Lancet. 1979;1:1128-33.

10. Liénard A, Merckaert I, Libert Y, Delvaux N, Marchal S, Boniver J, et al. Factors that influence cancer patients' anxiety following a medical consultation: impact of a communication skills training programme for physicians. Ann Oncol. 2006;17:1450-8.

11. Warwick HM, Salkovskis PM. Reassurance. Br Med J (Clin Res Ed). 1985;290:1028.

12. Giroldi E, Veldhuijzen W, Leijten C, Welter D, van der Weijden T, Muris J, et al. 'No need to worry': an exploration of general practitioners' reassuring strategies. BMC Fam Prac. 2014;15(1):133.

13. McDonald IG, Daly J, Jelinek VM, Panetta F, Gutman JM. Opening Pandora's box: the unpredictability of reassurance by a normal test result. Br Med J (Clin Res Ed). 1996;313:329-32.

14. Meechan GT, Collins JP, Moss-Morris RE, Petrie KJ. Who is not reassured following benign diagnosis of breast symptoms? Psychooncology. 2005;14:239-46.

15. Petrie KJ, Müller JT, Schirmbeck F, Donkin L, Broadbent E, Ellis CJ, et al. Effect of providing information about normal test results on patients' reassurance: randomised controlled trial. $\mathrm{Br}$ Med J (Clin Res Ed). 2007;334:352.

16. Rief W, Heitmüller AM, Reisberg K, Rüddel $H$. Why reassurance fails in patients with unexplained symptoms--an experimental investigation of remembered probabilities. PLoS Med. 2006;3:e269.

17. Donovan JL, Blake DR. Qualitative study of interpretation of reassurance among patients attending rheumatology clinics: "just a touch of arthritis, doctor?". Br Med J (Clin Res Ed). 2000;320:541-4.

18. McDonald IG, Daly J. On patient judgement. Intern Med J. 2001;31:184-7.

19. Pilowsky I. Aspects of abnormal illness behavior. Indian J Psychiatry. 1993;35(3):145-50.

20. Cegala DJ, Gade C, Lenzmeier Broz S, McClure L. Physicians' and patients' perceptions of patients' communication competence in a primary care medical interview. Health Com. 2004;16:289-304.

21. Kenny Da, Veldhuijzen W, Weijden TVD, Leblanc A, Lockyer J, Légaré F, et al. Interpersonal perception in the context of doctor-patient relationships: a dyadic analysis of doctor-patient communication. Soc Sci Med. 2010;70:763-8.

22. Lapane KL, Dubé CE, Schneider KL, Quilliam BJ. Misperceptions of patients vs providers regarding medication-related communication issues. Am J Manag Care. 2007;13:613-8.

23. Diefenbach MA, Leventhal $H$. The common-sense model of illness representation: Theoretical and practical considerations. J Soc Distress Homeless. 1996;5(1):11-38.

24. Coia P, Morley S. Medical reassurance and patients' responses. J Psychosom Res. 1998;45:377-86.

25. Hirani SP, Newman SP. Patients' beliefs about their cardiovascular disease. Heart. 2005;91:1235-9.

26. Leventhal H, Leventhal EA, Contrada RJ. Self-regulation, health, and behavior: A perceptual-cognitive approach. Psychol Health 1998;13:717-33.

27. Lyle J. Stimulated recall: a report on its use in naturalistic research. Br Educ Res. 2003;29:861-78. 
28. Watling CJ, Lingard L. Grounded theory in medical education research: AMEE Guide No. 70. Med Teach. 2012;34:850-61.

29. Tracy SJ. Qualitative Quality: Eight Big-Tent Criteria for Excellent Qualitative Research. Qual Inq. 2010;16(10):837-51.

30. Starcević V. Reassurance and treatment of hypochondriasis. Gen Hosp Psychiatry. 1991;13:122-7.

31. Gask L, Dowrick C, Salmon P, Peters S, Morriss R. Reattribution reconsidered: narrative review and reflections on an educational intervention for medically unexplained symptoms in primary care settings. J Psychosom Res. 2011;71:325-34.

32. Goldberg D, Gask L, O'Dowd T. The treatment of somatization: Teaching techniques of reattribution. J Psychosom Res. 1989;33:689-95.

33. Warwick HMC. Cognitive Therapy in the Treatment of Hypochondriasis. Adv Psychiatr Treat 1998;4:285-91.

34. Andén A, Andersson S-O, Rudebeck C-E. Satisfaction is not all--patients' perceptions of outcome of general practice consultations, a qualitative study. BMC Fam Prac. 2005;6:43.

35. Mikesell L. Medicinal relationships: caring conversation. Med Educ. 2013;47(5):443-52.

36. van Ravesteijn H, van Dijk I, Darmon D, van de Laar F, Lucassen P, Hartman TO, et al. The reassuring value of diagnostic tests: a systematic review. Patient Educ Couns. 2012;86:3-8.

37. Veldhuijzen W, Ram PM, van der Weijden T, Niemantsverdriet S, van der Vleuten CPM. Characteristics of communication guidelines that facilitate or impede guideline use: a focus group study. BMC Fam Prac. 2007;8:31.

38. Floyd MR, Lang F, McCord RS, Keener M. Patients with worry: presentation of concerns and expectations for response. Patient Educ Couns. 2005;57:211-6. 



\section{CHAPTER}

\section{'No need to worry': an exploration of general practitioners' reassuring strategies}

Esther Giroldi, Wemke Veldhuijzen, Carolien Leijten, Dionne Welter, Trudy van der Weijden, Jean Muris, Cees van der Vleuten

BMC Family Practice. 2014, 15:133. 


\section{ABSTRACT}

\section{Background}

In view of the paucity of evidence regarding effective ways of reassuring worried patients, this study explored reassuring strategies that are considered useful by general practitioners (GPs).

\section{Methods}

In a study using a qualitative observational design, we re-analysed an existing dataset of fifteen stimulated recall interviews in which GPs elaborated on their communication with patients in two videotaped consultations. Additionally we held stimulated recall interviews with twelve GPs about two consultations selected for a strong focus on reassurance.

\section{Results}

To reassure patients, GPs pursued multiple goals: 1. influencing patients' emotions by promoting trust, safety and comfort, which is considered to be reassuring in itself and supportive of patients' acceptance of reassuring information and 2 . influencing patients' cognitions by challenging patients' belief that their symptoms are indicative of serious disease, often followed by promoting patients' belief that their symptoms are benign. GPs described several actions to activate mechanisms to achieve these goals.

\section{Conclusions}

GPs described a wealth of reassuring strategies, which make a valuable contribution to the current literature on doctor-patient communication. This detailed description may provide practicing GPs with new tools and can inform future studies exploring the effectiveness of reassurance strategies. 


\section{BACKGROUND}

Reassuring patients that their symptoms are not caused by a serious disease is one of the most common interventions in primary care and thought to be essential to good clinical practice (1-5). There is nevertheless a paucity of research identifying effective reassuring strategies (6), despite its importance and the described difficulty of reassuring patients $(7,8)$. Studies measuring the effect of reassuring statements, e.g. on normal test results, have found no effect, a temporary reduction of or even an increase in anxiety (9-13). Failure to effectively reassure patients can lead to overutilization of health care due to unwarranted consultations and treatments, leaves patients being disabled by their condition, and can have a negative impact on patients' quality of life $(10,14,15)$.

There is some empirical support for approaches to reassurance used in groups of patients that are known to be highly anxious, including patients with medically unexplained symptoms (MUS) and cancer survivors. These patients tend to overestimate the likelihood of medical causes of symptoms and are not reassured by straightforward reassuring statements or after receiving normal test results $(12,16)$. Lower anxiety levels have been associated, however, with patients who consider the complaint to be bearable and feel they understand the seriousness of symptoms (17). It is therefore recommended that doctors explore and acknowledge patients' concerns (17-19) and give adequate explanations about a patient's condition $(20,21)$ and the meaning of normal test results (11). It is also suggested that doctors should check whether patients have understood what is explained to them by asking checkback questions and inviting patients to summarise what has been said (16). A recent review of Pincus et al. underpinned the reassuring effect of cognitive reassurance, i.e. changing patients' perceptions and beliefs by promoting patients' understanding, in patients with unexplained pain (22).

Concerns about the presence of serious illness are a common phenomenon among a much wider range of patients than the groups described above (2). Hence, doctors should be aware of communication strategies that are effective in a variety of situations where reassurance is required.

When scientific evidence is scarce, a common strategy is to explore what experts consider to be useful as a first step toward identifying what works in practice (23). In line with Lingard's theory on the development of expertise in communities (24), we took the perspective that doctors are members of a community that has developed professional expertise in how to reassure patients. Given that general practitioners 
(GPs) see a wide variety of patients and complaints and reassurance is a feature of $70 \%$ of consultations in family practice (5), we expected GPs to have developed strategies for reassuring patients in a variety of situations. GPs also often have a longlasting relationship with their patients, so they may have experienced the long-term effects of their reassurance.

Our aim was to identify reassuring practices that are considered useful by GPs and why as a starting point in the exploration of possible effective reassurance. As reassurance is a complex intervention that can lead to different outcomes in different situations, it is important to understand the underlying mechanisms of this intervention (25). Recognizing these mechanisms can be instrumental in determining what works, for whom, in what circumstances, and why (25). For this reason, our study does not solely explore GPs' reassuring actions, but also the mechanisms they belief to be activated by their actions and the goals they try to achieve. Together these three components, i.e. action, mechanism and goal, make up a strategy. Hence we explored which reassuring strategies GPs consider as useful in their daily practice.

\section{METHODS}

\section{General design}

We used a qualitative observational design combining two sets of stimulated recall interviews (26) with GPs (dataset A and dataset B). To identify reassuring strategies that GPs consider as useful we explored the strategies they used during videotaped consultations with their own patients. Dataset $A$ is an existing set of interviews that explored how GPs selected communicative actions during their patient encounters (27). Since GPs try to reassure patients in $70 \%$ of consultations (5), we expected a secondary analysis of this dataset to yield first insights with relevance to our research question. Dataset B consists of interviews conducted for the study in which GPs were prompted to reflect on reassurance in order to deepen and broaden the findings of dataset $A$ and obtain a rich dataset of reassuring strategies. We performed a thematic network analysis using principles of grounded theory, with an iterative process of data collection and analysis and a constant comparison method $(28,29)$. 


\section{Ethical approval and informed consent}

The Medical Ethics Committee of Maastricht University Medical Centre granted approval for our study. The participating GPs and patients gave written informed consent. Verbatim transcripts of the recorded interviews were anonymized with codes.

\section{Selection procedures}

\section{Dataset A}

The GPs in the existing dataset were purposively sampled in order to obtain a variety in age, gender, number of working years and practice settings. Each GP was interviewed about two videotaped consultations that were selected by the researcher to obtain a maximum variation sample with respect to the patients' age, gender, complaint, type of consultation and GPs' communication techniques assessed by the instrument MAAS-Global $(27,30)$.

\section{Dataset $B$}

We contacted eighty GPs in the Southern part of the Netherlands, with at least five years of experience in general practice and who were not recently approached for other studies by our university. GPs were sent an invitational letter containing information about the study, followed by a telephone call. If the GP worked in a group practice, his/her colleagues were approached as well. We aimed to include 10-15 participants as this number was considered to be sufficient for stimulated recall interviews (31).

A researcher watched and videotaped all consultations conducted on one morning by each of the GPs. GPs were asked to rate on a scale ranging from 0 to 10 the importance of reassurance in each of the consultations. Before their consultation, patients rated their level of concern on a scale ranging from 0 to 10 (17). For the stimulated recall interviews, the researcher used the rating on the GPs' reassurance scale and the rating of patients' concern to select two consultations of each GP in which the GP aimed to reassure and the patient was concerned. In case we could not find two of such consultations, we prioritized the GPs' rating. Reassurance needed to be a goal of the GP, otherwise they could not be interviewed about how they reassured their patients. 


\section{Interviews}

For both datasets, trained interviewers conducted the interviews shortly after the consultations. The interviewers discussed the interview procedure in depth before and during the period of data collection. GPs were asked to watch two videotaped consultations and stop the tape whenever they wished to reflect upon their thoughts, intentions and actions regarding their communication (dataset $A$ ) or reassurance (dataset B). Once the video was stopped, they were prompted further to clarify these, e.g. what did you want to achieve here, why/how do you think that works? In case they did not stop the tape at a moment the researcher considered important, the researcher could do so and invited them to reflect upon their behaviour. At the end of the interviews of dataset B, GPs were asked whether, in retrospect, they would have reassured differently and if yes, they were asked why and how. Additionally we asked them whether they use reassuring strategies in their daily practice other than those used during the two discussed consultations.

\section{Data analysis}

All the interviews were audiotaped and transcribed verbatim. We firstly analysed dataset A. Text fragments about reassurance were selected and coded using Atlas-ti software for qualitative data analysis. Actions, mechanisms and goals were extracted from the GPs' reflections during thematic coding. In line with thematic network theory, we constructed networks to structure and visualize relationships between global themes, consisting of the goals pursued by GPs, organizing themes, consisting of mechanisms that explained how GPs' actions promoted the goals, and basic themes, that is the actions performed by GPs (28). The networks helped us to obtain first insights into GPs' reassuring practices and aspects that needed to be explored further in subsequent interviews in order to acquire a better understanding of GPs' strategies. During the thematic analysis of the interviews of dataset $B$, the networks were revised and expanded. The networks were eventually used to develop a thematic table presenting a framework of goals, mechanisms, and actions related to reassuring patients.

All the transcripts were analysed independently by at least two researchers with different backgrounds: health sciences (EG) or medicine (WV/CL/DW). The researchers reached consensus on the coding through discussion. The thematic networks and table were validated through in-depth discussions between the researchers. 


\section{RESULTS}

\section{Data characteristics and saturation}

Table 5.1 presents an overview of GPs' and patients' characteristics of dataset A (27) and B. Characteristics of individual GPs and patients are described below every quotation.

Although there was overlap in reassuring strategies between the two datasets, dataset $B$ resulted in a large number of additional strategies. The last eight interviews revealed no new goals and the last four interviews revealed no new mechanisms. However, in each of the last two interviews one new action was identified.

\section{Interviews}

Average interview time for both datasets was 60-90 minutes. In both datasets, GPs most often stopped the tape to reflect upon on their actual behaviours and they were less likely to spontaneously describe their thoughts and intentions. However, when prompted they gave detailed reflections upon the reasons and purposes of their actions.

During the interviews the GPs primarily discussed strategies that they used during the two consultations and were visible on the videotape. All of the identified strategies were used during discussed consultations by at least one of the GPs, including those that were described when asking GPs whether they used strategies other than those seen in the two consultations.

Table 5.1 Characteristics of dataset $A$ and $B$

\begin{tabular}{lll}
\hline & Dataset A & Dataset B \\
\hline GPs (N) & 15 & 12 \\
Practices (N) & 12 & 10 \\
Practice settings & Mixture of solo, duo, & Mixture of solo, duo, \\
& group, urban, rural & group, urban, rural \\
GPs' age (mean) & 47.8 & 49.3 \\
GPs' sex (\% male) & 53,3 & 66.7 \\
GPs' years of working experience (mean) & 15.7 & 19.2 \\
Patients (N) & 30 & 24 \\
Patients' sex (\% male) & 33.3 & 58.3 \\
Number of complaints (range) & $1-4$ & $1-3$ \\
Patients' age (range) & $19-89$ & $2-86$ \\
Patients' level of concern pre-consultation & - & 4.9 \\
(mean) & & 7.9 \\
GPs' rating on importance of reassurance & - & \\
(mean) & & \\
\hline
\end{tabular}




\section{Goals that GPs pursue to achieve reassurance}

The goals GPs pursued to reassure patients related to the emotions and cognitions of patients (Figure 5.1). Emotions were involved in GPs' actions to generate an environment characterized by trust, safety and comfort, which they considered prerequisite to effectively address patients' cognitions. As shown in Figure 5.1, GPs mentioned that actions targeted at emotions could occur at different moments during the consultation, although it was often considered important to immediately start creating trust at the beginning (grey arrows). Efforts to influence patients' cognitions were concentrated on challenging patients' belief that their symptoms were indicative of serious disease and on promoting patients' belief that symptoms were benign. Several GPs argued that patients' concerns regarding serious disease should be addressed first in order to make patients more receptive to the possibility of an alternative, more harmless explanation (blue arrow). These different goals pursued within a reassuring consultation are illustrated with a quotation (Figure 5.1). GPs also explained that in order to successfully influence patients' cognitions, an adequate transmission of reassuring information is essential (dotted arrows).

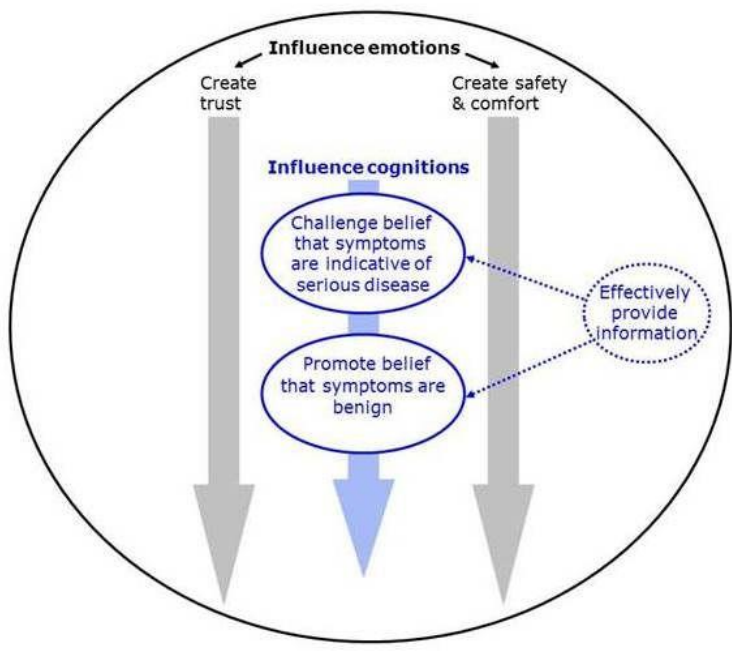

"The better I am able to make him see that I do understand his concerns the more he is likely to trust my judgment (First create trust, safety \& comfort,...). He is thinking: well what if it is cancer, or what if there is something wrong with my heart? So I first want to clear up any misconceptions (..then challenge beliefs..) and only after I have done that do I begin to explain what I think is going on (..and then promote beliefs). For I think that at that point the patient will be more ready to listen to what I have to say."

Figure $5.1 \mathrm{GPs}^{\prime}$ goals in a reassuring consultation

\section{Reassuring strategies: goals, mechanisms, and actions}

GPs described several mechanisms that promoted the goals of influencing patients' emotions and cognitions and several actions to activate these mechanisms. All the described strategies are listed in Table 5.2. Using the structure of Table 5.2 and 
illustrative quotations, we describe the goals, mechanisms and some examples of actions below. In addition, GPs described several actions to convey reassuring information to patients in an effective manner, enhancing clarity and understanding. These actions are outlined in a separate paragraph at the end of the results section.

Table 5.2 GPs' strategies for reassurance: goals, mechanisms and actions

\begin{tabular}{|c|c|}
\hline Mechanisms & Actions \\
\hline \multicolumn{2}{|c|}{ Goal 1. Influence emotions: Create trust } \\
\hline $\begin{array}{l}\text { Patient trusts } \\
\text { GP's expertise. }\end{array}$ & $\begin{array}{l}\text { - Give detailed explanations instead of only answering the patient's } \\
\text { questions. } \\
\text { - Show that you are fully informed about the patient's situation. } \\
\text { - Calm and unconcerned demeanour. } \\
\text { - Refer to scientific evidence. } \\
\text { - Emphasise experience and expertise. }\end{array}$ \\
\hline $\begin{array}{l}\text { Patient has trust in } \\
\text { doctor-patient } \\
\text { relationship. }\end{array}$ & $\begin{array}{l}\text { - Inform patient honestly, also about diagnostic uncertainties. } \\
\text { - Long-lasting GP-patient relationship. } \\
\text { - Create comfortable atmosphere.** } \\
\text { - Make patient feel heard and understood.** }\end{array}$ \\
\hline \multicolumn{2}{|c|}{ Goal 2. Influence emotions: Create safety and comfort } \\
\hline $\begin{array}{l}\text { Patient finds } \\
\text { him/herself in a } \\
\text { comfortable } \\
\text { atmosphere.** }\end{array}$ & $\begin{array}{l}\text { - Approach patient in a friendly manner. } \\
\text { - Make small talk with patient. } \\
\text { - Use humour. } \\
\text { - Make sure the patient understands what will happen during the } \\
\text { consultation. } \\
\text { - Comfortable, homey interior of doctor's office } \\
\text { - History taking / small talk during physical examination. }\end{array}$ \\
\hline $\begin{array}{l}\text { Patient feels heard } \\
\text { and understood.** }\end{array}$ & $\begin{array}{l}\text { - Allow the patient to tell his/her story. } \\
\text { - Listen attentively. } \\
\text { - Ask the patient to clarify statements. } \\
\text { - Explore patient's beliefs and ideas about diagnosis and treatment. } \\
\text { - Pay attention to patient's whole situation. } \\
\text { - Repeat / summarise patient's statements. } \\
\text { - Announce that you are about to take the patient's history. } \\
\text { - Name patient's concerns. } \\
\text { - Acknowledge that you understand the patient's complaint / reason for } \\
\text { visit / concerns. } \\
\text { - Respond to complaints and uncertainties expressed by the patient. }\end{array}$ \\
\hline $\begin{array}{l}\text { Patient feels GP takes } \\
\text { responsibility to } \\
\text { properly investigate, } \\
\text { treat and monitor } \\
\text { patient's complaints. }\end{array}$ & $\begin{array}{l}\text { - Make clear what will be done during: the consultation, history, physical } \\
\text { examination, investigations to help diagnose the patient's complaint. } \\
\text { - Explain actions during the physical examination. } \\
\text { - Perform: history focused on the feared diagnosis / careful physical } \\
\text { examination of the part(s) of the body related to the symptoms and } \\
\text { concerns / investigations / referral / consult with specialist / recommend } \\
\text { specialist. }\end{array}$ \\
\hline
\end{tabular}


- Repeat what was examined before discussing the findings.

- Propose treatment that is tailored to the patient's wishes and needs.

- Treat symptoms that are causing anxiety.

- Ensure continuity of care.

- Offer opportunity for / schedule follow-up appointment.

Goal 3. Influence cognitions: challenge belief that symptoms are indicative of serious disease

Patient is reassured about his/her misconceptions as GP understands patient's beliefs and concerns

Patient receives information that helps him/her to conclude that the complaint is not serious, both in this consultation and when the patient may experience similar symptoms in the future.

Patient does not interpret abnormalities and GPs' medical actions as indicative of serious disease.

Patient's belief that there is no reason for concern is strengthened
- Allow patient to tell his/her story.

- Ask open-ended / closed questions.

- Name / summarise concerns.

- Explore the burden of the complaint.

- Respond to (non-)verbal expressions of concern.

- Explore patient's beliefs about possible causes of the complaint.

- Explore concerns early in the consultation.

- Explore concerns after sharing the findings or the diagnosis.

- Explore concerns in a setting of physical proximity (e.g. during the examination).

- Emphasise reassuring signs.

- Describe alarm signals of the feared diagnosis.

- Ask questions related to the feared diagnosis (e.g. symptoms) which elicit answers that contradict that diagnosis.

- Explain how the findings of history, physical examination, and other investigations rule out the feared serious diagnosis

- Explain that if the physical examination or investigations reveal no abnormalities, the patient has the harmless condition.

- Remind the patient of similar complaints in the past that turned out to be no cause for concern.

- Discuss the cause of the patient's tendency to be concerned.

- Play down relevance of abnormalities by explaining: the interpretation of abnormalities in test results and (ir)relevant values / that the symptoms are not necessarily related to the feared diagnosis / that the complaint should be viewed as a discomfort rather than a threat / that not normal does not necessarily imply the presence of disease.

- Explain that history, physical examination, investigations, referral, treatment do not signify that the doctor is worried but are done: to exclude something / to reassure the patient / because it is standard procedure / because the patient experiences complaints.

- State: I am not worried / I can reassure you / I am absolutely sure that serious disease has been excluded / you are worrying more than is necessary / you were thoroughly examined and no abnormalities were found.

- Demonstrate non-verbally that you are not worried. 


\section{Goal 4. Influence cognitions: Promote belief that symptoms are benign}

Patient's attention is

shifted toward an alternative explanation

Patient receives information that supports or suggests a harmless diagnosis.
Patient is able to talk him/herself into a reassuring conclusion

Patient does not develop new worries that might overshadow the reassuring conclusion
- Explore patient's thoughts about the harmless diagnosis.

- Announce that you will examine the area related to harmless diagnosis.

- Correct misconceptions about a harmless diagnosis.

- Explain what causes the symptoms.

- Demonstrate the cause of the symptoms.

- Outline a normal, realistic prognosis.

- Explain that it is normal to experience these symptoms given the patient's situation.

- Make sure that the harmless diagnosis fits with the patient's selfimage.

- Explain that the complaint is self-limiting / easy to manage.

- Recommend home remedies.

- Let the patient tell his/her story.

- Check whether the patient is reassured.

- Ask questions about the harmless diagnosis which elicit answers that support that diagnosis.

- Change the subject shortly after the patient has arrived at a reassuring conclusion.

- Ignore expressions of new complaints, uncertainties, and assumptions.

- Link newly expressed symptoms to the benign diagnosis.

- Emphasise / show with impatience that consensus has been reached about the diagnosis.

- Show that you are certain about the diagnosis and do not share with the patient any doubts you might have.

- Do not perform a physical examination or make a referral.

Strategy = combination of an action, mechanism and goal

**'Create comfortable atmosphere' and 'make patient feel heard and understood' are actions to create trust in the doctor-patient relationship. However they also contribute directly to the goal of safety and comfort as two separate mechanisms

\section{Goal 1. Influence emotions: create trust}

GPs believed that for patients to buy into reassuring information they needed to have faith in their GP's expertise and in the trustworthiness of the doctor-patient relationship. They emphasised that in gaining the patient's trust it was important to give non-verbal signs that they were confident of their judgment, because patients are likely to pick up any signal that the doctor is worried too. GPs also tried to create trust by thorough explanations, e.g. about the GPs' procedures, the absence of serious 
disease and the cause of the symptoms. They thought this generated more trust in the GP's expertise than merely answering the patient's questions.

If someone only answers your questions it is hard to be sure what they are getting at. When someone tells you what they are doing, how things work, you give the impression: I know what I am talking about and that inspires a sort of trust, and that is reassuring.

GP 10B (GP 10 from dataset B), + (female), 57 y (57 years of age) 20 exp (20 years of working experience). Patient 1, $+48 \mathrm{y}$, excessive sweating (complaint for which reassurance is given at this moment)

Some GPs emphasised that trust depended on factors like a long-standing trusting doctor-patient relationship, which could not be established in one single consultation

What helps is when you know people well. When you have seen them before, the seeds you have sown earlier, which gives them confidence that what you say is correct and that you would be honest about any doubts you might have.

GP 11B,, 47 y, 17 exp. Patient 2,,+ 47 y, hip complaints

\section{Goal 2. Influence emotions: create safety and comfort}

GPs argued that in order to make patients feel safe and comfortable it was important to create a calm and relaxed atmosphere. This could be achieved by approaching the patient in a friendly manner engaging in small talk and using humour and by carefully explaining what would happen during the physical examination, especially when the patient was very anxious or the examination would involve actions that were not expected by the patient.

I have known him for quite some time and he is very friendly toward other people, so I try to be friendly too, to establish rapport with him so that he feels at ease and consequently is more inclined to believe and value what I say. GP 6B, $\widehat{\sigma}, 48$ y, 19 exp. Patient 1, $\widehat{\sigma}, 68$ y, sudden shaking attack

GPs explained that it was important for patients to feel heard and understood by their GP. 
I confirm that I can imagine that this is a burden. When people feel they are not heard, that they are talking at a wall, that you brush aside everything they bring up, they will only get more worried.

GP 11B,,+ 47 y, 17 exp. Patient 1,,, 36 y, weight gain

To ensure that patients knew that their whole situation was taken into account, GPs asked about the patient's social situation or mentioned that they understood that symptoms were worse when the patient was at home.

According to GPs, patients needed to be shown that the GP took responsibility for their complaints. This could be done by announcing and explaining the different stages of the consultation, showing that they were aware of the patient's concerns and took them seriously.

His complaint is that he is worried. So I think if I can show him that I ask questions about his concerns he will know that his problem has my full attention.

GP 12A,,+ 47 y, 16 exp. Patient 1, $\hat{\sigma}, 49$ y, dyspnoea

\section{Goal 3. Influence cognitions: challenge patients' belief that symptoms are indicative of serious disease}

GPs described that for reassurance to be effective it was not enough to simply state that the symptoms were no cause for concern, and they used a range of strategies to persuade patients that they were mistaken in thinking they were suffering from a serious disease.

\section{Patient is reassured about his/her misconceptions as GP understands patients' concerns}

GPs mentioned that they aimed to understand patients' concerns, and in dealing with patients' cognitions they let themselves be guided by specific misconceptions expressed by the patient. That is why most GPs preferred to explore the patient's concerns at an early stage in the consultation.

I am thinking: are you worried that it is associated with cancer? I first want to know her line of thinking. Also, discharge and lung cancer, those are totally unrelated. When I focus too much on exploring things that go in another direction without asking her what she is thinking I will be on a totally different track. In my opinion it 
has nothing to do with that, but to her there may be a connection and I had better go along with that.

GP 11A,,+ 40 y, 8 exp. Patient 2,, 69 y, vaginal discharge

Some GPs thought it was also effective to explore patient concerns during physical examination, as proximity creates a favourable environment for patients to share information, including concerns.

\section{Patient receives information that helps him/her to conclude that the complaint is not serious}

GPs described that giving patients information that negated their concerns about the presence of a serious condition could help to reassure patients during the consultation but also for the future when the patient might experience similar symptoms. GPs frequently mentioned that they described to patients the symptoms of a serious diagnosis while at the same time pointing out that these symptoms were absent.

Some GPs encouraged patients to reassure themselves. This involved asking the patient if certain alarming symptoms of the feared diagnosis were present thereby leaving it to the patient to discover that these symptoms were absent.

It is preferable that the patient says that it [the worrying symptom] is not present than that I point it out. This is clearly more reassuring. If the patient identifies the absence of worrisome symptoms that is more effective than when the GP says it is this or that.

GP 7B, $\widehat{O}, 48$ yrs, 14 yrs exp. Patient $1, \hat{\sigma}, 74$ y, chest pain

Several GPs thought this strategy, as well as other strategies for helping patients to reassure themselves - which will be described later -, was more effective than telling patients their symptoms were no cause for concern, especially when patients were prone to anxiety.

GPs said that after excluding a serious disease, they wanted to make anxious patients aware of their tendency to worry, for example by explaining that it was their anxious personality or the presence of illness in the family that made them worry every time they experienced bodily sensations that seemed slightly unusual. Again, some GPs described that by asking questions, such as whether the patient experienced these 
complaints before a certain stressful event, they could help patients to identify what triggered their concerns and this could offer effective reassurance.

\section{Patient does not interpret abnormalities and GPs' medical actions as indicative of serious disease}

When GPs informed patients about abnormalities which they thought were no cause for alarm they tried to soften the impact of the message by explaining that they described all abnormalities regardless of their clinical relevance or by explaining that deviations from normal findings had to be very large to be clinically relevant. Certain medical actions, such as referrals, were regarded as a sign of taking responsibility for the patient's problem but could be interpreted by the patient as signifying that the GP was worried too. In such cases GPs emphasised to the patient that they took those actions to reassure the patient, not themselves.

I try to say: o.k. I will refer you to the internist but that does not mean that I think you have cancer or something. If I thought, well this looks worrying, I would make a phone call right now and you could be seen by the specialist tomorrow. But I do not share your concerns.

GP 4A, §̂, 59 y, 27 exp. Patient 2,, 67 y, stool problems

\section{Patient's belief that there is no reason for concern is strengthened}

Several GPs tried to persuade patients that their symptoms were not severe by explicitly stating that they saw no reason for concern. They underpinned this by showing or stating that they were not worried or by emphasising that they had conducted a thorough examination and found no abnormalities.

No, I say there is no reason whatsoever for you to be concerned. So we have done more investigations. We have done a pelvic $x$-ray, a sonogram, blood tests and the outcomes so far indicate that nothing is seriously wrong, there is nothing for you to be worried about.

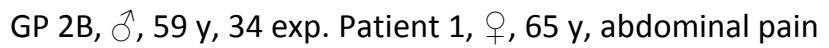

\section{Goal 4. Influence cognitions: promote belief that symptoms are benign}

In case GPs had insights into the actual cause of the patients' symptoms, they mentioned that they tried to replace patients' existing notion that their symptoms 
indicated serious disease with new cognitions that supported belief in an alternative explanation.

\section{Patients' attention is shifted toward an alternative explanation}

GPs mentioned undertaking several actions to stimulate patients to consider less serious explanations. By exploring the patient's thoughts about the probability of a harmless diagnosis, GPs tried to shift the patient's attention toward that diagnosis.

He went into it himself, the stress, then I thought, yes now we have a cue to address the stress. Then I thought, I really want to hear it from him, to what extent does he feel it has something to do with it.

GP 12A,,+ 47 y, 16 exp. Patient 1, $\widehat{\jmath}, 49$ y, dyspnoea

\section{Patient receives information that supports a harmless diagnosis.}

GPs provided information that supported an alternative diagnosis by explaining to patients what caused their symptoms, sometimes adding that these symptoms were not unusual given the patient's situation.

She is probably menopausal and at that time many ladies notice changes in their skin, their muscles, their joints, which cause stiffness. And when you explain that, it can also be very reassuring.

GP 9B, $\hat{\jmath}, 64$ y, 38 exp. Patient 1,,+ 49 y, joint pain

GPs described the natural course of the harmless condition to challenge patients' prognostic misconceptions. They also tried to frame complaints in accordance with the patient's self-image, for instance by attribution to normal ageing when the patient regarded himself as elderly. Again, this could provide reassurance not only in the present situation but also for future complaints.

\section{Patient is able to talk him/herself into a reassuring conclusion}

Some GPs used a strategy aimed at getting patients to reassure themselves by encouraging patients to tell their story following their own line of reasoning and asking them questions to elicit answers that would confirm a harmless diagnosis. In this way GPs stimulated patients to talk themselves into concluding that nothing was seriously wrong with them. 
This is a typical phenomenon in MUS patients, when you let them talk and arrive at a conclusion, they quite often give substantial reassurance to themselves. When you as the doctor take on the role of reassurer, they will oppose anything that may be only slightly inconsistent with your story.

GP 1B,,, 36 y, 5 exp. Patient 1,,+ 89 y, chest pain

\section{Patient does not develop new worries that might overshadow the reassuring} conclusion.

It was mentioned that it was important to steer clear of opportunities for patients to develop new concerns once the GP had convinced them of the non-serious diagnosis. When patients came up with new symptoms, some GPs responded briefly to make the patient feel heard, pointing out that these symptoms were consistent with the benign explanation. By contrast, GPs sometimes deliberately refrained from responding to show these symptoms were nothing to worry about. GPs believed this was only possible in case they had already invested sufficiently in making the patient feel heard and understood in the beginning of the consultation.

GPs were aware that their actions or statements could give rise to fresh concerns, especially when patients were very anxious or were confronted with illness in the family. To prevent anxiety in these patients, GPs refrained from sharing any doubts they might have about the diagnosis or from diagnostic procedures.

This is a very insecure person, which is understandable given his history, with a mother who had a brain tumour. On my part I really think it would be useless to refer him. I will send him home worrying if I show any doubt about that. He will be stressed, thinks he has a brain tumour. You can say with 90 per cent certainty that it is a migraine. The percentage is probably even higher. Then you just have to act as if you are one 100 percent certain.

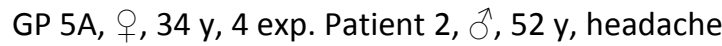

This strategy contrasted with the strategy of sharing diagnostic uncertainties with patients to inspire trust in the GP's openness or initiating investigations and referrals to show that complaints were thoroughly investigated. 


\section{Effectively provide reassuring information}

Providing information to patients was one of the cornerstones of GPs' attempts to influence patients' cognitions. GPs took a range of actions to ensure that patients understood and interpreted information correctly, such as repeating reassuring information and checking whether patients had understood everything. To ensure clarity, GPs used simple language without medical jargon and visual supports such as anatomical models and graphs. They also handed out information leaflets which patients could read at home to find confirmation that their symptoms are nothing to worry about. Several GPs demonstrated where the symptoms originated and explained their findings during physical examination. Most of these GPs repeated the findings when the patient was seated again after the examination. Some GPs did not share findings until after the examination because they believed that by then patients were better able to take in information.

\section{DISCUSSION}

The analysis of the interviews showed that GPs used a range of different strategies they considered useful when reassuring their patients. GPs specifically stressed that for effective reassurance it was important to target patients' emotions and cognitions. Influencing emotions by promoting trust, safety and comfort was considered essential to create an environment in which cognitions could be altered successfully. By influencing cognitions, GPs aimed to challenge patients' belief that their symptoms were serious, preferably before they tried to convince patients that their symptoms were benign. In order to successfully alter cognitions, GPs deemed it necessary to take specific actions to communicate information effectively. Depending on the situation, GPs used different actions to activate mechanisms that contributed to achieving their goals. For patients who were prone to anxiety it was considered wise to give them an active role in constructing reassuring information. For less anxious patients, GPs considered it to be sufficient to give the reassuring information.

The sequence of influencing cognitions that several GPs described was also suggested by Starcević as being useful in reassuring hypochondriacal patients (32). Some of the actions we identified were reported in the literature to have an effect on anxiety in specific subgroups of anxious patients. In MUS patients it was shown to be effective to explain the actual cause of their symptoms, which is often psychosocial, and use information leaflets to transmit this information (21). Re-attributing somatic 
complaints to a psychosocial cause can be supported by explanation and demonstration, such as explaining how symptoms can be caused by stress or demonstrating that complaints are caused by muscle tension $(33,34)$. Also in cancer survivors, anxiety levels decrease after adequate transmission of information, preferably using written support (20). In both sub-groups it has been shown that feeling heard and understood by exploring and acknowledging concerns, beliefs, and ideas; showing empathy and summarising can ameliorate anxiety $(19,21,33-35)$.

Actions ensuring that the patient feels listened to and understands the information are included in well-known models of consultations skills such as the CalgaryCambridge guides and the SEGUE Framework $(36,37)$. Our results support the notion that reassurance includes both affective and cognitive components (7). Pincus et al. concluded that cognitive reassurance directly effects patient outcomes, while the impact of affective reassurance remains unclear (22). The current study suggests that cognitive reassurance cannot be given effectively without affective reassurance. GPs seem to argue that affective reassurance works via an indirect pathway, i.e. by facilitating cognitive reassurance. This is in line with Epstein et al. who recommended that empathy should be expressed in the beginning of the consultation, as it facilitates biomedical inquiry, reassurance and action (15). However, affective reassurance seems to directly reassure patients who worry about the impact of their complaints on their daily functioning and do not feel heard and taken seriously by others (38).

The majority of the strategies involved the giving of information to influence patients' cognitions but GPs also used strategies in which they asked the patient questions to encourage them to actively construct the reassuring information for themselves. This type of strategy was believed to be especially effective in patients who were prone to anxiety. This is in line with the principle of Cognitive Behavioural Therapy to invite patients to correct their cognitive errors (39).

Importantly, several contrasting reassuring strategies were identified. For example, GPs estimated that some patients could not handle GPs' diagnostic uncertainties or diagnostic procedures, whilst other patients needed these in order to trust the GP or to feel taken seriously. Goals such as creating trust required more attention in some consultations than in others. Some strategies that are generally believed to be counterproductive, such as not responding to new symptoms and concerns, were believed to be effective under certain conditions. Thus, GPs seemed to tailor their 
reassurance to the context of that specific consultation, which explains why they described such a wide variety of strategies. The context-specific and goal-directed character of doctor-patient communication has also been shown in previous research $(27,40,41)$. The situation-specificity of reassurance has also been demonstrated in our study exploring the patients' perspective on reassurance, which showed that what is experienced as reassuring by patients largely depends on their specific worrying cognitions (38).

In this study we used GPs' own recent consultations as cues for stimulated recall stimulating GPs to reflect on what really happened during their patient encounters, thereby reducing the chance of incomplete, unreliable, or unfeasible answers. However, when describing the reasons for their actions, GPs may have given post-hoc rationalizations for their behaviour.

Secondly, our findings do not allow us to make conclusions on the actual effectiveness of the described strategies. Nevertheless, the descriptions of reassuring strategies, comprising actions, mechanisms, and goals, do facilitate the formulation of specific hypotheses to be tested in systematic, experimental studies in larger populations.

Furthermore, all interviews were independently coded by researchers with an insider perspective (GP and/or medical student) and an outsider perspective (health sciences) to enhance the validity of the results. The study sample of 27 interviews is relatively large considering that 10-15 interviews is the standard for stimulated recall interviews (31), though only twelve interviews focused solely on reassurance. Saturation of data collection was achieved for goals and mechanisms but not for actions. To cover all types of actions in interviews probably requires a vast number of interviews as every context generates slightly different actions. As these additional actions are likely of rare occurrence the benefit of additional interviews seems limited. Hence, we concluded that sufficient data were available to answer our research question.

Although we believe that our results can also be of use to doctors working in clinical settings other than primary care, future studies exploring reassuring practices used by other specialties or health professionals could yield additional strategies more suitable to these settings. Emergency doctors are for instance frequently faced with extremely worried patients but have limited opportunities to build a trusting doctorpatient relationship, and may consequently rely on different strategies for reassurance. 


\section{Conclusions}

This study identified a rich variety of strategies that GPs use to reassure their patients. The descriptive framework of strategies, covering actions that activate mechanisms to achieve goals, can be helpful in answering questions about 'what works, when, for whom and why'. Until evidence is gathered on the actual effects of reassuring strategies, this framework may provide GPs with some new tools. Thus, it would be mistaken to conclude that the strategies described in this study must be used in every patient encounter or that the structure we describe is a reflection of how every consultation should be conducted. We do believe, however, that the description may support GPs in selecting actions and mechanisms to promote reassurance that are appropriate for the situation at hand. Medical schools could adopt this approach to train students in 'breaking good news'. 


\section{REFERENCES}

1. Buchsbaum DG. Reassurance reconsidered. Soc Sci Med. 1986;23:423-7.

2. Cooper C. The art of reassurance. Aust Fam Physician. 1996;25:695, 7-8.

3. Fitzpatrick R. Telling patients there is nothing wrong. BMJ. 1996;313(7053):311-2.

4. Kessel N. Reassurance. Lancet. 1979;1:1128-33.

5. Veldhuijzen W, Urlings J, Portegijs P, Weijden TVD, Muijtjens A, Elwyn G, et al. The goal driven nature of doctor-patient communication in primary care encounters. Challenging the patient-centred paradigm Designing feasible guidelines for doctor-patient communication. Maastricht: Universitaire pers Maastricht; 2011. p. 133-52.

6. Linton SJ, McCracken LM, Vlaeyen JW. Reassurance: help or hinder in the treatment of pain. Pain. 2008;134(1-2):5-8.

7. Coia P, Morley S. Medical reassurance and patients' responses. J Psychosom Res. 1998;45:377-86.

8. Warwick HM, Salkovskis PM. Reassurance. Br Med J (Clin Res Ed). 1985;290:1028.

9. McDonald IG, Daly J, Jelinek VM, Panetta F, Gutman JM. Opening Pandora's box: the unpredictability of reassurance by a normal test result. Br Med J (Clin Res Ed). 1996;313:329-32.

10. Lucock MP, Morley S, White C, Peake MD. Responses of consecutive patients to reassurance after gastroscopy: results of self administered questionnaire survey. Br Med J (Clin Res Ed). 1997;315:572 5.

11. Petrie KJ, Müller JT, Schirmbeck F, Donkin L, Broadbent E, Ellis CJ, et al. Effect of providing information about normal test results on patients' reassurance: randomised controlled trial. $\mathrm{Br}$ Med J (Clin Res Ed). 2007;334:352.

12. Stark D, Kiely M, Smith A, Morley S, Selby P, House A. Reassurance and the anxious cancer patient. Br J Cancer. 2004;91:893-9.

13. van Ravesteijn H, van Dijk I, Darmon D, van de Laar F, Lucassen P, Hartman TO, et al. The reassuring value of diagnostic tests: a systematic review. Patient Educ Couns. 2012;86:3-8.

14. Meechan GT, Collins JP, Moss-Morris RE, Petrie KJ. Who is not reassured following benign diagnosis of breast symptoms? Psychooncology. 2005;14:239-46.

15. Epstein RM, Hadee T, Carroll J, Meldrum SC, Lardner J, Shields CG. "Could this be something serious?" Reassurance, uncertainty, and empathy in response to patients' expressions of worry. J Gen Intern Med. 2007;22(12):1731-9.

16. Rief W, Heitmüller AM, Reisberg $\mathrm{K}$, Rüddel $\mathrm{H}$. Why reassurance fails in patients with unexplained symptoms--an experimental investigation of remembered probabilities. PLoS Med. 2006;3:e269.

17. van Bokhoven MA, Koch H, van der Weijden T, Grol RPTM, Kester AD, Rinkens PELM, et al. Influence of watchful waiting on satisfaction and anxiety among patients seeking care for unexplained complaints. Ann Fam Med. 2009;7:112-20.

18. Donovan JL, Blake DR. Qualitative study of interpretation of reassurance among patients attending rheumatology clinics: "just a touch of arthritis, doctor?". Br Med J (Clin Res Ed). 2000;320:541-4.

19. Liénard A, Merckaert I, Libert Y, Delvaux N, Marchal S, Boniver J, et al. Factors that influence cancer patients' anxiety following a medical consultation: impact of a communication skills training programme for physicians. Ann Oncol. 2006;17:1450-8.

20. Lobb EA, Butow PN, Barratt A, Meiser B, Gaff C, Young MA, et al. Communication and informationgiving in high-risk breast cancer consultations: influence on patient outcomes. $\mathrm{Br} J$ Cancer. 2004;90:321-7.

21. Hall-Patch L, Brown R, House A, Howlett S, Kemp S, Lawton G, et al. Acceptability and effectiveness of a strategy for the communication of the diagnosis of psychogenic nonepileptic seizures. Epilepsia. 2010;51:70-8.

22. Pincus T, Holt N, Vogel S, Underwood M, Savage R, Walsh DA, et al. Cognitive and affective reassurance and patient outcomes in primary care: a systematic review. Pain. 2013;154(11):2407-16.

23. Grol R. Improving Patient Care: The Implementation of Change in Clinical Practice: Elsevier; 2005.

24. Lingard L, Espin S, Evans C, Hawryluck L. The rules of the game: interprofessional collaboration on the intensive care unit team. Crit Care. 2004;8(6):R403-8.

25. Wong G, Greenhalgh T, Westhorp G, Pawson R. Realist methods in medical education research: what are they and what can they contribute? Med Educ. 2012;46(1):89-96. 
26. Lyle J. Stimulated recall: a report on its use in naturalistic research. British Educational Research Journal. 2003;29:861-78.

27. Veldhuijzen W, Mogendorff K, Ram P, van der Weijden T, Elwyn G, van der Vleuten C. How doctors move from generic goals to specific communicative behavior in real practice consultations. Patient Educ Couns. 2013;90:170-6.

28. Attride-Stirling J. Thematic networks: an analytic tool for qualitative research. Qual Res. 2001;1:385405.

29. Watling CJ, Lingard L. Grounded theory in medical education research: AMEE Guide No. 70. Med Teach. 2012;34:850-61.

30. van Thiel J RP, van Dalen J. MAAS-global manual. Maastricht: Maastricht University Press; 2000.

31. Schepens A, Aelterman A, Van Keer H. Studying learning processes of student teachers with stimulated recall interviews through changes in interactive cognitions. Teach Teach Educ. 2007;23:457-72.

32. Starcević V. Reassurance and treatment of hypochondriasis. Gen Hosp Psychiatry. 1991;13:122-7.

33. Gask L, Dowrick C, Salmon P, Peters S, Morriss R. Reattribution reconsidered: narrative review and reflections on an educational intervention for medically unexplained symptoms in primary care settings. J Psychosom Res. 2011;71:325-34.

34. Goldberg D, Gask L, O'Dowd T. The treatment of somatization: Teaching techniques of reattribution. J Psychosom Res. 1989;33:689-95.

35. Fogarty LA, Curbow BA, Wingard JR, McDonnell K, Somerfield MR. Can 40 seconds of compassion reduce patient anxiety? J Clin Oncol. 1999;17:371-9.

36. Silverman J, Kurtz S, Draper J. Skills for communicating with patients. Second ed. Oxford: Radcliffe Publishing; 2005.

37. Makoul G. The SEGUE Framework for teaching and assessing communication skills. Patient Educ Couns. 2001;45:23-34.

38. Giroldi E, Veldhuijzen W, Mannaerts A, van der Weijden T, Bareman F, van der Vleuten C. "Doctor, please tell me it's nothing serious": an exploration of patients' worrying and reassuring cognitions using stimulated recall interviews. BMC Fam Prac. 2014;15(1):73.

39. Warwick HMC. Cognitive Therapy in the Treatment of Hypochondriasis. Adv Psychiatr Treat. 1998;4:285-91.

40. Essers G, Kramer A, Andriesse B, van Weel C, van der Vleuten C, van Dulmen S. Context factors in general practitioner-patient encounters and their impact on assessing communication skills--an exploratory study. BMC Fam Prac. 2013;14:65.

41. Essers G, van Dulmen S, van Weel C, van der Vleuten C, Kramer A. Identifying context factors explaining physician's low performance in communication assessment: an explorative study in general practice. BMC Fam Prac. 2011;12:138. 



\section{CHAPTER}

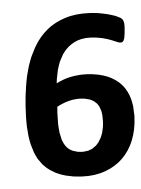

\section{Nurturing skilled communication in the workplace: towards a personalised communication repertoire}

Esther Giroldi, Wemke Veldhuijzen, Kristel Geelen, Jean Muris, Frits Bareman, Herman Bueving, Trudy van der Weijden, Cees van der Vleuten Submitted 


\section{ABSTRACT}

\section{Background}

To inform the development of didactic recommendations to facilitate learning of skilled doctor-patient communication in the workplace, this qualitative study explores experiences of trainees and supervisors regarding how trainees learn communication and how supervisors support trainees' learning in the workplace.

\section{Methods}

We conducted a qualitative study in a general practice (GP) training setting using triangulation as our research strategy: we held three general focus groups, five focus groups using training sessions as a stimulus and five individual interviews to explore the experiences of GP trainees and GP supervisors. Thematic network analysis was performed during an iterative process of data collection and analysis.

\section{Results}

We identified a communication learning cycle consisting of 6 consecutive phases: impactful experience, change in frame of reference, identification of communication strategies, experimentation with strategies, evaluation of strategies and mastery of a personalised communication repertoire. Supervisors supported trainees throughout this process by creating challenges, confronting trainees with their behaviour and helping them reflect on its underlying mechanisms, exploring and demonstrating communication strategies, giving concrete practice assignments, creating safety, exploring the effect of strategies and facilitating repeated practice and reflection.

\section{Conclusion}

To nurture skilled communication, it seems important that medical communication training fosters the development of a personal communication repertoire from which learners are able to apply strategies that fit the context and their personal style. After further validation of our findings, it may be recommended to give learners concrete examples, opportunities for repeated practise and reflection on personal frames of reference and the effect of strategies, as well as space for authenticity and flexibility. In the workplace, the clinical supervisor is able to facilitate all these essential conditions to support his/her trainee in becoming a skilled communicator. 


\section{INTRODUCTION}

Doctor-patient communication is a core medical competency involving complex behaviour (1-3). In 2011, Salmon \& Young called for a shift from 'communication skills' towards 'skilled communication' in communication training and research. They argued that communicative behaviours are too complex to be predetermined and assessed with behavioural checklists. A holistic and context-specific approach would be more appropriate to address this complexity (4). This view is empirically supported by studies that have demonstrated both the context-specific and goal-directed nature of communication in daily practice (5-9), as well as the transfer gap in generic communication training (10). As a consequence, it is believed that learning skilled communication cannot take place only in a teaching setting isolated from the clinical context, but is a continuous process in interaction with the clinical environment. Hence, there is growing attention for the role of the clinical workplace in learning communication $(4,11,12)$.

Several empirical studies and theories have emphasised the relevance of certain elements to learning communication in the workplace. The learner's frame of reference, for instance, that is, one's personal assumptions, knowledge, beliefs and emotions, seems to play a key role in becoming a skilled communicator $(11,13)$. According to Mezirow's Transformative Learning Theory (TLT), an experience is the starting point for learning. Becoming aware of one's own frame of reference and adjusting it accordingly through reflection on this initial experience creates scope for behavioural change (14). At such point, however, the learner still needs to develop effective and useful behaviours that fit the new frame of reference. As demonstrated in the literature, good clinical role models and practical rehearsal are vital to this process $(11,15-17)$. Mimetic Learning Theory (MLT), recently developed by Billet, describes how people learn in workplaces through a process called 'mimesis', in which the learner actively engages with others (e.g. observing behaviour), imitates and rehearses to accomplish the required performances (18).

The clinical supervisor, from his position as a mentor, coach and role model, is both a powerful inspirer for engagement in mimetic learning, and an influential reference point with whom learners compare their frames of reference. Hence, to be able to make didactic recommendations on how to facilitate the learning of doctor-patient communication in the workplace, it is important to understand in detail not only how 
learners learn communication, but also how clinical supervisors can make optimal use of their role to facilitate this learning. This qualitative study therefore explores experiences of trainees and supervisors regarding how trainees learn communication in the workplace and which supervisor behaviours support this learning.

\section{METHODS}

\section{Setting}

This study was set in the context of General Practice (GP) specialty training in the Netherlands, which offers its trainees periodic medical communication training during weekly peer-to-peer coaching sessions. GP supervisors also receive communication and didactic skills training to support trainees in learning communication.

\section{Ethics}

The Netherlands Association for Medical Education (NVMO) granted its approval for our study protocol. Participating trainees and supervisors gave written informed consent. All data were anonymized with codes.

\section{General design}

We tapped various sources of qualitative data (triangulation) to obtain a rich understanding of trainees and supervisors' take on learning communication: regular focus groups, focus groups using training sessions as a stimulus and individual interviews. Data were collected alternately from supervisors and trainees, allowing findings arising from one group to inform data collection in the other group. Guided by sensitizing concepts derived from existing relevant theoretical concepts (19), we applied constructivist grounded theory principles, i.e. iterative data collection and analysis, constant comparison and purposeful sampling (20), to develop a conceptual model on trainees' learning. To identify common themes and their relationships, we performed a thematic network analysis (21). 


A-priori themes:
Experience
Frame of reference
Reflection
Behavioural change
Work environment
Interaction
Observation
Imitation
Practice
Rehearsal
Evaluation
Skills/strategies

3 general focus

groups with

supervisors

$\mathrm{N}=25(\mathrm{~N}=7,8,10)$

14 male, 11 female

$3 \times 45$ minutes
$2 \times 2$ stimulated

focus groups

with trainees

$\mathrm{N}=11$

1 male, 10 female

$4 \times 90$ minutes

\begin{tabular}{|l||l|}
\hline 1 stimulated & Individual \\
focus group & interviews with \\
with supervisors & trainees \\
$\mathrm{N}=11$ & $\mathrm{~N}=5$ \\
4 male, 7 female & 5 female \\
$1 \times 90$ minutes & $5 \times 20$ minutes \\
\hline
\end{tabular}

Data collection

Figure 6.1 Process of data collection and analysis

\section{Data collection}

\section{General focus groups with supervisors}

We organised focus-group discussions with GP supervisors (Figure 6.1) since we expected that an interactive setting would stimulate reflection on own experiences and enable the expression of latent thoughts and beliefs. We invited 60 supervisors from two different GP specialty training centres, of which 25 supervisors participated. Three focus-group discussions were organised. An experienced chair (JM/WV/FB) guided the discussions and the primary researcher (EG) was present to take minutes. In order to stay close to daily practice, we jump-started the discussions by presenting communication issues GP trainees faced in real practice. Supervisors were invited to reflect on how trainees overcome these challenges in practice and how they support their trainees in this process.

\section{Stimulated focus groups with trainees}

In order to follow closely the actual learning process of trainees, we used a communication training as a stimulus for discussion (Figure 6.1). We asked two existing first year communication training groups to participate. Each group participated in two group sessions guided by EG or WV. During the first session, trainees extensively discussed how they planned to work in practice on their newlyformulated learning goals. Throughout the second session, which took place two weeks later, trainees discussed what they had done and what had helped them to achieve their learning goals. 


\section{Stimulated focus group with supervisors}

Similar to the aforementioned stimulated focus groups with trainees, we used a training on communication and didactics for supervisors as a stimulus to generate relevant data (Figure 6.1). We invited an existing training group of 11 supervisors to participate in the study. The session started with a 30-minute plenary discussion on how supervisors planned to support their trainees in tackling communication issues. Subsequently, supervisors were divided into four small groups, each led by a facilitator. During these 60-minute sessions, GP supervisors practised learning dialogues with their trainees through role play, after which the facilitator probed supervisors about what they had done during this dialogue and why.

\section{Individual interviews with trainees}

To obtain a more in-depth understanding of some specific elements of trainees' learning process, we invited the 11 trainees from the focus groups to participate in an individual interview two to three months after the second training session. Five trainees were interviewed by EG, who probed them about how they had worked on their learning goals during the past months.

\section{Data analysis}

All discussions and interviews were audiotaped and transcribed verbatim. At least two independent researchers with different backgrounds (EG: Health Sciences; KG/WV: Medicine) coded the transcripts using specialised software (ATLAS.ti). First, we derived a priori themes from Transformative Learning Theory and Mimetic Learning Theory (Figure 6.1). During the analysis of the first regular focus group with supervisors, we identified fragments relevant to how trainees learn and how supervisors support this learning. Fragments that fit the a priori themes were coded as such, while we also defined new themes. Themes were organised into a thematic network to visualise relationships. The coding structure that ensued guided the analysis of all subsequent focus-group discussions and individual interviews. During this process, we constantly grouped, split and refined themes and modified the thematic network. The network and written memos informed the development of a conceptual model visualising trainees' learning process. The analysts discussed differences in coding until consensus was reached. The thematic network and conceptual model were repeatedly discussed with all co-authors. 


\section{RESULTS}

\section{Trainees' learning process}

From trainees' and supervisors' reflections, we could distil six consecutive phases that together constitute the process of how trainees learn effective doctor-patient communication (Figure 6.2).

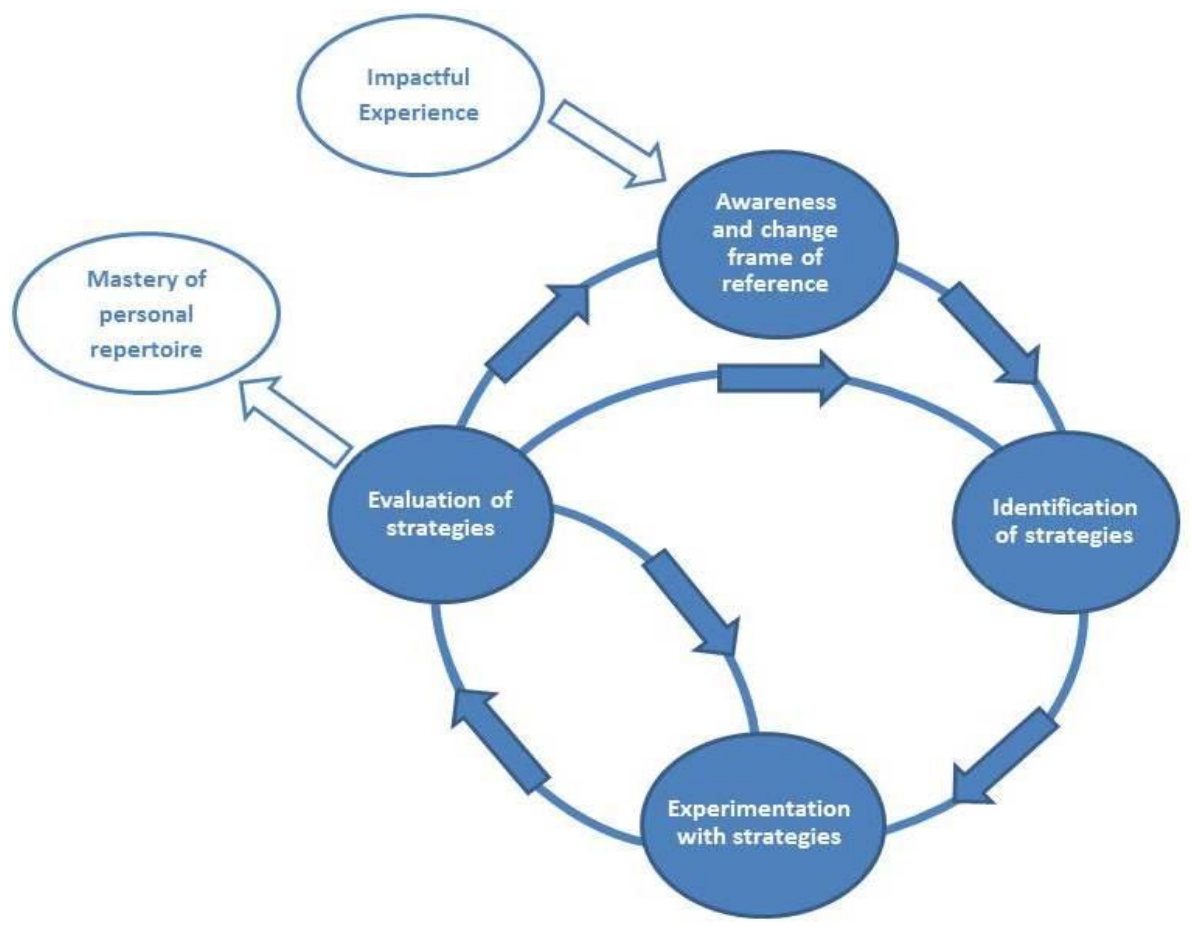

Figure 6.2 Trainees' communication learning process: six phases and three loops

Trainees and supervisors described that the learning process of a trainee is usually set in motion by an impactful experience, such as a challenging patient encounter or feedback from a peer, supervisor or trainer (phase 1). Such an experience triggers trainees' intrinsic motivation to learn to handle similar situations more effectively and typically forms the basis for reflection.

Well yes, I am aware of certain fallacies, which is why I am eager to learn. I notice that when I stumble, I start to practice these things. - Individual interview with trainee 
Upon reflection with others, trainees' initial feeling about the impactful experience 'this encounter did not feel quite right', for example - becomes more explicit. This process helps trainees to become aware of their actual behaviour and of the feelings, knowledge and attitudes that may have given rise to the behaviour of that moment (phase 2). Awareness and reflection create opportunities for changes in their frames of reference, for instance in their feelings and attitudes towards patients or assumptions about what makes good communication. As a result, trainees often wish to change their behaviour, by bringing their communication style in line with the new beliefs and attitudes.

It all depends on how the trainee experiences a consultation; is he uncomfortable? Does he sense that in time? Does he act on it? What is often the case in the beginning is that it just happens to them, so to speak. The next thing you get when you discuss it with them is the phase in which they become aware of it, they wake up as it were, and they try to regain control by changing the way they communicate. So the moment they themselves sense it, they become more watchful. - General FG with supervisors

When new effective behaviours are not yet available, trainees try to identify possible strategies through observations of and discussions with their supervisor, by discussing alternatives with their peers during communication training or by reading the communication literature (phase 3). Any specific wording, few words, or sentence that they can find may be helpful.

I am often searching for the right words, so yes, sometimes it is nice to just, yes, very childish, anyway to just have a clear sentence like: well yes, throw it in, right? And see what happens. - Individual interview with trainee

Trainees then try out these strategies in practice (phase 4). The decision to do so, however, must be a deliberate one, as trying out new behaviour takes up a lot of cognitive space and it is easy to revert to usual routine reactions. Trainees therefore use memory aids such as sticky notes to remind them to try out a new strategy during patient encounters. During this experimentation phase, trainees pay attention to wording and timing, as well as to the appropriateness of strategies in light of the situation. 
If I do not consciously think of it beforehand, then I will probably forget it (...). You must really make yourself aware of it in advance, like: OK, during this encounter I will make sure that somebody is being put at ease. That way you really focus on the reassurance, and then it does work. - Individual interview with trainee

After trying out a strategy, trainees evaluate its effectiveness (phase 5), by asking themselves questions such as: 1) Does it reflect my personal style?; 2) Is it effective, i.e., have I achieved my consultation goal?; 3) Do I apply it correctly?; and 4) Does it fit the situation at hand? When applying the strategy, trainees use their feelings and patient's responses as outcome measures. This fifth phase eventually results in one of three different outcomes: 1) trainees consider the strategy ineffective and immediately search for alternatives (Figure 6.2, middle loop); 2) they consider the strategy effective and continue to practise to achieve refinement, by reformulating it in such a way that they feel more comfortable with it, for example (Figure 6.2, inner loop); and 3) the evaluation changes their frame of reference (Figure 6.2, outer loop), for instance when trainees realise that respectfully interrupting a talkative patient does not harm the doctor-patient relationship, thereby changing their personal feelings and assumptions about interruptions.

So, when you ask that question, at some point you notice that: this is up my street, this is not up my street, this works, or this does not work. And to use that same sentence or strategy again in another situation. And when you realise that: well, this still does not work, then you put it aside and you think: yes, this is not up my street or I do not notice any desired effect. - Individual interview with trainee

Well, if trainees perceive that something works just fine and that it is OK to do so, then the next time they do it more easily. - General FG with supervisors

Through repetition and rehearsal, the new communication strategy, rather than being a technique learned from others, gradually becomes part of the trainees' personal repertoire (phase 6). The learner has now reached a point where the respective strategy is applied automatically, not deliberately. In this final phase of 'mastery', trainees have developed a personalised repertoire of communication strategies which they have learned to apply adaptively to the particular demands of the context. 
In the beginning you try to memorise standard sentences. And now you do it your own way and then it will come to you, without having to constantly think: request for help, request for help, request for help. Because you start practising, you are really using it, and when I am using it, it sticks with me, yes, in a way that I feel is right, say, like, and reflects my personal style, so now it is a part of me. - Individual interview with trainee

When you face something for the first time, you have no clue what to do. And what you see at some point is that trainees do recognise such a situation, but they know just one way to solve it. By practising and seeing it often, you also learn other strategies and eventually you know: this strategy might just work in this particular situation. - General FG with supervisors

\section{Supervisors' actions to support trainees' learning}

For every phase of a trainees' learning process, supervisors and trainees described actions that supervisors take to support trainees' learning. What actions supervisors take in each specific phase is presented in Figure 6.3 below. It must be noted, however, that this separation is somewhat artificial: in reality, the process is more integrated as actions flow naturally from one into another and can be applied within a very short time span.

\section{Impactful experience}

Most of the time, supervisors let their trainees decide which experiences will be brought up for discussion. Occasionally, however, they deliberately place their trainees in challenging situations by scheduling specific consultations in their trainees' diary. These are consultations of which supervisors suspect that they require communication competencies that their trainees have not yet mastered or actively worked on.

I think that the trainee must first have experienced it himself. So the first thing I do is to assign such a patient to the trainee and then we will see. You must have experienced it first before you know what to do with it. - General FG with supervisors 
GP supervisor

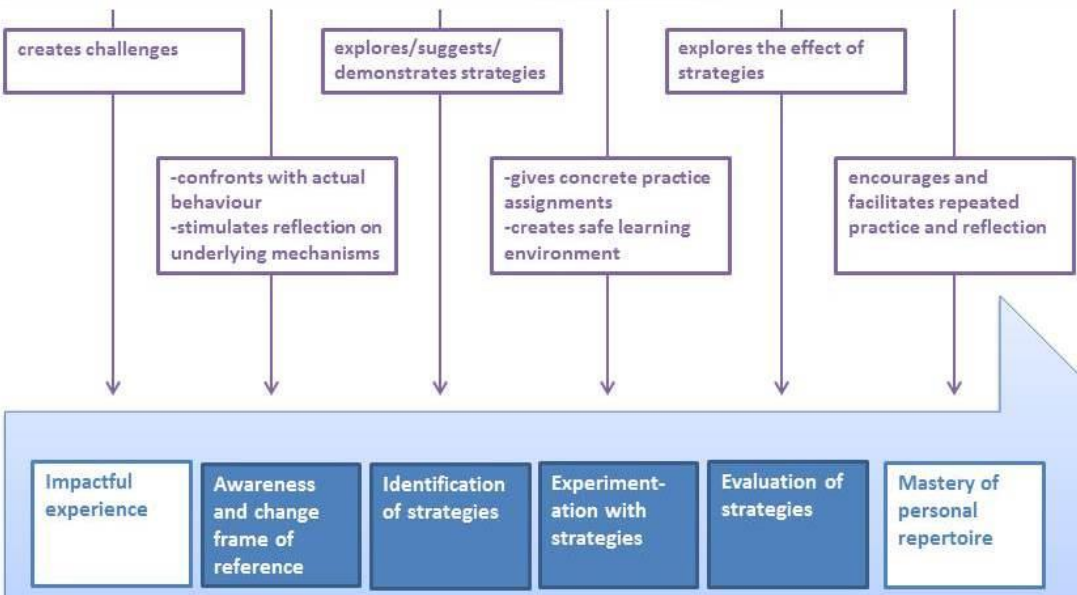

Figure 6.3 Supervisors' actions to support trainees in learning communication

\section{Awareness of and change in frame of reference}

To make trainees mindful of their frame of reference, supervisors confront them with their communication behaviour. They do so by viewing video-recorded consultations together with their trainees and discussing relevant instances, e.g. in case of prominent non-verbal cues or when the trainee feels he/she could have done something differently. They then ask their trainees to reflect upon the observed behaviour and the underlying thoughts, feelings and assumptions that triggered it.

And he keeps on pressing the "pause" button to ask: 'What happened there?'; 'What do you notice that the patient does?' 'Have you noticed it as well?'. Then I realise that, many things do go unnoticed. Really, it's only when you see the video played back. Suddenly you get it, like: ah, yes, that is the reason or this is what you feel or this is what is happening. - Individual interview with trainee

We are talking about patients, but also about the fear, uncertainty and concerns that may be felt by the trainee, right: 'Did I do the right thing?' I often spell it out, you know. 'Were you afraid of that?' Yes, yes, the unknown, that uncertainty indeed. - Stimulated FG with supervisors 
Once this frame of reference has been made explicit, they challenge their trainees to look at the encounter from a different perspective by helping them understand the underlying mechanisms of the interaction: Why did the patient and trainee communicate or respond the way they did? To promote understanding, supervisors focus on trainees' feelings of uneasiness and how these relate to their behaviour. In addition, they seek to arouse the trainees' curiosity about the patient's background. Both strategies aim to promote changes in how trainees interpret the patient's communication. Promoting insight into the patient's reactions helps trainees to view the encounter or the patient as a challenge instead of a burden.

I say: 'what happened to you there?'. 'Hmm, yes. I got rather annoyed'. 'OK, so what did you do with that feeling?'. 'Well, nothing, really'. 'You get annoyed but you just lean back calmly in your chair. That's not right, that's difficult for the patient.' General FG with supervisors

If you can counterbalance it and say: 'That may be so, but perhaps he has a reason for that?' That way you arouse their curiosity. - General FG with supervisors

Furthermore, supervisors challenge trainees' existing assumptions about what entails 'good communication'. They try to make clear that, although skills are important, trainees also need to learn occasionally to 'let go' of the general skills and structure they have learned during their communication training. It is important to be flexible and accept that it is not always possible or even desirable to apply all skills in one consultation; sometimes they may be counterproductive and should therefore be avoided or adjusted to the context. Finally, supervisors stress that there is a need for authenticity and individuality: trainees must be free to use the communication strategies that are appropriate to the clinical context as well as to their personal style.

Do something you did not learn to do with the communication technique you acquired at the institute. Trying to apply everything you learned will not work for every patient. Patients that should be cut short require a different approach. Patients of a different origin require yet another approach. So it is something you should learn: it cannot always be done the same way. - General FG with supervisors 


\section{Identification of strategies}

Since trainees often struggle to find the right words, they appreciate it when supervisors suggest concrete words or sentences that they can try out. Instead of suggesting sentences, some supervisors help trainees to brainstorm about alternative formulations to ensure a closer alignment with the trainees' personal communication style.

I don't always do what is good for the trainees. This is why I let them think through for themselves over ways to regain control. As far as developing your own, individual style goes, that's different for each trainee. They have to discover for themselves how they can best do it. - General FG with supervisors

Supervisors also invite trainees to observe them during consultations, while repeating that the style of the trainee need not necessarily reflect their own. Exact copying of observed behaviour may have unexpected effects due to differences in gender, age, position and background between trainee and supervisor. Nonetheless, such observations afford trainees the opportunity to become acquainted with alternative behaviours and to witness their outcomes in a variety of settings. Trainees can then adjust observed strategies in such a way that they feel comfortable using them, while still achieving the desired outcome.

You can carry on talking about it but, at a certain point, the chat has to turn into concrete action. This is why I say you should use every possible opportunity for observation: at the GP out of hours service, during visits and consultation hours. Use all these and then you see the greatest possible variety. Right, and that is exactly our skill, to know when to adapt, various models. He should also have the opportunity to observe you in all kinds of situations. - General FG with supervisors

\section{Experimentation with strategies}

Given that trying out new behaviours does not tend to be an automatic process for trainees, supervisors actively encourage trainees to practice. For instance, they instruct trainees to try out a specific sentence during a patient encounter, and sometimes first let them rehearse that strategy in a safe environment by means of a role-playing exercise. They also have trainees follow up challenging patients to ensure continuity, which fosters a trusting doctor-patient relationship, and, in turn, facilitates 
effective communication. At the same time, continuity allows trainees to try out different strategies on the same patient and to evaluate their effects, helping them discover what works best in the respective situation.

To maximise the benefit of this experimentation phase, a safe learning environment was viewed as vital: developing a personal style becomes easier when the trainee feels comfortable experimenting with different behaviours. Therefore, supervisors reassure trainees that it is okay to test alternatives and that, should they fail, they would still be able to find a solution together. Also by creating openness, such as admitting that they too find certain situations challenging, they put trainees at ease.

I think it is also important to reassure the trainee by saying that it is okay to make a mistake during an encounter. - General FG with supervisors

A final aspect related to safety is trainees' fear of making medical errors. Diagnostic uncertainty hampers trainees in improving their communication. Hence, it is important that trainees gain confidence in their medical knowledge, so that more cognitive space becomes available for the trainees to focus on communication issues.

\section{Evaluation of strategies}

To evaluate the effectiveness of the applied strategies, supervisors ask probing questions such as: 'How did you notice that your strategy was or was not effective?', 'Which verbal or non-verbal cues did the patient give?' and 'How did you verify whether your interpretation of the effect is correct?'. During this discussion, they also sometimes revert to the trainees' frame of reference by exploring how they felt when employing the strategies and whether this experience changed their attitudes towards patients or the way they see their communication habits. By making trainees aware of the change in their frame of reference, supervisors try to consolidate this change.

You can also start playing around together along the lines of, 'What do you do there?' and 'How did that work?' and 'Why do you think it worked better this time than last?'. Because you are talking about it, they can deliberately try things and then see how they work out and if they work. In this way, they also learn about what approach to use; what they feel comfortable using; what works with this particular patient? Because, after all, every case is, in itself, unique. - General FG with supervisors 


\section{Mastery of a personal repertoire}

In order for trainees to develop and internalise a personal repertoire of authentic and effective strategies, it was considered essential that trainees be encumbered with one communication theme at a time so as to avoid cognitive overload. They facilitated this process by encouraging repeated practice and reflection, for instance through repeated administration of concrete practice assignments, or by encouraging trainees to follow up patients and scheduling follow-up reflection sessions to discuss the effect of strategies.

Then you discuss it and suddenly another door opens and the next time she takes a different course and then you look at her, like: 'Did it work for you?' And then you bring it up again and again and just follow up such a patient over time in the next months. - General FG with supervisors

That is really just a small issue, which is really very specific, and that is what continues to be your focus until you notice that it has been absorbed. After that, there will be something else, of course. - Stimulated FG with supervisors

\section{DISCUSSION}

In this study we developed a conceptual model of how trainees learn to become skilled communicators and how supervisors support this process in the workplace. Interaction with patients and supervisors causes trainees to reconsider their frame of reference, and, consequently, to revisit their communication behaviours. By going through a continuous learning cycle of identifying, testing and evaluating alternatives, trainees learn to develop a personal repertoire of effective communication strategies that reflects their frame of reference. In every phase of this learning cycle, GP supervisors take specific action to facilitate the process.

A recent study by van den Eertwegh et al. also explored the communication learning process of GP trainees (22). The authors identified a five-phase learning model which bears much resemblance to our learning phases. Hence, the studies' findings are mutually reinforcing: both stress the value of repeated practice and reflection to ensure that communication strategies are integrated into the learners' personal repertoire. Similarly, both studies reiterate the importance of revisiting the learner's frame of reference, as did our previous study which explored communication issues 
encountered by trainees (23). At the same time, we observe that our findings overlap considerably with generic models of reflective learning, such as the learning cycles of Kolb and Korthagen $(24,25)$. What this study adds, however, is the insight that learning communication is very contextualised and personalised. There is more to being a skilled communicator than the mere mastery of a set of predetermined skills $(4,26)$. It involves being able to recognise a certain context and adapt the use of communication strategies accordingly. To be able to do so, trainees need impactful experiences, critical reflection on personal feelings and assumptions and repeated practice and evaluation. The resulting communication repertoire is highly idiosyncratic, that is, shaped to the individual.

Our paper also extends existing learning models by reinterpreting the role the clinical supervisor plays in learning communication in the workplace. Unlike previous literature suggesting that clinical supervisors may be negative communication role models $(10,15,27-30)$, our findings reveal that the supervisor does offer valuable support in every step of the communication learning process. Trainees do not feel comfortable being left to their own devices when it comes to learning communication. Instead, they need concrete examples (e.g. words, sentences), a safe learning environment in which there is space for trying out alternatives and individuality, as well as repeated confrontation with and reflection on their own and the patient's communication behaviour and its underlying mechanisms. The supervisor can facilitate and nurture all these essential conditions, allowing their trainee to develop into a skilled communicator. It seems that an accurate description of how trainees learn to communicate with patients in the workplace can be derived by integrating principles of Transformative Learning Theory (14) and Mimetic Learning (18). This study confirms that trainees indeed learn through interaction with others (e.g. peer, trainer and supervisor) and by continuously evaluating and adjusting behaviour and their underlying frames of reference.

\section{Strengths and limitations}

The use of data, method and theory triangulation has enhanced the credibility of our findings (31). Using the experiences of both trainees and supervisors has given us a rich understanding of how trainees learn medical communication in the workplace. Our strategy to combine individual interviews, regular focus groups and focus groups in which we used communication training sessions as stimuli for discussion facilitated in-depth reflection as well as close proximity to actual practice. However, since we did 
not perform any observations in the workplace, we cannot draw conclusions on whether our findings truly represent the actual learning practices. Triangulating two theories with empirical data has allowed us to test and refine our understanding of these theories in the specific context of communication learning. By iteratively collecting and analysing the data until no new themes could be identified, we ensured that our findings were consistent with the GP context. Nonetheless, we should refrain from making any inferences regarding the generalisability of our findings to other medical specialties or the actual effectiveness of supervisor support on trainees' learning outcomes.

\section{Implications}

Further validating our conceptual learning model with observations and studying the actual effectiveness of supervisors' support in facilitating trainees' learning are two important areas for further research. To allow extrapolation of our findings, trainees' communication learning process needs to be explored in other medical specialties as well. In addition, future studies could investigate whether our model is also applicable to clinical competencies other than medical communication that involve complex behaviours to be learned in the working environment, such as professionalism, shared decision-making and collaboration. In communication training, attention needs to be paid to how learning communication takes place in clinical practice. The workplace should allow trainees to develop their personal communication repertoire. After further validation of our findings, we may conclude that achieving mastery requires: being able to work on a communication theme for a longer period of time; space for reflection on behaviours and underlying frames of reference; an environment in which trainees feel save to practise alternatives; and opportunities to evaluate the effect of strategies. The latter also necessitates trainees following up on their own patients. Considering the significance of the supervisor's role, it is important supervisors receive didactic training in which they obtain insight into their trainees' learning process and what they can do to support this. 


\section{REFERENCES}

1. Bensing J. Communication in context: new directions in communication research. Patient Educ Couns. 2003;50:27-32.

2. Epstein RM. Whole mind and shared mind in clinical decision-making. Patient Educ Couns. 2013;90(2):200-6.

3. Henry SG, Holmboe ES, Frankel RM. Evidence-based competencies for improving communication skills in graduate medical education: a review with suggestions for implementation. Med Teach. 2013;35(5):395-403.

4. Salmon P, Young B. Creativity in clinical communication: from communication skills to skilled communication. Med Educ. 2011;45:217-26.

5. Essers G, Kramer A, Andriesse B, van Weel C, van der Vleuten C, van Dulmen S. Context factors in general practitioner-patient encounters and their impact on assessing communication skills--an exploratory study. BMC Fam Prac. 2013;14:65.

6. Essers G, van Dulmen S, van Weel C, van der Vleuten C, Kramer A. Identifying context factors explaining physician's low performance in communication assessment: an explorative study in general practice. BMC Fam Prac. 2011;12:138.

7. Veldhuijzen W, Mogendorff K, Ram P, van der Weijden T, Elwyn G, van der Vleuten C. How doctors move from generic goals to specific communicative behavior in real practice consultations. Patient Educ Couns. 2013;90:170-6.

8. Giroldi E, Veldhuijzen W, Mannaerts A, van der Weijden T, Bareman F, van der Vleuten C. "Doctor, please tell me it's nothing serious": an exploration of patients' worrying and reassuring cognitions using stimulated recall interviews. BMC Fam Prac. 2014;15(1):73.

9. Veldhuijzen W. Challenging the patient-centred paradigm: Designing feasible guidelines for doctorpatient communication. Maastricht: Datawyse; 2011.

10. Kramer AWM, Düsman H, Tan LHC, Jansen JJM, Grol RPTM, van der Vleuten CPM. Acquisition of communication skills in postgraduate training for general practice. Med Educ. 2004;38:158-67.

11. van den Eertwegh V, van Dalen J, van Dulmen S, van der Vleuten C, Scherpbier A. Residents' perceived barriers to communication skills learning: Comparing two medical working contexts in postgraduate training. Patient Educ Couns. 2014.

12. van den Eertwegh V, van Dulmen S, van Dalen J, Scherpbier AJ, van der Vleuten CP. Learning in context: identifying gaps in research on the transfer of medical communication skills to the clinical workplace. Patient Educ Couns. 2013;90(2):184-92.

13. Aper L, Veldhuijzen W, Dornan T, van de Ridder M, Koole S, Derese A, et al. "Should I prioritize medical problem solving or attentive listening?": the dilemmas and challenges that medical students experience when learning to conduct consultations. Patient Educ Couns. 2015;98(1):77-84.

14. Mezirow J. Transformative learning: Theory to practice. New Directions for Adult and Continuing Education. 1997;1997(74):5-12.

15. Côté $\mathrm{L}$, Leclère $\mathrm{H}$. How clinical teachers perceive the doctor-patient relationship and themselves as role models. Acad Med. 2000;75:1117-24.

16. Stok-Koch L, Bolhuis S, Koopmans R. Identifying factors that influence workplace learning in postgraduate medical education. Education for health (Abingdon, England). 2007;20(1):8.

17. Silverman J. Clinical communication training in continuing medical education: possible, do-able and done? Patient Educ Couns. 2011;84:141-2.

18. Billet S. Mimetic learning at work: Learning in the circumstances of practice. Dordrecht: Springer; 2014.

19. Bowen GA. Grounded theory and sensitizing concepts. International Journal of Qualitative Methods. 2006;5(3).

20. Watling CJ, Lingard L. Grounded theory in medical education research: AMEE Guide No. 70. Med Teach. 2012;34:850-61.

21. Attride-Stirling J. Thematic networks: an analytic tool for qualitative research. Qual Res. 2001;1:385405. 
22. van den Eertwegh V, van der Vleuten C, Stalmeijer R, van Dalen J, Scherpbier A, van Dulmen S. Exploring residents' communication learning process in the workplace: a five-phase model. PLoS ONE. 2015;10(5):e0125958.

23. Giroldi E, Veldhuijzen W, de Leve $T$, van der Weijden $T$, Bueving $H$, van der Vleuten C. 'I still have no idea why this patient was here': An exploration of the difficulties GP trainees experience when gathering information. Patient Educ Couns. 2015;98(7):837-42.

24. Kolb DA, Fry, R. E. Toward an applied theory of experiential learning: MIT Alfred P. Sloan School of Management; 1974.

25. Korthagen FAJ, Kessels, J., Koster, B., Lagerwerf, B., Wubbels, T. Linking practice and theory: The pedagogy of realistic teacher education. Mahwah, NJ: Lawrence Erlbaum Associates; 2001.

26. Salmon P, Young B. Core assumptions and research opportunities in clinical communication. Patient Educ Couns. 2005;58(3):225-34.

27. Haidet $\mathrm{P}$, Kelly PA, Chou C. Characterizing the patient-centeredness of hidden curricula in medical schools: development and validation of a new measure. Acad Med. 2005;80:44-50.

28. Haidet $P$, Dains JE, Paterniti Da, Hechtel $L$, Chang $T$, Tseng E, et al. Medical student attitudes toward the doctor-patient relationship. Med Educ. 2002;36:568-74.

29. Egnew TR, Wilson HJ. Role modeling the doctor-patient relationship in the clinical curriculum. Fam Med. 2011;43(2):99-105.

30. Vernooij-Dassen MJ, Ram PM, Brenninkmeijer WJ, Franssen LJ, Bottema BJ, van der Vleuten CP, et al. Quality assessment in general practice trainers. Med Educ. 2000;34(12):1001-6.

31. Frambach JM, van der Vleuten CP, Durning SJ. AM last page. Quality criteria in qualitative and quantitative research. Acad Med. 2013;88(4):552. 

General Discussion 



\section{INTRODUCTION}

As introduced in Chapter 1 of this dissertation, it is recommended that goaldirectedness and context-specificity be incorporated into medical communication training. This is not an easy undertaking given the complex nature of doctor-patient communication. The main objective of this dissertation, therefore, was to gather knowledge on how to put context-specific and goal-directed communication into clinical and educational practice. To this end, we first sought to understand what constitutes effective communication given a specific goal and context, to find out what we should train. We used two consultation goals that are important for doctors as case studies: gathering information and reassuring patients. We then continued our journey, endeavouring to understand how trainees learn context-specific and goaldirected communication and how they can be supported in this process so that we know how we should train. By making use of different qualitative research methods and research populations within the context of general practice, and consistent with our "what" and "how" objectives, we tried to find an answer to the following three research questions:

1) Which communication strategies are useful for gathering information from patients?

2) Which communication strategies are useful for reassuring worried patients?

3) How can we help trainees to learn goal-directed, context-specific communication?

In the next sections, we will first outline the main findings of each research question, and discuss these in the light of existing literature. We will then proceed with a discussion of the methodological considerations of this research, which is followed by a description of the main lessons drawn from our research, as well as their implications for educational practice. We will end with an overview of our recommendations for future research. 


\section{MAIN FINDINGS}

\section{Which communication strategies are useful for gathering information from patients?}

To determine which type of information-gathering strategies GP trainees may benefit from, we first identified information-gathering situations that were reported as particularly difficult (Chapter 2). During consultations, trainees experience difficulties when: their goal to gather information conflicts with other goals such as relationshipbuilding and time management; the communication skills they learned during medical training are ineffective or counterproductive; their own emotions interfere with information gathering; the trustworthiness of the information that the patient provides is difficult to determine; or when the information points so strongly in a specific direction that trainees develop tunnel vision. Consultations are experienced as particularly challenging when more of these difficulties present themselves in one consultation, potentially leading to feelings of frustration and disempowerment. A situation that appeared challenging for all trainees is to gather information from talkative patients. Trainees explicitly mentioned that they lacked the necessary communication tools to effectively handle this situation. Effective communication with talkative patients, moreover, has received scant attention in the literature. Hence we decided to zoom in on this particularly challenging context within our case study of "information gathering".

More precisely, we explored communication strategies that experienced GPs considered effective to gather information from talkative patients (Chapter 3). We were interested in how they did this in an efficient yet respectful manner, since this was the trainees' main struggle. We found that GPs did not adopt a one-size-fits-all approach when communicating with talkative patients. Rather, they adapted their strategies to the underlying cause of patients' talkativeness. It was therefore considered essential to identify this cause as a first step. Some emotional causes such as nervousness could be immediately addressed by creating safety and comfort. In case of relational causes such as loneliness, patients often visit the doctor for emotional support. In these consultations, doctors may choose to provide that support at the expense of biomedical information gathering and decision-making. However, talkativeness may also be part of the patients' personal communication style, which is a cause that is more difficult to address. In most cases, it remains GPs' mission to develop an adequate diagnosis and treatment plan, so they will need specific communication strategies with which they can continuously contain the 
talkativeness. To handle these situations, GPs adopt a more directive stance, for instance by using a "closed-ended summary." To prevent damage to the relationship, GPs use strategies such as taking a stepped approach in which they try not to be overly directive, making the patient co-responsible for efficient time management, and ensuring that the patient does not lose face, e.g. by making use of empathic interrupting.

\section{Which communication strategies are useful for reassuring worried patients?}

Drawing on the experiences of patients (Chapter 4) and GPs (Chapter 5), we have identified an array of reassuring strategies. When combining the findings of both studies, a number of consultation goals appear to be important in achieving successful reassurance (Figure 7.1). In order for patients to accept the doctor's reassuring conclusions, they must have trust in the doctor-patient relationship and in the doctor's expertise. In case this trust is not sufficiently present, attention must go to creating this trust (Figure 7.1, grey arrows). Chapter 4 highlights that patients' concerns may stem from different types of worries and underlying cognitions. Therefore, it seems important that doctors explore patients' concerns and adapt their reassuring approach accordingly (Figure 7.1, blue arrow). For instance, if patients believe they are suffering from something serious, a first issue of concern must be to challenge this belief. Once this has been addressed, the patient will be more inclined to accept the actual harmless diagnosis or cause of the problem. If patients worry about the impact of the problem on their daily life, it becomes important to foster the belief that the problem will disappear or not worsen. In order to successfully influence patients' cognitions, information needs to be provided in a manner that is understandable for patients (Figure 7.1, blue circle). Depending on the situation, GPs took a host of actions to activate mechanisms that helped them achieve their goals. These actions could be either generic, that is, used in every consultation, such as "acknowledging the patient's concerns," or specific to the situation, as in the case of patients that the GP knew were prone to anxiety and who would be given an active role in the construction of reassuring information. 


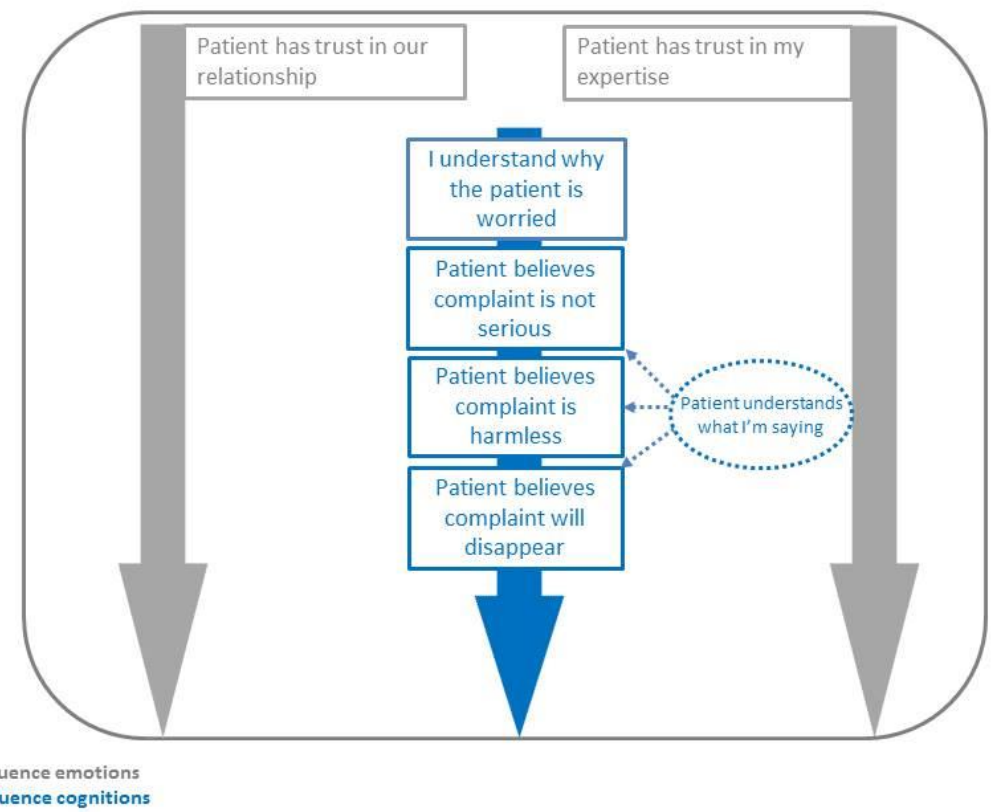

Figure $7.1 \mathrm{GPs}^{\prime}$ goals in a reassuring consultation

How can we help trainees to learn goal-directed, context-specific communication?

In order to identify didactic recommendations to support trainees' learning, we first explored the process by which trainees learn skilled communication in the workplace (Chapter 6). Informed by existing learning theories, i.e. Transformative Learning Theory (1) and Mimetic Learning (2), we explored the experiences of trainees and supervisors concerning this learning process. This has led to the development of a conceptual model (Figure 7.2). An impactful experience, usually involving interaction with patients and/or supervisors, challenges trainees' frames of reference. This motivates them to improve their communication behaviour. To develop a repertoire of communication strategies that aligns with their new frames of reference, trainees repeatedly go through a learning cycle during which they identify, try out, and evaluate communication strategies. By going through this continuous learning process, trainees learn to master a personal repertoire of strategies and to apply them adaptively according to the particular demands of the context. 


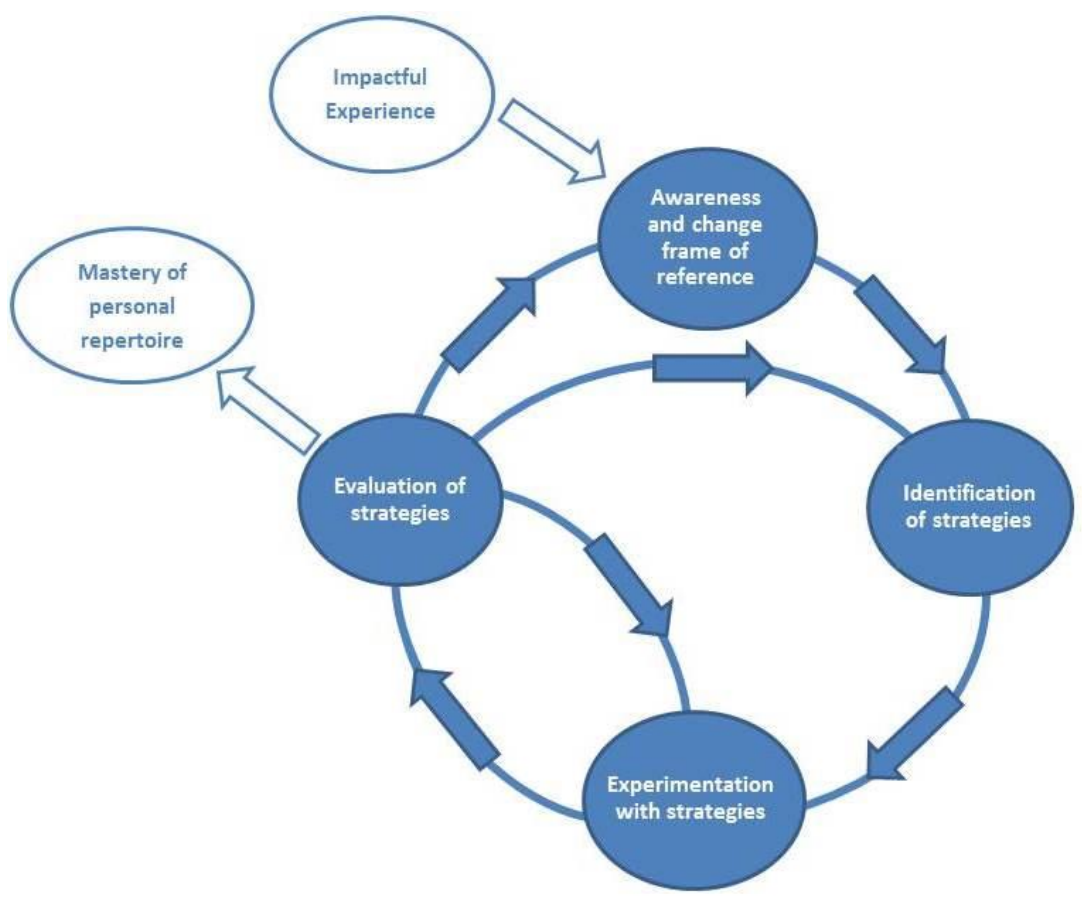

Figure 7.2 Trainees' communication learning process: six phases and three loops

Based on the experiences of supervisors and trainees, we explored how supervisors support their trainees' learning within this process, and integrated these findings into a didactic model (Chapter 6). GP supervisors have developed interventions for each phase of the learning cycle. These interventions include: confronting trainees with and reflecting on their behaviour and its underlying mechanisms; exploring and demonstrating helpful communication strategies; giving trainees concrete practice assignments; creating safety; exploring the effect of strategies; and facilitating repeated experimentation and reflection.

\section{DISCUSSION OF THE MAIN FINDINGS}

\section{What to train}

As described in the introduction of this dissertation, there is an ongoing debate about medical communication training: should we teach generic communication skills or skilled communication that takes into account the uniqueness of the consultation? (3) This dissertation contributes to this discussion by emphasising the relevance of the uniqueness of consultations, confirming that communication processes depend upon 
the goals that doctors and patients have $(4,5)$ and the specific context in which they interact (6-9). Our studies have demonstrated that even in our specific case study of "gathering information from talkative patients," doctors' communication depends on factors such as the cause of patients' talkativeness, which, in turn, influence doctors' specific consultations goals and underlying behavioural actions. We observed a similar process in our second case study of "reassuring patients." A variety of worries and cognitions underlie patients' concerns, and GPs pursue different sub-goals depending on how they interpret these concerns. With each sub-goal, there is a wide array of behavioural actions that can be applied. Various mechanisms appeared to mediate between all these specific behavioural actions and goals. This research has clarified in which manner context is relevant, while it has also demonstrated the challenge involved in integrating the complexity of practice into medical communication training. Overwhelming learners with every possible behavioural action given a certain context could easily lead to cognitive overload. It has already been found that lengthy and detailed behavioural guidelines are too difficult to memorize and apply in practice (10). From the studies in this dissertation that have explored communication practices (Chapters 2 to 4 ) we have learned that being a skilled communicator is not simply a matter of mastering each and every skill, but means being able to choose the right strategy in the right situation. Although goal-specific communication theory and training may provide learners with some guidance (11), they still need to be supported in making the right choices. We know that it is important that learners understand why and how a certain communication skill is effective (12). Promoting understanding of the working mechanisms behind communication actions may be key in supporting trainees in choosing strategies effectively.

\section{How to train}

Our research has identified several key elements for supporting trainees in becoming skilled communicators, i.e. in helping them to choose the most effective strategy in a certain situation. We have seen that skilled communication training demands a more holistic view that does not merely address behaviour (3). It has also been demonstrated that, in order for trainees to become skilled communicators, it is essential they go through a continuous learning cycle of repeated practice, refinement and evaluation of their communication strategies, and reflection upon their personal frames of reference. This finding coincides with one of the key messages of van den Eertwegh's recently published dissertation: “improving one's communication skills 
should be regarded as a form of lifelong personal development" (13). As has been emphasised earlier, there should be ample space for reflection on personal emotions, attitudes, and the effect of the applied communication strategies in this continuous learning process $(13,14)$. Although this reflection is a standard concept in many traditional learning models $(15,16)$, it seems the case that this is not always applied in educational communication practice. Little research has been devoted to the evaluation of the effect of communication strategies: how does this evaluation take place? Does it take place in the right manner? During the evaluation of a pilot training that was designed according to the principles of the identified learning process (Figure 7.2), trainees emphasised that the repeated practice and evaluation integrated in this training helped them to personalise new strategies. With regards to their usual communication training, they reported that although they often made a start in applying new strategies during their own consultations, opportunities to evaluate were usually limited: how does it make them feel? How does the patient respond? Does it change their initial viewpoint? Opportunities to rehearse and refine their strategies were usually also limited, since they generally had to move on to the next communication theme or focus on other aspects of their medical training. Hence, it seems that efforts should be made to prevent interruptions to this evaluation process in communication training. This requires longitudinal training that facilitates repeated practice and reflection at the institution and in the clinical workplace. Such a longitudinal skilled communication training also requires a different take on feedback and assessment. It has been shown that the use of behavioural checklists impedes learning $(10,17)$. In parallel with the shift in perspective from communication skills toward skilled communication in the communication literature, the feedback and assessment literature is transitioning from ratings/scores/grades to words/narratives (18-21). Skilled communication training calls for a feedback and assessment instrument that takes into account the context, facilitates the collection of rich, longitudinal information about trainees' learning process, and supports learning by providing meaningful, rich feedback.

As regards the identification of new communication behaviours, we have found that trainees highly value very concrete examples in the form of specific words or sentences that they can try out in practice. This need for specific wording is also confirmed by a recent study exploring communication learning processes (22). Obtaining such a specific wording gives trainees the necessary confidence to try out alternative behaviours. Hereby, trainees expressed a clear wish for authentic 
examples. Communication guidelines have been criticized for their limited involvement of the actual end users in their development (11). Although they can be useful, learners in our institution have also expressed the shortcomings of 'artificial' examples such as video recordings of simulated encounters. To ensure alignment of the provided examples with actual practice, it is important that they are based on real-life experiences of doctors and patients.

\section{METHODOLOGICAL CONSIDERATIONS}

\section{Qualitative design}

Since this research focused on theory development rather than on theory testing, we used qualitative research methods. In all the qualitative studies we conducted, we have sought to enhance the trustworthiness (23) of our findings by fulfilling the following criteria: 1 ) independent coding by researchers from different backgrounds, 2 ) iterative data collection and analysis, 3) debriefing of the findings to team members and/or participants, 4) data collection until saturation was achieved, and 5) triangulation of data and/or methods. A drawback to our qualitative design is that we cannot make any inferences about the actual effectiveness of the identified communication strategies (Chapters 3 and 5) and learning strategies (Chapter 6). Although our research has delivered us a thorough understanding of what experienced doctors do to achieve a certain communication goal or to support their trainees' learning, we do not know whether these strategies indeed have the desired effect on patient outcomes or trainees' learning outcomes. However, since we explored patients' and trainees' perspectives in Chapters 4 and 5 respectively, we do have some understanding of the effect of the identified strategies.

In all the studies performed, we used stimuli for reflection to render the communication and learning processes explicit: a real-life video-recorded consultation (Chapters 3 -5), an observed consultation (Chapter 2), a case/situation description (Chapter 3 and 6), or a communication training session (Chapter 6). In this manner, we have tried to remain close to what is actually happening in practice, thereby minimizing chances of incomplete, unreliable, or unfeasible answers. Nonetheless, there is always a risk of participants constructing answers using hindsight knowledge or post-hoc rationalizations. The data on communication and learning we obtained would have been more natural if processed without interference of the researcher, e.g. by performing discourse analysis and/or observations of consultations and learning moments without interviews. However, this approach would not have led to 
a complete and in-depth understanding of the underlying mechanisms involved in these processes.

\section{Setting}

We chose general practice as the setting for our research. By focusing on a specific setting as opposed to exploring different settings, we were able to obtain a deeper understanding of the communication and learning processes. Because the GP specialty training programme has a long history of communication training, the basic conditions for learning communication were met, enabling us to study learning processes more in depth. Moreover, we found the GP setting to provide a rich source of useful communication strategies. There may be limitations to the extent that the communication strategies identified may not be fully generalisable to other clinical settings. For example, in an urgent care context, there may be less opportunity to build long-term relationships, and doctors need to rely on different strategies. Additionally, we have explored the role of goals and context in two specific case studies (i.e., gathering information and reassuring patients). Similarly, this has allowed us to study communication processes in depth, yet we have to be careful in drawing general conclusions about communication processes. The question also remains to what extent the learning processes identified will be similar in other settings. We know, for instance, that there are large differences between GP residents and surgical residents in the type of communication training they receive $(17,22)$. In other clinical settings, there seems to be more room for improvement with regard to the basic conditions to develop communication skills (13), such as the presence of emotional and cognitive space and a safe learning environment. Even when all the basic learning conditions have been met, learning needs may differ across clinical contexts, e.g. due to differences in personalities, learning strategies, time constraints, type of patients/medical problems, et cetera $(24,25)$.

\section{Participants}

When identifying useful communication strategies, our starting point was to draw on the experiences of experienced GPs, and, whenever possible, on the experiences of their patients. The selection of GPs was likely biased in favour of GPs who took a specific interest in doctor-patient communication. However, since we specifically aimed to identify best practices, we consider this a strength rather than a weakness. The same holds for the learning strategies we identified on the basis of supervisor experiences: Given that our development of a didactic model to support 
communication is still in its infancy, we consider it a strength that the supervisors we selected most likely all take an interest in communication training. It should be noted, however, that the didactic strategies we identified demand an active role of the supervisor, which may make their implementation among less motivated supervisors a challenging task.

\section{LESSONS LEARNED: EDUCATIONAL IMPLICATIONS}

This dissertation has provided us with insights into what we should teach in communication training given specific goals and contexts and how trainees' learning can be supported. This begs the question: How will this knowledge help us solve the complex puzzle of how we should teach goal-directed, context-specific communication? What major lessons can we draw from these insights and what do they mean to educational practice? How can communication training be designed in such a manner that it helps learners to become skilled communicators?

\section{Lesson 1: Cognitive overload can be prevented by promoting insight into mechanisms}

To align training with doctor's actual communication behaviour, it seems logical to structure communication training around consultation goals. However, what to teach in such a goal-directed training remains difficult to define given the complexity and changing communication context of the clinical setting. How can we do justice to this complexity without overwhelming our students with cognitive overload? Our studies have pointed out the relevance of mechanisms in communication processes. We therefore believe that a promising alternative to training behavioural skills or actions is to enhance learners' insight into the underlying mechanisms that explain why these actions are effective (26). For example, by "summarising the patient's story" (behavioural action) one can "create trust" (goal) because "it makes the patient feel heard and understood" (mechanism). Understanding of these mechanisms likely provides learners with insight into what works, for which patients, and why. It thereby helps them to flexibly apply the strategies in their communication repertoire assembled during the respective stages of medical training. Information about effective communication can be provided to trainees in the form of communication strategies, comprising three levels: 1) the goal that you want to achieve, 2) the mechanisms that help achieve this goal, and 3) the behavioural actions that facilitate these mechanisms. We have already piloted a training on a specific communication 
topic (effective reassurance) during which strategies were provided in this manner. Trainees were given a visual scheme (see Figure 7.2) that represented the first level of goals. Via a computer program, they could click on the goals that were relevant to them, after which the corresponding mechanisms appeared. When they clicked on a relevant mechanism, concrete communicative actions would appear. Trainees confirmed that being able to go through these three levels and receiving a schematic overview of goals helped them to identify areas of improvement, i.e., the goals they still found difficult to achieve, to select appropriate actions to achieve these goals, and to understand how these actions work. Because trainees were able to focus on their personal learning needs and select whatever strategy they deemed relevant, they did not experience any cognitive overload. More insight is needed as to whether this approach could be helpful and feasible when expanded to the entire communication curriculum.

\section{Lesson 2: Trainees need examples that are concrete and authentic}

Trainees need examples that are authentic to ensure feasibility and credibility, which motivates to them to experiment with new communication strategies. This authenticity can be ensured by deriving strategies from real-life practice, for instance from interviews with doctors and patients referring to real-life videotaped consultations, as in the studies described in Chapters 3 to 5 of this dissertation. One could use video recordings of consultations, together with quotations from the interviews, to illustrate these strategies. Such quotations provide trainees with more background information on a certain strategy, such as how and why it was used by doctors and how it was experienced by patients. The video recording offers trainees a clear, authentic case of how the strategy could be employed, enabling them to try out and refine the strategy during their own patient encounters. In doing so, it is important that adequate informed consent procedures be in place and that secure access to and safe storage of the video footage be ensured to warrant patient confidentiality.

\section{Lesson 3: We must encourage trainees to repeatedly go through a learning cycle of experimentation and evaluation}

Medical communication training should afford ample opportunity for repeated practice and reflection and offer support both at the institution and in the workplace. We know that longitudinal training programmes can make such a continuous cycle 
possible. In addition, we now know that trainees must be given the opportunity to devote multiple reflection moments to a certain communication theme/goal. This allows in-depth evaluation of the effect of strategies and personal frames of reference and enables trainees to experiment with strategies in between these moments. In the workplace, one can encourage trainees to go through this continuous learning cycle by giving them concrete instructions to try out strategies in practice and to evaluate them with their supervisor.

\section{Lesson 4: The clinical supervisor is able to support trainees' entire learning process}

We have seen that clinical supervisors take specific action to facilitate each phase of trainees' learning process. Although the important role of the clinical supervisor as a coach and role model is generally recognized, supervisors' shortcomings have often been highlighted as well (27-32). Involving and motivating supervisors is a well-known challenge. A helpful approach may be to structure communication training for supervisors around consultation goals that are also relevant for experienced doctors. Like trainees in communication training, supervisors may enhance their insight into the mechanisms of effective communication behaviours, thereby creating a better fit between training and how they themselves communicate in practice. Finally, it is important that the identified learning cycle be incorporated into supervisors' didactic training and that they be taught how to support their trainees' learning process.

\section{RECCOMENDATIONS FOR FUTURE RESEARCH}

\section{Validation, development, and evaluation}

Our research has led to the development of a conceptual model of how GP trainees learn skilled communication in the workplace. Given that this model is contextual in nature and therefore aligned with actual practice, we expect it to be highly instrumental in the provision of current medical communication training and in supporting the transfer of learning. A precondition for the formulation of didactic recommendations to support trainees' learning is that we understand the learning processes of trainees. However, the evidence base of this model consists of only one interview study (Chapter 6), although largely confirmed by the learning process developed by van den Eertwegh et al. (22). Hence, before it is implemented in educational practice, the model must first be further explored, refined, and validated. This could be done by scrutinizing the learning process of trainees in real-life practice, 
followed by an exploration and evaluation of how the model can be used for skilled communication training. Such research would best be conducted using a design-based research (DBR) methodology (33). Characterized by a continuous cycle of design, evaluation, and redesign, and involving close interaction between practitioners and researchers, DBR is an appropriate method for studying the nature of learning in authentic environments with a view to refining theories and enhancing educational practice. Such a DBR study could be designed as follows:

First, one could conduct an observational study of trainees' learning process throughout GP specialty training, triangulating various qualitative research methods, such as stimulated recall interviews with trainees using video-recorded consultations as a stimulus, audio diaries of trainees, and observations of communication training sessions at the institution. In this manner, one can collect authentic data on trainees' learning processes with little interference from the researcher, while also obtaining more in-depth reflections. Second, one may explore how trainees can be optimally supported in becoming skilled communicators, given the identified, validated learning process. Within DBR, participatory action research would be of great value, which is typically conducted with motivated, relevant stakeholders with certain ideas on the topic of interest, in this case communication training, who in a group discuss and elaborate these ideas, experiment with them in educational practice, and meet again to discuss their experiences (34). Multiple groups of GP trainees, supervisors, and trainers could be set up, who meet to reflect upon and experiment with how trainees can effectively be supported in becoming skilled communicators. A third step may be to develop and evaluate curriculum components, taking into account the learning process and supporting factors identified, to support GP trainees in becoming skilled communicators. The ideas that emerge from the participatory action research could be translated into concrete training materials that may be piloted in the regular curriculum. Qualitative evaluations may be complemented with some fundamental experiments, e.g. to test effect of the use of schemes and mechanisms on learners' cognitive load.

\section{Effectiveness}

It is desirable to provide evidence-based communication strategies to learners during communication training. Since we have seen that consultation goals tend to be accompanied by a very large number of possible communication strategies, it does not seem feasible to measure effectiveness of each individual strategy in a 
quantitative manner. As a corollary, we must seek new ways to study the effectiveness of communication strategies. A possible method may be 'integrative qualitative communication analysis' (35), during which various sources of data are combined (e.g. patient perspective, doctor perspective and researcher observation) to perform a within-case analysis.

\section{Transferability}

Given the previously described differences between clinical contexts in terms of dynamics and type of patients/problems, more research is needed to explore whether our findings are generalisable to clinical settings other than family practice, such as internal medicine and surgery. Another important area of research is communication training in undergraduate medical school. During their pre-clinical years, medical students receive continuous communication training, while such type of support is largely absent during their clinical rotations. This is odd, as this is the period that they have to transfer what they have learned to practice. More insight is needed into how the communication curriculum of medical schools can be optimized to enhance transfer to clinical practice. Hereby, we also need to gain more understanding of how to realize a better transition from undergraduate to postgraduate curricula. Our research has led to theoretical knowledge on how competencies involving complex behaviours are learned. In addition to medical communication, it would be valuable to explore whether the theoretical model we developed may also be applicable to other clinical competencies that involve complex behaviours to be learned in the working environment, such as professionalism, shared decision-making and inter-professional collaboration. 


\section{REFERENCES}

1. Mezirow J. Transformative learning: Theory to practice. New dir adult contin educ. 1997;74:5-12.

2. Billet S. Mimetic learning at work: Learning in the circumstances of practice. Dordrecht: Springer; 2014.

3. Salmon P, Young B. Creativity in clinical communication: from communication skills to skilled communication. Med Educ. 2011;45:217-26.

4. Veldhuijzen W, Urlings J, Portegijs P, Weijden TVD, Muijtjens A, Elwyn G, et al. The goal driven nature of doctor-patient communication in primary care encounters. Challenging the patient-centred paradigm Designing feasible guidelines for doctor-patient communication. Maastricht: Universitaire pers Maastricht; 2011. p. 133-52.

5. Veldhuijzen W, Mogendorff K, Ram P, van der Weijden T, Elwyn G, van der Vleuten C. How doctors move from generic goals to specific communicative behavior in real practice consultations. Patient Educ Couns. 2013;90:170-6.

6. Essers G, van Dulmen S, van Weel C, van der Vleuten C, Kramer A. Identifying context factors explaining physician's low performance in communication assessment: an explorative study in general practice. BMC Fam Prac. 2011;12:138.

7. Essers G, Kramer A, Andriesse B, van Weel C, van der Vleuten C, van Dulmen S. Context factors in general practitioner-patient encounters and their impact on assessing communication skills--an exploratory study. BMC Fam Prac. 2013;14:65.

8. Feldman-Stewart D, Brundage MD, Tishelman C. A conceptual framework for patient-professional communication: an application to the cancer context. Psychooncology. 2005;14:801-9

9. Bensing J. Communication in context: new directions in communication research. Patient Educ Couns. 2003;50:27-32.

10. Veldhuijzen W, Ram PM, van der Weijden T, van der Vleuten CPM. Communication guidelines as a learning tool: an exploration of user preferences in general practice. Patient Educ Couns. 2013;90:213-9.

11. Veldhuijzen W, Ram PM, van der Weijden T, Niemantsverdriet S, van der Vleuten CP. Characteristics of communication guidelines that facilitate or impede guideline use: a focus group study. BMC Fam Pract. 2007;8:31.

12. Silverman J, Kurtz S, Draper J. Skills for communicating with patients. Second ed. Oxford: Radcliffe Publishing; 2005. 58-105 p.

13. Eertwegh $\mathrm{Vvd}$. Unravelling postgraduate communication learning: from transfer to transformative learning. Maastricht: Universitaire Pers Maastricht 2015.

14. Bombeke K, Symons L, Vermeire E, Debaene L, Schol S, De Winter B, et al. Patient-centredness from education to practice: the 'lived' impact of communication skills training. Med Teach 2012;34(5):e338-48.

15. Kolb DA, Fry, R. E. Toward an applied theory of experiential learning: MIT Alfred P. Sloan School of Management; 1974.

16. Korthagen FAJ, Kessels, J., Koster, B., Lagerwerf, B., Wubbels, T. Linking practice and theory: The pedagogy of realistic teacher education. Mahwah, NJ: Lawrence Erlbaum Associates; 2001.

17. van den Eertwegh V, van Dalen J, van Dulmen S, van der Vleuten C, Scherpbier A. Residents' perceived barriers to communication skills learning: Comparing two medical working contexts in postgraduate training. Patient Educ Couns. 2014.

18. DeWitt D, Carline J, Paauw D, Pangaro L. Pilot study of a 'RIME'-based tool for giving feedback in a multi-specialty longitudinal clerkship. Med Educ. 2008;42(12):1205-9.

19. van der Vleuten CP, Schuwirth LW, Driessen EW, Dijkstra J, Tigelaar D, Baartman LK, et al. A model for programmatic assessment fit for purpose. Med Teach. 2012;34(3):205-14.

20. Schuwirth LW, Van der Vleuten CP. Programmatic assessment: From assessment of learning to assessment for learning. Med Teach. 2011;33(6):478-85.

21. Govaerts $M$, van der Vleuten $C P$. Validity in work-based assessment: expanding our horizons. Med Educ. 2013;47(12):1164-74. 
22. van den Eertwegh V, van der Vleuten C, Stalmeijer R, van Dalen J, Scherpbier A, van Dulmen S. Exploring residents' communication learning process in the workplace: a five-phase model. PLoS ONE. 2015;10(5):e0125958.

23. Frambach JM, van der Vleuten $\mathrm{CP}$, Durning SJ. AM last page. Quality criteria in qualitative and quantitative research. Acad Med. 2013;88(4):552.

24. Markert RJ, Rodenhauser P, El-Baghdadi MM, Juskaite K, Hillel AT, Maron BA. Personality as a prognostic factor for specialty choice: a prospective study of 4 medical school classes. Medscape $J$ Med. 2008;10(2):49.

25. Bitran M, Zuniga D, Lafuente M, Viviani $P$, Mena B. [Influence of personality and learning styles in the choice of medical specialty]. Rev Med Chil. 2005;133(10):1191-9.

26. Wong G, Greenhalgh T, Westhorp G, Pawson R. Realist methods in medical education research: what are they and what can they contribute? Med Educ. 2012;46(1):89-96.

27. Haidet P, Kelly PA, Chou C. Characterizing the patient-centeredness of hidden curricula in medical schools: development and validation of a new measure. Acad Med. 2005;80:44-50.

28. Haidet $P$, Dains JE, Paterniti Da, Hechtel L, Chang T, Tseng E, et al. Medical student attitudes toward the doctor-patient relationship. Med Educ. 2002;36:568-74.

29. Kramer AWM, Düsman H, Tan LHC, Jansen JJM, Grol RPTM, van der Vleuten CPM. Acquisition of communication skills in postgraduate training for general practice. Med Educ. 2004;38:158-67.

30. Côté $\mathrm{L}$, Leclère $\mathrm{H}$. How clinical teachers perceive the doctor-patient relationship and themselves as role models. Acad Med. 2000;75:1117-24.

31. Egnew TR, Wilson HJ. Role modeling the doctor-patient relationship in the clinical curriculum. Fam Med. 2011;43(2):99-105.

32. Vernooij-Dassen MJ, Ram PM, Brenninkmeijer WJ, Franssen LJ, Bottema BJ, van der Vleuten CP, et al. Quality assessment in general practice trainers. Med Educ. 2000;34(12):1001-6.

33. Dolmans $\mathrm{DH}$, Tigelaar D. Building bridges between theory and practice in medical education using a design-based research approach: AMEE Guide No. 60. Med Teach. 2012;34(1):1-10.

34. Heron J, Reason P. The practice of co-operative enquiry: research with rather on people In: Reason $\mathrm{P}$, Bradbury $\mathrm{H}$, editors. Handbook of Action Research: Participative Inquiry and Practice. London: Sage; 2001. p. 179-88.

35. Salmon P, Mendick N, Young B. Integrative qualitative communication analysis of consultation and patient and practitioner perspectives: towards a theory of authentic caring in clinical relationships. Patient Educ Couns. 2011;82(3):448-54. 
SUMMARY 



\section{Chapter 1}

The first chapter introduces the topic of this dissertation: goal-direct and contextspecific doctor-patient communication. We first elaborate on the importance of effective doctor-patient communication. We explain that despite the efforts put in training future doctors in communication skills, various studies have revealed that the skills learned during training are insufficiently transferred to daily clinical practice. This has sparked a debate on whether training and assessing generic skills is the right approach to take in teaching medical communication, inspiring researchers to explore the nature of doctor-patient communication in actual practice. In the clinical workplace, doctor-patient communication has been shown to be a complex process that depends highly on the uniqueness of the consultation, that is, on the goals that doctors and patients try to pursue and the specific contextual factors that play a role. In view of this knowledge, it is recommended that goal-directedness and contextspecificity be incorporated into medical communication training. Instead of focusing on 'communication skills', we should train learners in 'skilled communication'. This is not an easy undertaking given the complexity involved. The purpose of this dissertation, therefore, is to explore how goal-directed and context-specific doctorpatient communication can be put into clinical and educational practice. To this end, we must first understand what constitutes effective communication given a certain goal and context, so that we know what we should train. For this, we have selected two consultation goals that are important for doctors as case studies: 'gathering information' and 'reassuring patients'. Subsequently, we need to understand how trainees learn context-specific and goal-directed communication, so that we know how we should train. Consistent with these what and how objectives, we try to find an answer to the following research questions:

1) Which communication strategies are useful for gathering information from patients?

2) Which communication strategies are useful for reassuring worried patients?

3) How can we help trainees to learn goal-directed, context-specific communication?

The remaining part of the introduction explains the rationale behind the chosen research setting, i.e. general practice (GP) and the GP vocational training, the theoretical orientation of this dissertation and the selected methodology. 


\section{Chapter 2}

As our first case study, we have selected the consultation goal 'information gathering'. Gathering information during patient encounters is essential for adequate diagnostics and treatment and for the delivery of patient-centred care. To determine which type of information-gathering strategies GP trainees may benefit from, we first identified information-gathering situations that are experienced as particularly difficult. In a phenomenological study, we observed a morning clinic of $15 \mathrm{GP}$ trainees. To explore trainees' experiences with information-gathering, we held brief interviews after every consultation and a lengthier interview directly after the morning clinic. The resulting data were analysed using template analysis. Trainees experience information gathering as difficult when 1) it conflicts with other goals such as relationship-building and time management; 2) the communication skills they learned are ineffective; 3 ) trainees' own emotions hamper open communication; 4) the trustworthiness of the information that the patient provides is difficult to determine; 5) trainees develop tunnel vision. Consultations during which more of these difficulties present themselves are experienced as particularly challenging, potentially leading to feelings of frustration and disempowerment. One such situation that appeared challenging for all trainees is to gather information from talkative patients. Trainees explicitly mentioned that they lacked the necessary communication tools to effectively handle this situation. We concluded that information-gathering is difficult for GP trainees. Current generic communication skills training does not seem to support trainees sufficiently to handle effectively the challenges they encounter during consultations. For medical communication training this means that trainees need to be supported in handling their goal-conflicts and feelings that hamper information-gathering, while also providing them with communication strategies adapted to handling specific challenging situations, such as effectively gathering information from talkative patients.

\section{Chapter 3}

As we have seen in the previous chapter, gathering information from talkative patients presents a major challenge to trainees. Effective communication with talkative patients, moreover, has received scant attention in the literature. Hence, we decided to focus on this particularly challenging context within our case study of 'information gathering'. Specifically, this study explored communication strategies and their underlying mechanisms that GPs consider effective when gathering information 
from talkative patients. We conducted a qualitative study with experienced GPs. We held individual stimulated-recall interviews with 6 GPs using their videotaped consultations as a stimulus. These interviews were triangulated with data from three focus-group discussions. We performed a thematic network analysis during an iterative process of data collection and analysis. To deal with talkative patients during consultations, GPs first try to pinpoint the cause of patients' talkativeness before deciding on the approach to take. Moreover, they resort to the familiar communication strategies, however, in doing so take a more directive attitude. To prevent such attitude from damaging the relationship, GPs take a stepped approach in which they try not to be overly directive, make the patient co-responsible for efficient time management, and ensure that the patient doesn't lose face, e.g. by making use of empathic interrupting. We concluded that, in the absence of evidence, the description of GPs' communication strategies can guide doctors and learners in gathering information from talkative patients in an efficient, yet empathic and respectful manner. When developing best practices, heed should be paid to the causes of patients' talkativeness and the tension between taking a directive approach and building a doctor-patient relationship.

\section{Chapter 4}

As our second case study, we explored the goal 'reassuring patients'. Many patients who consult their GP are worried about their health, but there is still little empirical data on strategies for effective reassurance. To gain a better understanding of mechanisms for effective patient reassurance, we explored cognitions underlying patients' worries, cognitions underlying reassurance and factors supporting patients' reassuring cognitions. In a qualitative study, we conducted stimulated recall interviews with 21 patients of 12 different GPs shortly after their consultation. We selected consultations in which the GPs aimed to reassure worried patients and used their videotaped consultation as a stimulus for the interview. The interviews were analysed with thematic coding and by writing interpretive summaries. Patients expressed four different core cognitions underlying their concerns: 'I have a serious illness', 'my health problem will have adverse physical effects', 'my treatment will have adverse effects' and 'my health problem will negatively impact my life'. Patients mentioned a range of person-specific and context-specific cognitions as reasons for these core cognitions. Patients described five core reassuring cognitions: 'I trust my doctor's expertise', 'I have a trusting and supporting relationship with my doctor', 'I 
do not have a serious disease', 'my health problem is harmless' and 'my health problem will disappear'. Factors expressed as reasons for these reassuring cognitions were GPs' actions during the consultation as well as patients' pre-existing cognitions about their GP, the doctor-patient relationship and previous events. Patients' worrying cognitions were counterbalanced by specific reassuring cognitions, i.e. worrying and reassuring cognitions seemed to be interrelated. We concluded that patients described a wide range of worrying cognitions, some of which were not expressed during the consultation. Gaining a thorough understanding of the specific cognitions and tailoring reassuring strategies to them should be an effective way of achieving reassurance. The identified reassuring cognitions can guide doctors in applying these strategies in their daily practice.

\section{Chapter 5}

While chapter 4 described the patients' experiences with regards to our case study 'reassurance', this study explored reassuring strategies that are considered useful by experienced GPs. We again performed a qualitative study with stimulated recall interviews. We first re-analysed an existing dataset of fifteen stimulated recall interviews in which GPs elaborated on their communication with patients in two videotaped consultations. Additionally we held stimulated recall interviews with twelve GPs about two consultations selected for a strong focus on reassurance. To reassure patients, GPs pursued multiple goals: 1 . influencing patients' emotions by promoting trust, safety and comfort, which is considered to be reassuring in itself and supportive of patients' acceptance of reassuring information and 2. influencing patients' cognitions by challenging patients' belief that their symptoms are indicative of serious disease, often followed by promoting patients' belief that their symptoms are benign. GPs described several actions to activate mechanisms to achieve these goals. We concluded that GPs described a wealth of reassuring strategies, which make a valuable contribution to the current literature on doctor-patient communication. This detailed description may provide other doctors and learners with new tools. Specifically, we concluded that the mechanisms described may help doctors in choosing the most appropriate reassuring strategy in the situation at hand and can inform future studies that aim to explore the effectiveness of reassuring strategies. 


\section{Chapter 6}

While the first four studies focused on 'what to train' in goal-directed and contextspecific communication training, our final study aimed to obtain insight into 'how' to train. To inform the development of didactic recommendations, this qualitative study described in this chapter explored the experiences of GP trainees and GP supervisors regarding how trainees learn communication in the workplace and how clinical supervisors support trainees' learning. We explored these experiences by triangulating general focus groups, focus groups using training sessions as a stimulus and individual interviews. Thematic network analysis was used during an iterative process of data collection and analysis. A learning cycle with six consecutive communication learning phases could be identified: impactful experience; change in frame of reference; identifying communication strategies; trying out strategies; evaluating strategies and mastery of a personalised communication repertoire. Supervisors' actions that support these phases include: creating challenges; confronting with and reflecting on behaviour and its underlying mechanisms; exploring and demonstrating communication strategies; giving concrete practice assignments; creating safety; exploring the effect of strategies; facilitating repeated practice and reflection. We concluded that to nurture skilled communication, it seems important that communication training fosters the development of a personalized communication repertoire from which the learners are able to apply strategies that fit the context and their personal style. To develop this, it is likely that learners need concrete examples, opportunities for repeated practise and reflection on personal frames of reference and the effect of strategies, as well as space for authenticity and flexibility. The clinical supervisor can facilitate these essential conditions to support his/her trainee in becoming a skilled communicator.

\section{Chapter 7}

In this final chapter, the main findings of each research question are described and discussed in the light of existing literature. This is followed by a discussion of the methodological considerations of our research, which relate to the chosen study design, setting and participants in relation to the generalisability of our findings. Then, the main lessons drawn from our research are outlined. These lessons include: 1) Cognitive overload can be prevented by promoting insight into underlying mechanisms of communication strategies, 2) Trainees need concrete, authentic examples, 3) We must encourage trainees to repeatedly go through a learning cycle of 
experimentation and evaluation and 4) The clinical supervisor is able to support trainees' entire communication learning process. We elaborate on each of these lessons in the light of their implications for medical communication training. We end the discussion with an overview of our recommendations for future research, which include: validating our findings, developing and evaluating of curriculum components for skilled communication training, developing evidence for effective communication strategies and exploring the transferability of our findings to other clinical settings and medical competencies. 
SAMENVATTING 



\section{Hoofdstuk 1}

In het eerste hoofdstuk wordt het onderwerp van dit proefschrift geïntroduceerd: doelgerichte en context-specifieke arts-patiënt communicatie. Eerst wordt het belang van effectieve arts-patiënt communicatie toegelicht. Ondanks het feit dat er veel moeite wordt gestoken in het trainen van toekomstige artsen in communicatieve vaardigheden, laten studies zien dat de geleerde vaardigheden in de dagelijkse praktijk onvoldoende worden toegepast. Deze bevindingen hebben een discussie ontketend rondom de vraag of het trainen en beoordelen van generieke vaardigheden wel de juiste benadering is. Ook heeft het onderzoekers aangezet om de aard van arts-patiënt communicatie in de dagelijkse praktijk onder de loep te nemen. Communicatie is een complex proces gebleken dat bepaald wordt door de doelen die artsen en patiënten nastreven en verschillende contextfactoren. Het wordt aanbevolen om deze doelgerichtheid en contextspecificiteit te integreren in communicatie training. In plaats van toekomstige artsen te trainen in generieke 'communication skills' ('communicatieve vaardigheden'), lijkt het trainen in 'skilled communication' ('vaardige communicatie') beter aan te sluiten bij de praktijk. Het doel van dit proefschrift is exploreren hoe doelgerichte en context-specifieke artspatiënt communicatie in de onderwijskundige en klinische praktijk gebracht kan worden. Hiervoor moeten we eerst begrijpen wat effectieve communicatie is gezien het doel /de context, zodat we begrijpen wat te trainen. We hebben hiervoor twee consultdoelen die belangrijk zijn voor artsen als 'case studies' geselecteerd: 'het verzamelen van informatie' en 'het geruststellen van de patiënt'. Vervolgens proberen we te begrijpen hoe context-specifieke en doelgerichte communicatie geleerd wordt, zodat we beter begrijpen hoe te trainen. In lijn met deze wat en hoe doelstellingen, tracht dit onderzoek een antwoord te vinden op de volgende drie onderzoeksvragen:

1. Welke communicatiestrategieën zijn helpend om informatie te verzamelen van patiënten?

2. Welke communicatiestrategieën zijn helpend om ongeruste patiënten gerust te stellen?

3. Hoe kunnen we artsen in opleiding helpen bij het leren van doelgerichte en context-specifieke communicatie?

In het resterende gedeelte van dit introducerende hoofdstuk wordt een onderbouwing gegeven voor de gekozen onderzoeksetting, (huisartsenpraktijk en opleiding), theoretische oriëntatie en methodologie van dit onderzoek. 


\section{Hoofdstuk 2}

Als eerste case study hebben we gekozen voor het consultdoel informatie verzamelen'. Het verzamelen van informatie tijdens consulten is essentieel voor adequate diagnostiek en beleid voor het leveren van patiëntgerichte zorg. Om te bepalen welke strategieën helpend zouden kunnen zijn voor AIOS, hebben we eerst situaties geïdentificeerd die door AIOS als lastig worden ervaren tijdens de informatieverzameling. In een fenomenologisch onderzoek hebben we van 15 AIOS een ochtendspreekuur geobserveerd en ze na ieder consult kort bevraagd over hoe de informatieverzameling verliep. $\mathrm{Na}$ afloop van het spreekuur werden de AIOS uitgebreider over deze situaties geïnterviewd. De data zijn geanalyseerd door middel van template analysis. AIOS ervaren problemen in de informatieverzameling indien: 1) het conflicteert met andere doelen zoals het opbouwen van een arts-patiënt relatie en tijdmanagement, 2) de communicatievaardigheden die ze geleerd hebben ineffectief zijn, 3) hun eigen emoties open communicatie belemmeren, 4) de betrouwbaarheid van de gegeven informatie moeilijk te bepalen is en 5) ze last hebben van tunnel visie. Consulten waarin meerdere van deze moeilijkheden zich voordeden werden als bijzonder lastig ervaren, soms leidend tot gevoelens van frustratie en onmacht. Een specifieke situatie die als zeer lastig werd ervaren door alle AIOS is het verzamelen van informatie van breedsprakige patiënten. AIOS benoemden expliciet dat ze in deze situatie niet beschikken over de juiste vaardigheden. We concludeerden dat huidige generieke communicatievaardigheden AIOS niet voldoende lijken te ondersteunen om effectief om te kunnen gaan met de uitdagingen die ze tegenkomen tijdens consulten. Voor communicatietraining betekent dit dat AIOS ondersteund moeten worden in het hanteren van doelconflicten en emoties die effectieve informatieverzameling belemmeren. Daarnaast moeten er strategieën aangereikt worden die zijn afgestemd op specifieke uitdagende situaties, zoals het communiceren met breedsprakige patiënten.

\section{Hoofdstuk 3}

Zoals bleek uit het voorgaande hoofdstuk is het verzamelen van informatie bij breedsprakige patiënten een grote uitdaging voor AIOS. Echter, in de literatuur wordt tot op heden weinig aandacht besteed aan hoe effectief te communiceren met breedsprakige patiënten. Om deze redenen besloten we om deze specifieke uitdagende context binnen onze case study 'informatie verzamelen' nader te exploreren. Door middel van stimulated recall interviews met 6 ervaren huisartsen 
hebben we geïnventariseerd welke communicatiestrategieën zij effectief vinden om informatie te verzamelen van breedsprakige patiënten. Hierbij werd de opname van een consult gebruikt als stimulus. Deze data zijn getrianguleerd met drie focusgroep discussies met huisartsen en geanalyseerd d.m.v. thematische netwerk analyse. Om met breedsprakigheid om te gaan, proberen huisartsen allereerst de oorzaak van de breedsprakigheid te achterhalen om vervolgens een passende aanpak te kunnen kiezen. Ze gebruiken veelal gebruikelijke communicatiestrategieën, maar hanteren hierbij een directievere communicatiestijl. Om te voorkomen dat deze benadering de relatie schaadt, proberen artsen niet meer directief te zijn dan nodig, verantwoordelijkheid voor timemanagement te delen met de patiënt en ervoor te zorgen dat de patiënt geen gezichtsverlies lijdt, bijvoorbeeld door middel van empathisch onderbreken. We concludeerden dat bij gebrek aan empirisch bewijs, de bij huisartsen geïdentificeerde communicatiestrategieën andere (toekomstige) artsen kan helpen om informatie van breedsprakige patiënten op een efficiënte maar tevens respectvolle wijze te verzamelen. Bij de ontwikkeling van 'best practices' dient aandacht besteed te worden aan de oorzaak van de breedsprakigheid en het spanningsveld tussen een directieve benadering en het opbouwen van de arts-patiënt relatie.

\section{Hoofdstuk 4}

Onze tweede case study was het consultdoel 'geruststellen'. Veel patiënten die hun huisarts bezoeken zijn ongerust, maar er is weinig empirisch bewijs rondom effectieve geruststellingsstrategieën. Om de mechanismes van effectieve geruststelling van patiënten beter te kunnen begrijpen, hebben we bij patiënten verontrustende cognities en geruststellende cognities geëxploreerd, evenals factoren die geruststellende cognities ondersteunen. In een kwalitatieve studie hebben we 'stimulated recall interviews' uitgevoerd met 21 patiënten van 12 verschillende huisartsen. We hebben consulten geselecteerd waarin de patiënt ongerust was en de huisarts beoogde de patiënt gerust te stellen. De video-opname van het consult werd gebruikt als stimulus voor het interview. De interviews werden geanalyseerd door middel van thematische analyse en het schrijven van interpretatieve samenvattingen. Patiënten uitten vier verschillende kerncognities die ten grondslag lagen aan hun ongerustheid: 'Ik ben bang dat ik iets ernstigs heb', 'mijn klacht zal ernstige lichamelijke gevolgen hebben', 'mijn behandeling zal ernstige gevolgen hebben', en 'mijn klacht zal een negatieve impact hebben op mijn leven'. Patiënten noemden 
verschillende persoonsgebonden en contextgebonden factoren die deze gedachtes veroorzaakten. Patiënten beschreven vijf geruststellende kerncognities: 'Ik heb vertrouwen in de expertise van mijn arts', 'ik heb een vertrouwensrelatie met mijn arts', 'ik heb geen ernstige aandoening', 'mijn klacht is onschuldig van aard' en 'mijn klacht zal weer overgaan'. Factoren die benoemd werden als redenen voor deze geruststellende cognities bevatten de handelingen/communicatie van de arts tijdens het consult, evenals reeds bestaande gedachtes over de arts, de arts-patiënt relatie en voorgaande gebeurtenissen. Verontrustende cognities werden weerlegd door specifieke geruststellende cognities, ofwel verontrustende en geruststellende cognities leken met elkaar samen te hangen. We concludeerden dat patiënten verschillende verontrustende cognities hebben, waarvan sommigen niet geuit worden tijdens het consult. Een goed begrip verkrijgen van de specifieke cognities van de patiënt, om vervolgens geruststellende strategieën hierop af te stemmen zou een effectieve manier moeten zijn om geruststelling te bereiken. De geïdentificeerde geruststellende cognities kunnen als leidraad dienen voor andere artsen om deze strategieën in hun eigen praktijk toe te passen.

\section{Hoofdstuk 5}

Terwijl hoofdstuk 4 het patiëntperspectief weergeeft binnen onze 'case study' 'geruststellen', beschrijft hoofdstuk 5 geruststellingstrategieën die als effectief ervaren worden door ervaren huisartsen. Wederom betrof dit een kwalitatieve studie met 'stimulated recall interviews' waarin opnames van twee van hun eigen consulten als stimulus werden gebruikt. Allereerst hebben we een bestaande dataset van 15 interviews met huisartsen over de communicatie met hun patiënten geheranalyseerd. Vervolgens hebben we 12 nieuwe huisartsen geïnterviewd over consulten waarin geruststellen een expliciet doel was. Huisartsen streven meerdere doelen na om hun patiënten gerust te stellen: 1 ) het beïnvloeden van de emoties van de patiënt door het creëren van vertrouwen, veiligheid en comfort, wat werd beschouwd als geruststellend op zichzelf en ondersteunend aan het accepteren van geruststellende informatie en 2 ) het beïnvloeden van de cognities van de patiënt door de gedachte dat de klacht duidt op iets ernstigs weg te nemen, vaak gevolgd door de gedachte dat de klacht onschuldig is te versterken. Huisartsen beschreven meerdere acties die via bepaalde mechanismes leiden tot deze doelen. De conclusie van deze studie was dat huisartsen een breed scala aan geruststellende strategieën gebruiken die een waardevolle toevoeging zijn aan de huidige communicatieliteratuur. Onze 
gedetailleerde beschrijving zou andere artsen nieuwe tools kunnen aanreiken. De beschreven mechanismes kunnen helpend zijn bij het kiezen van de juiste strategie op het juiste moment en kan informatief zijn voor toekomstige studies naar de effectiviteit van de geïdentificeerde strategieën.

\section{Hoofdstuk 6}

Terwijl de eerste vier studies zich richtten op de vraag 'wat' te trainen in doelgerichte en context-specifieke communicatietraining, beoogden we met onze laatste studie inzicht te krijgen in 'hoe' te trainen. Ten behoeve van de ontwikkeling van didactische aanbevelingen voor communicatietraining, beschrijft deze kwalitatieve studie de ervaringen van AIOS en opleiders met betrekking tot hoe AIOS communicatie leren en hoe opleiders hun AIOS ondersteunen bij dit leerproces. Deze ervaringen zijn geëxploreerd door het trianguleren van focusgroepen, discussies tijdens trainingsbijeenkomsten en individuele interviews. Thematische netwerk analyse resulteerde in een leercyclus van zes opeenvolgende leerfases: impactvolle ervaring; bewustwording en verandering van het referentiekader; identificeren van communicatiestrategieën; experimenteren met communicatiestrategieën; evalueren van communicatiestrategieën; en het beheersen van een gepersonaliseerd communicatie repertoire. De acties van opleiders om deze leerfasen te ondersteunen bestonden uit: het creëren van uitdagingen; het confronteren met en het reflecteren op gedrag en onderliggende mechanismes; het exploreren en demonsteren van communicatiestrategieën; het geven van concrete oefenopdrachten; het creëren van veiligheid; het exploreren van het effect van strategieën; en het faciliteren van herhaalde oefening en reflectie. We concludeerden dat ondersteuning bij de ontwikkeling van een gepersonaliseerd communicatie repertoire, waaruit AIOS strategieën kunnen kiezen die passen bij de context, een aandachtspunt is voor communicatietraining. Hierbij lijken concrete voorbeelden, mogelijkheden voor herhaaldelijke oefening van en reflectie op persoonlijke referentiekaders en het effect van strategieën, en ruimte voor authenticiteit en flexibiliteit belangrijk te zijn. De opleider kan al deze voorwaarden faciliteren om hun AIOS te ondersteunen in hun ontwikkeling tot een 'skilled communicator'.

\section{Hoofdstuk 7}

In dit laatste hoofdstuk worden de hoofdbevindingen horende bij de drie onderzoeksvragen beschreven in het licht van bestaande literatuur. Deze beschrijving 
wordt gevolgd door een discussie van de methodologische overwegingen van dit onderzoek. Deze zijn gerelateerd aan het gekozen studie design, de setting en de deelnemers in relatie tot de generaliseerbaarheid van onze bevindingen. De discussie wordt voortgezet met een beschrijving van de lessen die getrokken kunnen worden uit dit onderzoek: 1) cognitieve overload kan voorkomen worden door inzicht te vergroten in mechanismes 2) AIOS hebben concrete, authentieke voorbeelden nodig 3) AIOS dienen ondersteund te worden bij het herhaaldelijk doorlopen van de leercyclus en 4) de opleider vervult een belangrijke ondersteunde rol gedurende het gehele leerproces van AIOS. leder van deze lessen wordt bediscussieerd in het licht van de implicaties voor communicatie training. We eindigen de discussie met een overzicht van onze aanbevelingen voor toekomstig onderzoek. Deze hebben betrekking op het valideren van onze bevindingen, de ontwikkeling en evaluatie van curriculum componenten voor 'skilled communication' training, de ontwikkeling van 'evidence' voor effectieve communicatie strategieën en de vertaalbaarheid naar andere klinische contexten en competenties. 


\section{VALORISATION}



Valorisation is defined as 'The process of value creation from knowledge, by making it applicable and available for economic or societal utilization, and by translating it in the form of new business, products, services, or processes'. While the previous chapters of this dissertation have addressed the scientific value of our findings, this valorisation chapter describes their societal value. The findings will be discussed with regards to the following aspects: their societal relevance, the target groups from whom they are relevant, potential resulting products and activities, implementation strategies and innovativeness.

\section{SOCIETAL RELEVANCE}

Adequately training future doctors in effective doctor-patient communication has a large societal impact. Effective communication is essential for good health care $(1,2)$. Its positive effects on patient satisfaction (3-5), doctors' work-related satisfaction (6), health status $(3,7)$, adherence $(8)$, and the doctor-patient relationship (9) have been well demonstrated. Furthermore, effective communication has shown to reduce health care costs and malpractice claims (10). Effective communication becomes increasingly important for doctors due to the aging population with chronic conditions and multi-morbidity. Moreover, the societal shift from doctor-centred and diseasecentred care to patient-centred care demands more attention for patients' ideas, concerns, expectations and goals. Studies have demonstrated that there is still much room for improvement when it comes to patient-centred communication $(6,11-13)$. Very recently, Dutch media and politicians have stressed the importance of improving communication as a result of a study performed by the Dutch patient federation, showing that four out of ten patients feel that they have not made a valuable contribution to the conversation with their doctor (14). These findings have initiated a national campaign ('Samen Beslissen') to increase awareness among doctors and patients about the importance of involving the personal context of the patient in medical decision making. This campaign also stresses the importance of training doctors in patient-centred communication.

Our research explored doctor-patient communication in the General Practice (GP) setting. Given the key values of patient-centeredness, patient-participation, the holistic approach and long-term relationship-building in family medicine, communication is considered a core competence of GPs (15). Given its importance, a lot of effort has been put in communication skills training, yet growth in 
communication competence throughout the GP specialty training has shown to be insufficient given the pre-set educational goals (16). Trainees report difficulties with applying the skills learned during training in their actual practice (17). Research among experienced doctors also shows that the use of the widely advocated patient-centred communication skills, e.g. exploring the patients' ideas concerns and expectations, is limited $(6,11-13)$. It is crucial that communication training is developed that both aligns to daily practice, but also transforms practice. The 'skilled communication approach' takes a more holistic view, creates space for the learners' flexibility and creativity and takes the uniqueness of consultations into account. This approach, seems to be a promising alternative to training students in generic communication skills (18).

This research project has resulted in some valuable insights for the development of skilled communication training. First, we have identified a range of communication strategies that can be integrated in goal-directed, context specific communication training. The rich description of these strategies, including their underlying mechanisms, can help (future) doctors in communicating with their patients in a tailored manner. Moreover, we have obtained an understanding of how learners can be supported in becoming skilled communicators, which has resulted in several concrete recommendations for the design of communication training at the institution and at the clinical workplace. We believe that implementing these recommendations may enhance transfer from the training to practice. The clarification provided on how communication skills turn into skilled communication, including the importance of repeated reflection and experimentation, authentic examples, safety of learning and role modelling, may have considerable impact on postgraduate training. If communication is representative of other complex skills such as collaboration, professionalism or social responsibility, then the ramifications are massive. With our current insight learners may be supported in communicating with their patients in a skilled manner, i.e. adjusted to the context and to the goals that the doctors and patients have, and therefore could possibly contribute to better patient-centred care and patient outcomes.

\section{TARGET GROUPS, PRODUCTS AND IMPLEMENTATION}

The findings of this project are relevant for several target groups and result in various products and activities. As described above, we have obtained relevant insights for the development of skilled communication training and formulated several concrete 
recommendations. Some of these recommendations have already been translated into actual training products. Based on our findings, a goal-directed training on 'effective reassurance' has been developed, piloted, evaluated, refined and implemented in the GP vocational training in Maastricht. The content of the training was based on the experiences of patients and doctors (chapters 4 and 5), and the didactic format was informed by the identified communication learning process and supporting factors (chapter 6). Moreover, the training has been adjusted for the GP vocational training in Rotterdam, including a larger focus on reassuring patients with medically unexplained symptoms. The lessons learned from the evaluation of the pilot training in Maastricht are informative for the design for the whole communication curriculum. As described in the discussion of this dissertation (chapter 7), some elements of the identified learning process (chapter 6) that were integrated in the training seemed to help trainees in obtaining and internalizing new communication strategies, and to use them in a tailored manner. These elements include: devoting multiple training sessions to one communication theme, illustrating strategies by making use of concrete, authentic examples, facilitating reflection of the effect of new strategies and strengthening the didactic and role model function of the clinical supervisor by training the supervisors as well. Integrating these elements into the entire communication curriculum needs to be done in close collaboration with local stakeholders such as the curriculum coordinator, trainers, trainees and clinical supervisors. To ensure dissemination to the relevant stakeholders of all the GP specialty training institutes, the findings will be presented at work conferences organized by the national GP working group on doctor-patient communication, as well as on the national and local staff days of the GP specialty training centres. For effective implementation, it is necessary to integrate the recommendations as much as possible in the national communication curriculum, the national educational plan of the Dutch GP specialty training and the Entrustable Professional Activities (EPA's).

The results will not only be informative for the GP vocational training, but also for other postgraduate medical specialties, as well as for undergraduate communication training. For the latter, our results may be of value for educators involved in improving transfer from pre-clinical to the clinical medical training. During their pre-clinical years, medical students receive continuous communication training, while such type of support is largely absent during their clinical rotations. This is odd, as this is the period that students have to transfer what they have learned to practice. According to 
the learning process described in chapter 6 , actual mastery of new skills and strategies requires learners to repeatedly experiment with these during patient encounters and reflect on their outcome. This requires students to receive structural support in improving their communication from communication trainers and their clinical supervisors. Our insights may be a starting point in understanding how to realize a better transition from undergraduate to postgraduate curricula. The themes that were explored in this dissertation, i.e, information gathering and reassurance, are also very relevant for medical students and build well upon the basic skills that they have learned during their first years of medical training. Hence, our findings may therefore provide some first directions for the content of communication training for medical students in their clinical years.

In addition to educational target groups, the research findings are also directly informative for practicing clinicians. During our research we noticed that many experienced doctors are still motivated to improve their communication. For example, GPs who participated in the focus groups on how to communicate with talkative patients (chapter 3), highly enjoyed sharing their experiences and learning new strategies from peers that they could implement in their own practice. An important motivation for doctors to share their expertise regarding reassuring patients (chapter 5) was that they were able to watch their own videotaped consultations and that they received verbal and written feedback on their communication skills. Chapters' three to five provide clinicians with useful communication strategies that they could experiment with during their own consultations. Clinicians could learn about these strategies in training programmes. Doctors involved in supervising trainees can be quite easily reached via the vocational training centres, e.g. GP supervisors have monthly release days during which they receive training. Clinicians who are not involved in teaching can be reached by offering accredited refresher courses. To further disseminate our findings, it is important to publish them in national medical journals which have a large and broad readership of clinicians. We have already done this for the findings of chapter 3, which have been published in the 'Nederlands Tijdschrift voor Geneeskunde' (Dutch Journal of Medicine) (19), and will do the same for the other chapters as well. 


\section{INNOVATIVENESS}

Our study findings will inform the development of a new approach in communication training that will move away from generic behavioural communication guidelines and checklists, towards training that creates space for the learners' flexibility and authenticity and does justice to the complexity of daily practice (14). Supporting (future) doctors in communicating with their patients in a tailored manner will contribute to good medical care that fits the personal context of the patient.

\section{REFERENCES}

1. Street RL, Jr., Makoul G, Arora NK, Epstein RM. How does communication heal? Pathways linking clinician-patient communication to health outcomes. Patient Educ Couns. 2009;74(3):295-301.

2. Makoul G. The SEGUE Framework for teaching and assessing communication skills. Patient Educ Couns. 2001;45:23-34.

3. Stewart M, Brown JB, Donner A, McWhinney IR, Oates J, Weston WW, et al. The impact of patient-centered care on outcomes. J Fam Pract. 2000;49(9):796-804.

4. Bertakis KD, Roter D, Putnam SM. The relationship of physician medical interview style to patient satisfaction. J Fam Pract. 1991;32(2):175-81.

5. Kinnersley P, Stott N, Peters TJ, Harvey I. The patient-centredness of consultations and outcome in primary care. Br J Gen Pract. 1999;49:711-6.

6. Silverman J, Kurtz S, Draper J. Skills for communicating with patients. Second ed. Oxford: Radcliffe Publishing; 2005. 58-105 p.

7. Stewart MA. Effective physician-patient communication and health outcomes: a review. CMAJ. 1995;152(9):1423-33.

8. Zolnierek KB, Dimatteo MR. Physician communication and patient adherence to treatment: a meta-analysis. Med Care. 2009;47(8):826-34.

9. Bensing JM, Deveugele M, Moretti F, Fletcher I, Vliet LV, Bogaert MV, et al. Patient Education and Counseling How to make the medical consultation more successful from a patient 's perspective ? Tips for doctors and patients from lay people in the United Kingdom , Italy, Belgium and the Netherlands. Patient Educ Couns. 2011;84:287-93.

10. Huntington B, Kuhn N. Communication gaffes: a root cause of malpractice claims. Proceedings (Baylor University Medical Center). 2003;16(2):157-61; discussion 61.

11. Marvel MK, Epstein RM, Flowers K, Beckman HB. Soliciting the Patient's Agenda: Have We Improved? JAMA. 1999;281:283-7.

12. Levinson W, Gorawara-Bhat R, Lamb J. A study of patient clues and physician responses in primary care and surgical settings. JAMA. 2000;284(8):1021-7.

13. Rhoades DR, McFarland KF, Finch $\mathrm{WH}$, Johnson aO. Speaking and interruptions during primary care office visits. Fam Med. 2001;33:528-32.

14. Nederland P. Patiënten en artsen starten campagne over samen beslissen in het ziekenhuis 2016 [Available from: https://www.patientenfederatie.nl/nieuws/patienten-en-artsen-startencampagne-over-samen-beslissen-in-het-ziekenhuis.

15. Genootschap LHVNH. Toekomstvisie Huisartsenzorg 2022. Utrecht 2012.

16. Kramer AWM, Düsman H, Tan LHC, Jansen JJM, Grol RPTM, van der Vleuten CPM. Acquisition of communication skills in postgraduate training for general practice. Med Educ. 2004;38:158-67.

17. van den Eertwegh V, van Dalen J, van Dulmen S, van der Vleuten C, Scherpbier A. Residents' perceived barriers to communication skills learning: Comparing two medical working contexts in postgraduate training. Patient Educ Couns. 2014. 
18. Salmon P, Young B. Creativity in clinical communication: from communication skills to skilled communication. Med Educ. 2011;45:217-26.

19. Giroldi E, Veldhuijzen W, Bareman F, Bueving $H$, van der Weijden $T$, van der Vleuten $C$, et al. [Effective communication with talkative patients: 10 tips]. Ned Tijdschr Geneeskd. 2016;160:D184 
DANKWOORD 

Toen ik het goede nieuws kreeg dat dit proefschrift was goedgekeurd, dacht ik dat alle grote 'schrijf-hobbels' van het promotietraject inmiddels overwonnen waren. Echter, toen ik me over het dankwoord ging buigen, bleek dit toch niet helemaal het geval. Er zijn zoveel personen die op een unieke manier een bijdrage geleverd hebben aan dit proefschrift, dat het onvermijdelijk is dat ik mensen zal vergeten. Aangezien het dankwoord het meest gelezen hoofdstuk van een proefschrift is, ga ik hier helaas ook niet ongezien mee wegkomen. Ik heb een poging gewaagd...

Uiteraard wil ik allereerst mijn promotieteam bedanken. Cees, het was ontzettend fijn dat je mij, ondanks jouw overvolle agenda, altijd snelle en concrete feedback gaf zodat ik weer vooruit kon. Tijdens vergaderingen was je steeds in staat om de essentie van de discussie en verbeterpunten te formuleren. Je gaf me de juiste dosis vrijheid en waardering om er uiteindelijk iets heel moois van te maken. Trudy, jouw enthousiasme, betrokkenheid en lovende woorden hebben steeds gezorgd voor zelfvertrouwen en motivatie om met goede moed verder te gaan. Ik kon altijd bij je binnenlopen en je gaf me steeds uitgebreid feedback op mijn stukken. Wemke, jouw passie voor arts-patiënt communicatie in combinatie met je huisartsgeneeskundige expertise en kritische blik, hebben mij geholpen om dit proefschrift naar een hoger niveau te tillen. Ik heb veel van je geleerd over kwalitatief onderzoek, met name op het gebied van analyseren en schrijven.

Naast mijn promotoren wil ik de overige leden van het projectteam bedanken. Jean, jij was weliswaar op papier niet mijn promotor, maar die rol heb je in de praktijk wel degelijk aangenomen. Je nam altijd uitgebreid de tijd om mijn stukken van commentaar te voorzien en was zeer betrokken. Herman en Frits, jullie Rotterdamse invalshoek was ontzettend waardevol. Ook dank voor het faciliteren van de dataverzameling in Rotterdam. Fijn dat het einde van dit promotietraject niet het einde van onze samenwerking betekent.

Mijn dank gaat uit naar de leden van de leescommissie die de tijd hebben genomen om dit proefschrift zorgvuldig te lezen.

Ik wil graag alle huisartsen, patiënten, AIOS en opleiders bedanken die we hebben mogen observeren en/of interviewen. 
Mereke, Carol en Angelique, jullie hebben meer gedaan dan simpelweg de 'Engels correctie' van de hoofdstukken. Jullie maakten er steeds echt iets moois van.

Ik heb ontzettend geboft met alle WESP studenten die meegeholpen hebben met data verzameling, analyse en rapportage: Carolien, Alexandra, Dionne, Maxime, Tijme, Annika en Kristel, ontzettend bedankt voor jullie inzet!

Veel dank aan diegenen die de werving van de onderzoekdeelnemers mogelijk hebben gemaakt. Voor de AIOS en opleiders waren dit Bas Maiburg, Henk Goettsch en de docenten van de huisartsopleiding; voor de huisartsen en patiënten was dit Babette van Doorn.

Angelique, jij hebt een grote rol gespeeld bij de implementatie van mijn onderzoeksbevindingen in de onderwijspraktijk, heel veel dank hiervoor!

Lilian en Karin V (Maastricht) en Nannette en Willeke (Rotterdam), dank voor al jullie hulp bij het inplannen van projectgroep vergaderingen en bij de praktische zaken rondom het proefschrift en de verdediging.

Judith, Ellen, Marga, Anneke, Susanne, Karin A, Hilde, Frits, het was heel fijn dat ik altijd bij jullie binnen kon lopen voor praktische vragen of een kletspraatje.

Ine, bij jou kon ik echt altijd terecht. Al was het voor praktische hulp, een luisterend oor, levensadvies, complimentjes, noem het maar op. Wat bisse toch een leeve, daaanke!

Jos, onze reddende ICT-engel. Meerdere keren heb je van mij een mail gekregen met 'HELP' als onderwerp, en binnen een mum van tijd waren de problemen opgelost.

Erie van den Heuvel, dank voor je hulp bij het regelen van de financiën van het project.

Toen ik in 2012 begon bij Huisartsgeneeskunde werd ik meteen opgenomen in het groepje van 'de dames van de tweede verdieping'. Hierdoor voelde ik mij gelijk welkom en op mijn gemak. Petra, Mandy, Sil, Martine, Janaica, Tineke en Viola, ik heb genoten van alle gezellige lunchwandelingen. 
Mijn collega promovendi van HAG, Eefje, Eva, Krista, Nicole, Luc, Angel, Kirsten, Jeanny, Floor, Ramon en Laury, dank voor de zinvolle 'HAG promovendi-overleggen' en voor de gezelligheid.

Mark en Jochen, dank voor de lekkere koffie! Jochen, leuk dat je mij betrokken hebt bij jouw project zodat ik even een zijstapje kon nemen.

Mijn kamergenootjes en paranimfen Anneke en Annerika. Wat bof ik toch met jullie! Het is zo fijn om een kamer te delen met zulke gezellige, slimme en behulpzame meiden. Anneke, ik heb veel bewondering voor de manier waarop jij je werk met je gezinsleven combineert. Ondanks dat je werkdagen ontzettend druk zijn, ben je altijd bereid om mee te denken. Annerika, wat is het toch fijn om al mijn 'ups en downs' met jou te kunnen delen. Jij geeft mij veel positieve energie, niet alleen op mentaal maar ook op fysiek vlak. Jij zorgt er namelijk voor dat ik genoeg drink, eet en beweeg gedurende de dag. Meiden, wat fijn dat we voorlopig nog niet van elkaar af zijn, want onze 'promovendus-kamer' verandert nu in een 'post-doc' kamer...

Het nadeel van het horen bij twee afdelingen is dat je niet overal bij aan kunt sluiten. Automatisch heb je meer binding met de afdeling waar je gehuisvest zit. Toch wil ik iedereen bij O\&O bedanken voor de inspirerende SHE Academies, presentatie- en lunch meetings en cursussen. Ik heb veel gehad aan de Masterclass Qualitative analysis, veel dank aan Renee Stalmeijer, and many thanks to Nigel King and Tim Dornan. Ik ga mijn gezicht in de toekomst vaker laten zien!

Graag wil ik alle (oud-)leden van de Journal Club Maastricht bedanken voor de gezellige etentjes en interessante discussies: Francine, Eline, Laura, Maike, Sanne, Eefje, Eva, Carolien, Annerika, Joris, Merijn, Myriam, Petra en Mandy.

Helaas kon ik er niet zo vaak bij zijn als ik zou willen, maar de PPI-bijeenkomsten bij het NIVEL in Utrecht waren altijd zeer inspirerend.

Many thanks to all the participants and faculty of the EACH Junior Investigators Summer School 2015 in London for your extensive feedback and for the inspiring discussions. 
Mama en Hans, Papa en Nicole, ik prijs mij gelukkig met jullie onvoorwaardelijke liefde en steun. Erik, grote broer, ik kan altijd op je rekenen, dank je!

Mijn lieve vriendinnen, Malou, Fleur, Inge, Rachel, Sarah, Daphne, Joyce, Yvonne, Jill, Sanne, Judith en Renee, jullie hebben gezorgd voor de nodige ontspanning en afleiding.

Lieve Martijn, you make me happy!! Need I say more...? 
CURRICULUM VITAE 

Esther Giroldi was born on June 25, 1989 in Kerkrade, the Netherlands. She completed high school at Eijkhagen College, Landgraaf. In 2010 she completed her Bachelor's degree in Health sciences at Maastricht University, after which she started with the Master's programme Global Health, also at Maastricht University. She did her research internship at the Kenya Red Cross Society in Nairobi, where she studied perceptions on obesity and diabetes. After her graduation in 2011, she shortly worked as a tutor and trainer in the Health Sciences Bachelor programme. In January 2012

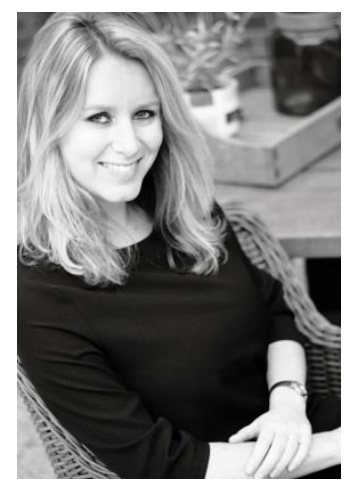
she started working as a PhD-student at Maastricht University, department of Family Medicine. During her PhD trajectory she continued teaching, mainly as a communication skills teacher in undergraduate medical school. In October 2016 she started working as a postdoctoral researcher and teacher at the department of Family Medicine, continuing her research on skilled doctor-patient communication and being involved in a research project on the development of an educational programme in Shared Decision Making. She also has a part-time position at the department of Family Medicine in Rotterdam, where she works as a post-doctoral researcher on the educational value of 'exchange of experience' of the GP vocational training. 


\section{PUBLICATIONS}

Giroldi E, Veldhuijzen W, Bareman F, Bueving H, van der Weijden T, van der Vleuten C, Muris J. Consultvoering bij breedsprakige patiënten: 10 tips. Nederlands Tijdschrift voor Geneeskunde. 2016, 160: D184.

Invited paper

Sundling V, Bravo P, Nguyen M, Alders I, Visser L, Woudstra A, Giroldi E, McHale C, Savarese L, Kim Brandes K. EACH Junior Investigators Summer School: Lessons learned from the joint venture with the EACH Summer Event. Accepted for publication in Patient education and counselling, 2016.

Giroldi E; Veldhuijzen W; Dijkman A; Rozestraten M; Muris J; van der Vleuten C; van der Weijden T. How to gather information from talkative patients in a respectful and efficient manner: a qualitative study of GPs' communication strategies. Family Practice, 2016, 33:100-6.

Giroldi E, Veldhuijzen W, de Leve T, van der Weijden T, Bueving H, van der Vleuten C. 'I still have no idea why this patient was here': An exploration of the difficulties GP trainees experience when gathering information. Patient education and counselling. 2015, 98:837-42.

Giroldi E, Veldhuijzen W, Leijten C, Welter D, van der Weijden T, Muris J, van der Vleuten C. 'No need to worry': an exploration of general practitioners' reassuring strategies. BMC Family Practice. 2014, 15:133.

Giroldi E, Veldhuijzen W, Mannaerts A, van der Weijden T, Bareman F, van der Vleuten C. "Doctor, please tell me it's nothing serious": an exploration of patients' worrying and reassuring cognitions using stimulated recall interviews. BMC Family Practice, 2014, 15:73.

\section{MANUSCRIPTS SUBMITTED FOR PUBLICATION}

Giroldi E, Freeth R, Hanssen M, Muris J, Kay M, Cals J. Managing medical requests from family and friends: an exploration of doctors' experiences and attitudes. 
Giroldi E, Veldhuijzen E, Geelen K, Muris J, Bareman F, Bueving H, van der Weijden T, van der Vleuten C. Nurturing skilled communication in the workplace: towards a personalised communication repertoire.

\section{MEDIA}

Newspaper article 'Dokter, ik neem dit gesprek op'. Ron Langenveld. Dagblad de Limburger, 11-03-2016.

\section{AWARDS}

NTvG Jonge Auteursprijs 2016, uitgereikt op 5 november 2016 in Amsterdam, voor het artikel 'Consultvoering bij breedsprakige patiënten: 10 tips'.

\section{PRESENTATIONS}

14th International Conference on Communication in Healthcare (ICCH), organised by the European Association of Communication in Healthcare (EACH). September 7-10, 2016, Heidelberg, Germany. Nurturing skilled communication in the workplace: towards a personalised communication repertoire (Oral Presentation).

SHE presents, organised by the School for Health Professions Education, Maastricht University, October 9, 2015, Maastricht, the Netherlands. Goal-directed doctorpatient communication: Developing practical and didactic recommendations (Oral Presentation).

EACH Summer School, organised by the European Association of Communication in Healthcare (EACH), August 27-29, 2015, London, UK. Goal-directed doctor-patient communication: Lessons learned (Oral Presentation).

EACH Summer Event, organised by the European Association of Communication in Healthcare (EACH), August 24-26, 2015, London, UK. How to gather information from talkative patients in a respectful and efficient manner: a qualitative study of GPs' communication strategies (Poster presentation).

SHE Academy, organised by the School for Health Professions Education, Maastricht University. March 2-4, 2015, Maastricht, the Netherlands. 'I still have no idea why this 
patient was here': an exploration of the difficulties GP trainees experience when gathering information (Poster presentation).

12th International Conference on Communication in Healthcare (ICCH), organised by the European Association of Communication in Healthcare (EACH). September 28 October 1, 2014, Amsterdam, the Netherlands. "Doctor, please tell me it's nothing serious": an exploration of patients' worrying and reassuring cognitions (Oral presentation).

12th International Conference on Communication in Healthcare (ICCH), organised by the European Association of Communication in Healthcare (EACH). September 28October 1, 2014, Amsterdam, the Netherlands. 'I still have no idea why this patient was here': an exploration of the challenges GP trainees experience when gathering information (Oral presentation).

11th International Conference on Communication in Healthcare (ICCH) organised by the American Association of Communication in Healthcare (AACH). September 29October 2, 2013, Montréal, Canada. 'No need to worry': a qualitative study of best practices in reassurance according to primary care physicians (Oral presentation).

SHE Academy, organised by the School for Health Professions Education, Maastricht University, 5-6 March 2012, Maastricht, the Netherlands. The development of recommendations for goal-directed doctor-patient communication: implications for education and practice (Poster Presentation).

10th International Conference on Communication in Healthcare (ICCH), organised by the European Association of Communication in Healthcare (EACH), September 4-7, 2012, St. Andrews, UK. Developing goal directed communication guidelines: describing strategies for effectively reassuring patients (Symposium).

\section{WORKSHOPS/EDUCATION}

LOVAH Wetenschapsdag, Landelijke Organisatie Van Aspirant Huisartsen, 25 november 2016, Maastricht. Effectief communiceren met breedsprakige patiënten. 
'MIK (Moeilijk Interpreteerbare Klachten)-dag', Huisartsopleiding Rotterdam. 2 december 2015. Effectief Geruststellen.

Stafdag, Huisartsopleiding Rotterdam, 8 oktober 2015. Doelgerichte arts-patiënt communicatie: de ontwikkeling van praktische en didactische adviezen.

'MIK (Moeilijk Interpreteerbare Klachten)-dag', Huisartsopleiding Rotterdam. 3 juni 2015. Effectief Geruststellen.

Training 'Effectief Geruststellen', Huisartsopleiding Maastricht, december 2014.

Interstavendag, georganiseerd door Huisartsopleiding Maastricht, 2 oktober 2014, Eindhoven. Doelgericht communiceren: hoe doe je dat en hoe leer je dat? 